Florida International University

FIU Digital Commons

FIU Electronic Theses and Dissertations

University Graduate School

$11-16-2017$

\title{
A Path Analysis Exploration of Teacher's Effect, Self-Efficacy, Demographic Factors, and Attitudes toward Mathematics among College Students Attending s Minority Serving Institution in Face-to- Face and Hybrid Mathematics Courses
}

Nelson De La Rosa

Florida International University, ndela007@fiu.edu

DOI: 10.25148 /etd.FIDC004034

Follow this and additional works at: https://digitalcommons.fiu.edu/etd

Part of the Curriculum and Instruction Commons, Higher Education Commons, Higher Education and Teaching Commons, Online and Distance Education Commons, and the Science and Mathematics Education Commons

\section{Recommended Citation}

De La Rosa, Nelson, "A Path Analysis Exploration of Teacher's Effect, Self-Efficacy, Demographic Factors, and Attitudes toward Mathematics among College Students Attending s Minority Serving Institution in Face-to-Face and Hybrid Mathematics Courses" (2017). FIU Electronic Theses and Dissertations. 3532.

https://digitalcommons.fiu.edu/etd/3532

This work is brought to you for free and open access by the University Graduate School at FIU Digital Commons. It has been accepted for inclusion in FIU Electronic Theses and Dissertations by an authorized administrator of FIU Digital Commons. For more information, please contact dcc@fiu.edu. 


\title{
FLORIDA INTERNATIONAL UNIVERSITY
}

Miami, Florida

\begin{abstract}
A PATH ANALYSIS EXPLORATION OF TEACHER'S EFFECT, SELF-EFFICACY, DEMOGRAPHIC FACTORS, AND ATTITUDES TOWARD MATHEMATICS AMONG COLLEGE STUDENTS ATTENDING A MINORITY SERVING INSTITUTION IN FACE-TO-FACE AND HYBRID MATHEMATICS COURSES
\end{abstract}

A dissertation submitted in partial fulfillment of the requirements for the degree of DOCTOR OF PHILOSOPHY in CURRICULUM AND INSTRUCTION by

Nelson De La Rosa 
To: $\quad$ Dean Michael R. Heithaus

College of Arts, Sciences and Education

This dissertation, written by Nelson De La Rosa, and entitled A Path Analysis

Exploration of Teacher's Effect, Self-Efficacy, Demographic Factors, and Attitudes

Toward Mathematics among College Students Attending a Minority Serving Institution in Face-To-Face and Hybrid Mathematics Courses, having been approved in respect to style and intellectual content, is referred to you for judgment.

We have read this dissertation and recommend that it be approved.

M. O. Thirunarayanan

Sneh Gulati

Maria L. Fernandez, Major Professor

Date of Defense: November 16, 2017

The dissertation of Nelson De La Rosa is approved.

Dean Michael R. Heithaus

College of Arts, Sciences and Education

Andrés G. Gil

Vice President for Research and Economic Development and Dean of the University Graduate School

Florida International University, 2017 
(C) Copyright 2017 by Nelson De La Rosa

All rights reserved. 


\section{DEDICATION}

I dedicate this doctoral dissertation to my mother Margarita, my example of strength, patience, and perseverance. I also dedicate this work to Ed, Nina, Leici, and all other family members from which I have gathered the strength, discipline, dedication and persistence to complete this strenuous exercise of intellectual growth. 


\section{ACKNOWLEDGMENTS}

I would like to express special gratitude to Dr. Maria L Fernandez, my major professor and dissertation chair. I have learned so much from you during the many years we have interacted. I am grateful for the countless hours you have spent in reviewing my papers and for all the dedication and effort you have deployed in supporting me and in guiding me to finish my goal of completing this research study. The patience you have shown when providing me with support is remarkable. I am grateful for all you have done.

I would like to express my deepest gratitude to Dr. Mido Chang, who in addition to my chair, agreed to serve on my committee. Thanks for providing me with the guidance I needed for the completion of this project. I am grateful to you for your leadership, consistent commitment and availability to clarify questions and assist me when I needed it. Your inspiration, motivation, strength, and persistence have been crucial. I honestly believe that you came to FIU to rescue students like me. You have my eternal gratitude.

To Dr. M. O. Thirunarayanan and Dr. Sneh Gulati, also members of my doctoral committee, I want to thank you for your support and willingness to be part of this process. Dr. Thirunarayanan, I want to personally thank you for your encouragement and all the support you provided so I could succeed in writing my dissertation. Dr. Gulati, I want to thank you for being on my side when I was in need.

I am grateful to Dr. Zoe Ansorena Morales for her words of encouragement and decisive support when I needed it most. 
To all students I have had the pleasure to teach and all the educational institutions I have been lucky to serve. They have all been part of my life and they have all contributed to furnish my desire to advance education for everyone.

Finally, I also thank all the individuals who have made the completion of this work arduous for me. Their actions have just served to empower my commitment and desire to finish my dissertation. 


\begin{abstract}
OF THE DISSERTATION
A PATH ANALYSIS EXPLORATION OF TEACHER'S EFFECT, SELF-EFFICACY, DEMOGRAPHIC FACTORS, AND ATTITUDES TOWARD MATHEMATICS AMONG COLLEGE STUDENTS ATTENDING A MINORITY SERVING INSTITUTION IN FACE-TO-FACE AND HYBRID MATHEMATICS COURSES
\end{abstract} by

Nelson De La Rosa

Florida International University, 2017

Miami, Florida

Professor Maria L. Fernandez, Major Professor

Graduation rates in colleges and universities have not kept up with the increase in enrollment. Lack of mathematics competence is a factor that impairs students from completing higher education studies. This problem is even more pervasive in minority groups. The existing body of research on mathematics education have not favored emerging minority populations in terms of addressing their needs for academic program completion across mode of instruction.

The study analyzed the relationship between type of instruction and the factors underlying students' attitudes toward mathematics. Further, this study examined the effect of factors underlying the constructs of teacher's effect and self-efficacy as well as gender and mode of instruction on factors underlying attitudes of students to learn mathematics. Data were collected from a sample of 390 students enrolled in College Algebra delivered in face-to-face and hybrid learning at a minority-serving college, using 
three well established instruments. A one-way MANOVA and Path Analyses were used to analyze the data.

There were significant differences in the level of importance students attributed to learning mathematics for their life in terms of mode of instruction. Those students who learned mathematics in the hybrid setting believed that learning and mastering mathematics would become an advantageous factor for their life.

Beliefs of encouragement from the teacher and mathematics capability to solve procedural problems predicted judgments of satisfaction for being enrolled in College Algebra, as well as judgments of the importance students attributed to learning mathematics for their life. Mode of instruction was also a significant predictor of importance. Mathematics apprehension was significantly predicted by discouragement. Perceptions with respect to performing mathematics problems that required applying several procedures was significantly predicted by the combined effect of judgments of encouragement and discouragement from the teacher. Perceptions of being encouraged from the teacher predicted beliefs to perform critical thinking problems in mathematics. 


\section{TABLE OF CONTENTS}

CHAPTER

PAGE

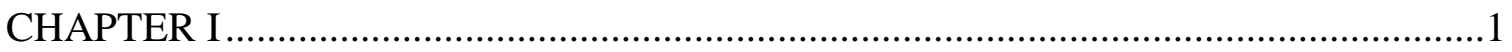

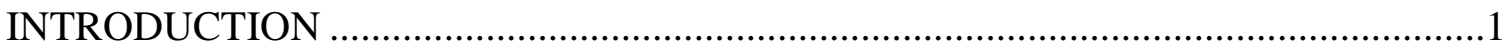

Background Information ........................................................................

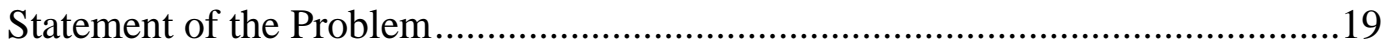

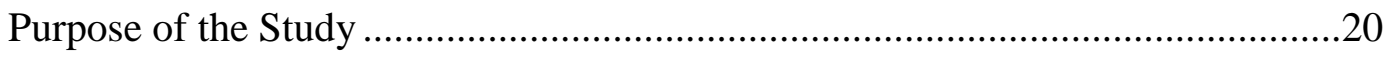

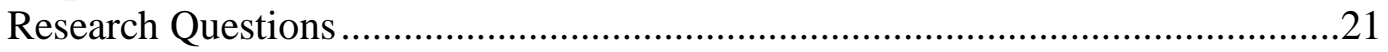

Theoretical Perspectives ……………………………......................................22

Operational Definitions of Terms and Variables ...............................................26

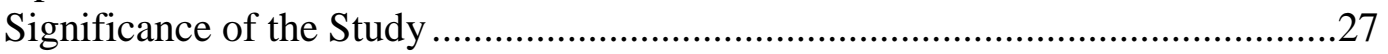

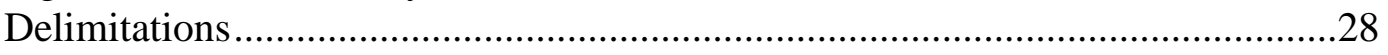

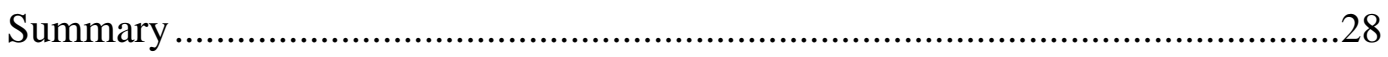

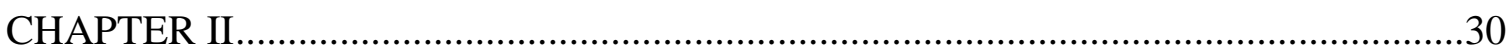

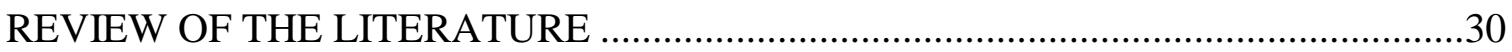

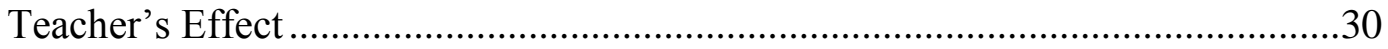

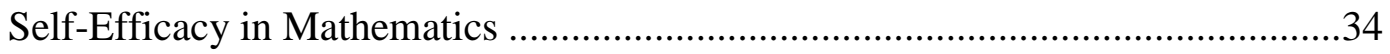

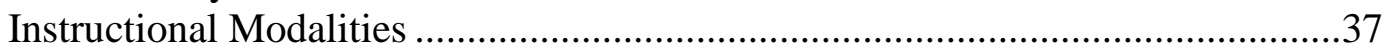

Meta-Analyses on Instructional Modalities ............................................................

Synthesis of Findings of Meta-Analyses .............................................................

A Reflection on the Findings of the Meta-Analyses..............................................47

Highlights of Prior Research on Instructional Modalities in Mathematics.............50

Demographics in Mathematics ......................................................................63

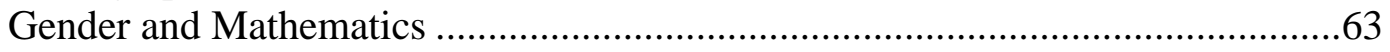

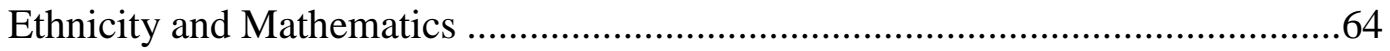

Attitude toward Mathematics.........................................................................67

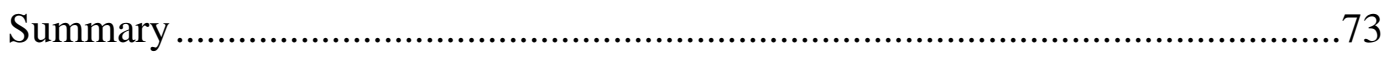

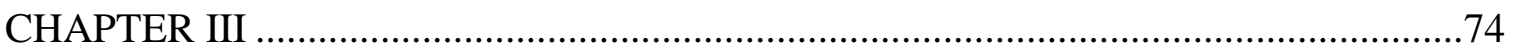

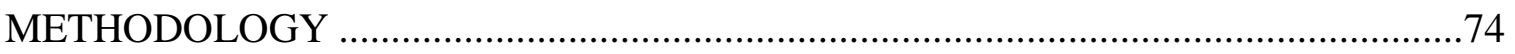

Research Questions and Hypotheses .................................................................76

Operational Definitions of Variables ...............................................................78

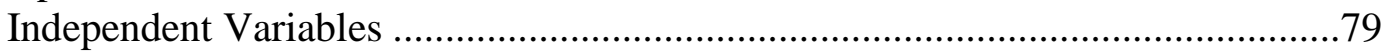

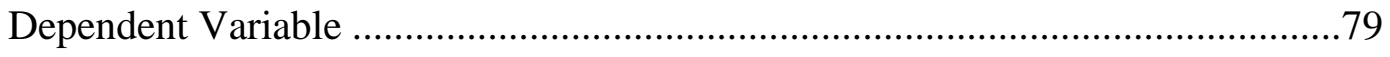

Research Design......................................................................................

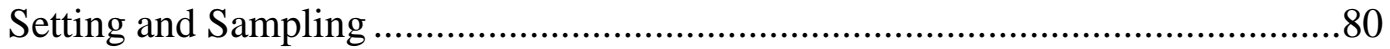

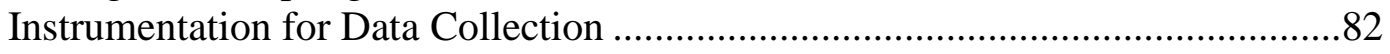

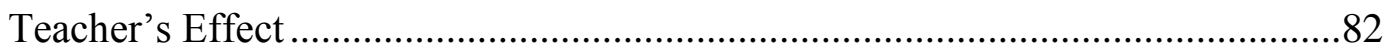




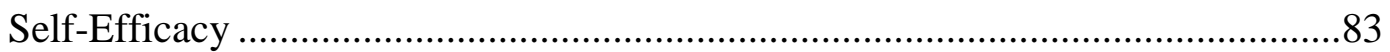

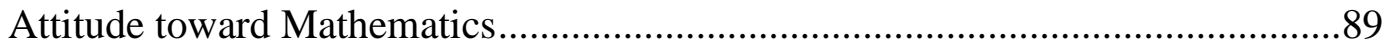

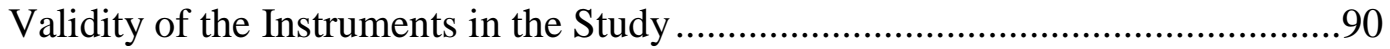

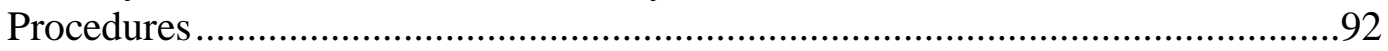

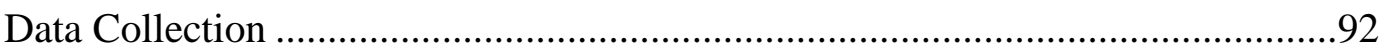

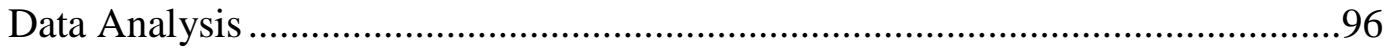

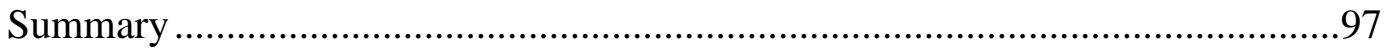

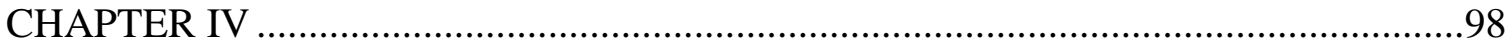

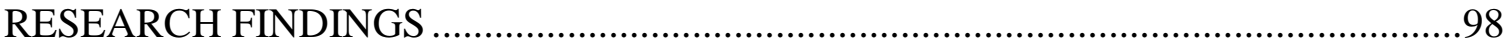

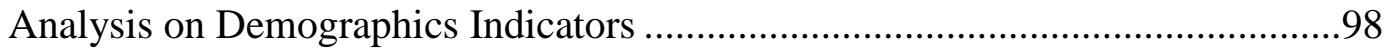

Statistical Analysis Conducted to Respond to Research Question 1 ....................106

Statistical Analysis Conducted to Respond to Research Question 2 ...................145

Statistical Analysis Conducted to Respond to Research Question 3 ..................149

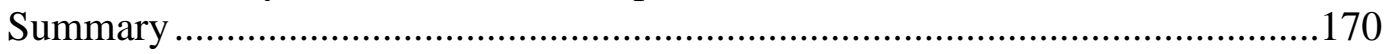

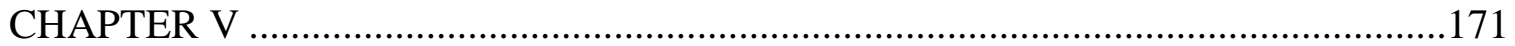

DISCUSSION, IMPLICATIONS, AND RECOMMENDATIONS …………..............171

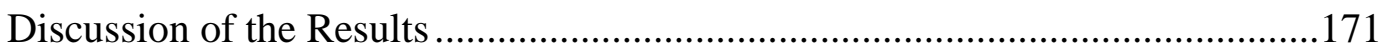

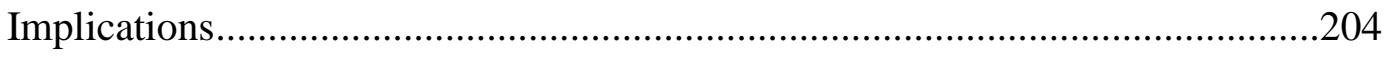

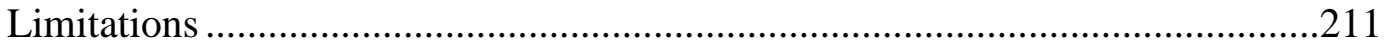

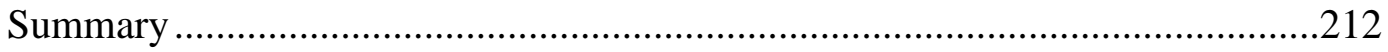

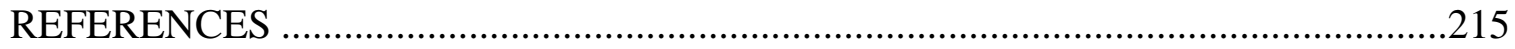

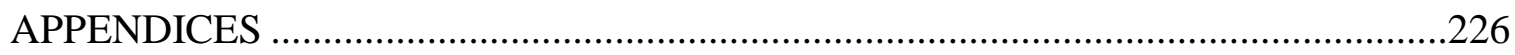

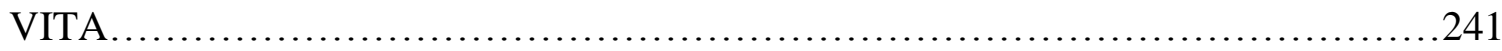




\section{LIST OF TABLES}

TABLE

PAGE

1. Percentage of 25 to 29 -year-olds students who have completed a bachelor's or higher degree, by race/ethnicity and gender: 2013. .11

2. Demographic Indicators of Students Participants in the Study

3. Demographic Indicators for Students in the Hybrid Group

4. Demographic Indicators for Students in the Face-to-Face Group 104

5. Independent-Samples t-Test Results for Demographics Differences of Indicators in Hybrid and Face to Face Groups .106

6. Cronbach alpha coefficient for individual and combined instruments in the study.

7. Intercorrelations for Scores on the 12 items of Teacher's Effect measure 110

8. Summary of the initial Solution from an Exploratory Factor Analysis Results on 12 Items of the Teacher's Effect Measure Using Principal Axis Factoring Estimation and Promax Rotation.

9. Summary of the Final Solution from an Exploratory Factor Analysis Results after removing Items 4, 7, and 8 of the Teacher's Effect Measure Using Principal Axis Factoring Estimation and Promax Rotation

10. Intercorrelations for Scores on the 18 items of Self-Efficacy in Mathematics Measure 
11. Summary of the initial Solution from an Exploratory Factor Analysis Results on 18 Items of the Self-Efficacy in Mathematics Measure Using Principal Axis Factoring Estimation and Promax Rotation

12. Summary of the Intermediate Solution from an Exploratory Factor Analysis Results on 18 Items of the Self-Efficacy in Mathematics Measure Using Principal Axis Factoring Estimation and Promax Rotation

13. Summary of the Final Solution from an Exploratory Factor Analysis Results on 18 Items of the Self-Efficacy in Mathematics Measure Using Principal Axis Factoring Estimation and Promax Rotation

14. Intercorrelations for Scores on the 19 items of Attitudes toward Mathematics Measure

15. Summary of the Initial Solution from an Exploratory Factor Analysis Results on 19 Items of the Attitudes toward Mathematics Measure Using Principal Axis Factoring Estimation and Promax Rotation 128

16. Summary of Final Solution from an Exploratory Factor Analysis Results on 19 Items of the Attitudes toward Mathematics Measure Using Principal Axis Factoring Estimation and Promax Rotation

17. Summary of the Exploratory Factor Analysis Results on the Retained Items of the Teacher's Effect, Self-Efficacy in Mathematics, and Attitudes toward Mathematics Measure Using Principal Axis Factoring Estimation and Promax Rotation

18. Distribution of Items per Factor after Performing the Exploratory Factor Analysis

19. Pearson Correlations, Means, and Standard Deviation Associated with Subscales that Emerged from the EFAs

20. One- way MANOVAs with Importance and Satisfaction as Subscales 148 
21. One- way ANOVAs with Importance and Satisfaction as Subscales of Attitudes toward mathematics and Mode of Instruction as Independent Variables

22. Skewness, Kurtosis, Kolmogorov-Smirnov test, and Shapiro-Wilk test 151

23. Regression Analysis Summary for the Prediction of Satisfaction 160

24. Regression Analysis Summary for the Prediction of Satisfaction 161

25. Regression Analysis Summary for the Prediction of Importance. 162

26. Summary of causal Effects of the Hypothesized Model. 165 


\section{LIST OF FIGURES}

TABLE

PAGE

1. Model for the relationship between teacher effect, self-efficacy toward mathematics, demographics, instructional modalities, and attitudes toward mathematics.

2. Model Synthesizing Results of EFAs and Hypothesis in Model 1

3. Bivariate Scatter Plot

4. Regression Standardized Predicted Values versus the Regression Standardized Residuals Values for Satisfaction.

5. Regression Standardized Predicted Values versus the Regression Standardized Residuals Values for Mathematics Apprehension.

6. Regression Standardized Predicted Values versus the Regression Standardized Residuals Values for Importance.

7. Distribution of the residuals for Satisfaction

8. Distribution of the residuals for Mathematics Apprehension

9. Distribution of the residuals for Importance.

10. The path Model with Importance, Mathematics Apprehension, Satisfaction, Mathematical Procedures, Critical Thinking, Encouragement, and Discouragement

Predicted. 163 


\section{CHAPTER I}

\section{INTRODUCTION}

Chapter I presents the background information, statement of the problem, purpose of the study, research questions, theoretical perspectives, operational definitions of terms and variables, significance of the study, and delimitations. The chapter ends with a summary and a description of the content of the rest of the proposal.

\section{Background Information}

Mathematics is one of the general curriculum areas students must master at the undergraduate level. Proficiency in mathematics is a requirement for students pursuing postsecondary education (Bargagliotti, Botelho, Geason, Haddock, \& Windsor, 2012; National Center for Education Statistics [NCES], 2015). Consequently, the lack of mathematics competence is a factor that impairs students from completing higher education studies (Bargagliotti et al., 2012; Birgan, 2010; Brewer, 2009; Clutts, 2010; Hood, 2012; NCES, 2015). Students' decisions, actions, and persistence related to mathematics problem solving are important for their success in this area (Ellington \& Frederick 2010; Parker, 2004; Schoenfeld, 1985; Schoenfeld, 1992). Self-efficacy beliefs regulate individuals' decisions and actions through their life, the goals they set, and the persistence and the effort they deploy to attain those goals (Bandura, 1997; Zimmerman, Bandura \& Martinez-Pons, 1992). Thus, students'self-efficacy in mathematics, defined as the judgements students hold to complete mathematics tasks, is an important trait related to students' learning of mathematics.

Academic literature in the discipline of mathematics has reported the influence of self-efficacy in modifying students' thoughts and behaviors toward mathematics 
(Bargagliotti et al., 2012; Birgan, 2010; Brewer, 2009; Clutts, 2010; Hackett \& Betz, 1989; Hood, 2012). Bandura (1997) stated that "self-efficacy beliefs influence the level at which goals are set, the strength and commitment to them, the strategies used to reach them, the amount of effort mobilized in the endeavors, and the intensification of effort when accomplishments fall short in aspirations" (p. 136). Hackett and Betz (1989) conducted a study on the relationship between performance, self-efficacy, and career choice in mathematics and found a moderate correlation between student performance and self-efficacy beliefs in mathematics. A further analysis showed that there was a positive correlation between mathematics performance and self-efficacy, showing that students who had a positive attitude towards learning mathematics also had a higher achievement in the subject (Hackett and Betz, 1989). Hood (2012) studied the effect of differentiated instructions in boosting self-efficacy in a study of achievement in developmental mathematics that used a sample of 42 African American students in a college with open enrollment. In Hood's study, differentiated instructions consisted of using several teaching techniques adapted to the particular learning styles and readiness of each student. Hood (2012) found a slight yet significant increase of self-efficacy in learning behavior and improvement of mathematics skills. Nevertheless, limitations and sampling techniques in Hood's study fail to support this encouraging finding about the increase in mathematics significance. Hood used a small sample size and the disproportionate distribution of cases across groups (33 students in the treatment group and 9 students in the control group); furthermore, the variability of the mathematics background of students attending this institution does not support Hood's results. 
The influence of self-efficacy on an individual's agency to take actions in a particular environment does not occur by chance (Bandura, 1997). It is the combined effect of cognitive, motivational, affective, and selective processes that act to enhance or undermine individuals' behaviors toward an activity. According to Bandura (1997) becoming an efficacious individual involves moments of failures and successes, and only when individuals are exposed to success do they get discouraged and disappointed when failure arises. Failures are stages where individuals may learn to overcome the effect of negative experiences and regulate their skills to become efficacious. A balance between failures and successes builds a strong sense of self-efficacy (Bandura, 1997). Perceived self-efficacy is an important condition to persevere in attaining goals (Bandura, 1997). As such, the way individuals perceived self-efficacy influences their decisions for future endeavors.

In the context of education, self-efficacy plays a key role in developing students' affective motivation on learning as self-efficacy influences the way students envision their academic aspirations and the process they follow to materialize them as concrete outcomes (Bandura, 1997). Self-efficacy beliefs have explained psychological aspects such as beliefs, attitudes, and decisions of students as well as their academic outcomes (Aldridge, Afari, \& Fraser, 2012). School influence is an important source in developing self-efficacy and making it sustainable for all students (Bandura, 1997). Classroom climate as a part of school influence is associated with the instructional strategies used by teachers to conduct instruction and inform students of their progress. Results from research studies indicate that students embrace learning and achieve good academic scores in mathematics when they perceive they have support from the teacher (Aldridge 
et al., 2012; Peters, 2013). In other words, students enjoy learning mathematics when they perceive that teachers care about student progress and have explicit and systematic expectations.

A teacher may change students' negative attitudes into positive attitudes toward mathematics by providing feedback about areas of strengths and weaknesses in order to help students regulate discomfort or anxiety (Bandura, 1997; Peters, 2013). Teachers' guidance through constructive feedback motivates and inspires students to try harder, as well as it serves as a moralizing incentive for students to assess their learning (Bandura 1993; Bandura \& Jourden, 1991; Zimmerman, 2000). On the other hand, learning environments that neglect to address students' deficiencies and do not provide ways to overcome those deficiencies will likely exacerbate negative beliefs in those students. Students may not perform adequately in mathematics when they are in a classroom environment that causes them to feel stressed or anxious. These students may also be discouraged from pursuing their educational goals (Bandura, 1997). According to Zimmerman et al. (1992), students refuse to adopt high academic aspirations when they are forced to reach a set goal. Zimmerman et al. add that persuasion works better than imposition for students to enhance their academic self-efficacy.

According to Bandura (1997), students with low self-efficacy may give up in attaining their goals if they are not exposed to learning experiences that stimulate their positive attitudes towards mathematics. These students need additional support from school through explicit and systematic feedback that helps them develop actual abilities in mathematics. Teachers play a key role in fostering and molding students' ability toward mathematics that lead those unprepared students to overcome performance 
deficiencies from the past (Hall \& Ponton, 2005). On the other hand, efficacious students may compensate lack of feedback for alternative ways of guidance that overcome biased or negligent practices from instructors. Overall, school practices that fail to provide adequate guidance and stimulate academic goals attainment represent a delay in students' progression with potential negative outcomes than include frustration and even dropout from course or career completion (Bandura, 1997).

In addition to teacher feedback, classroom climate includes instructional resources teachers may use to make students' experiences enjoyable and meaningful (Wheeler \& Montgomery, 2009). Adult learners enroll in postsecondary education with different mathematics backgrounds having a multitude of learning experiences and with a preconceived notion of motivation to inquiry. The first college mathematics course for some students is a remedial course while others have satisfied the entrance requirements and enrolled in college level mathematics courses (Hall \& Ponton, 2005). Research studies show that the effect of instructional style and the strategies teachers choose to adopt in class influence students' attitudes and beliefs (Bandura, 1997; Hall \& Ponton, 2005), and further influence students' satisfaction, motivation, engagement, and success in college level mathematics courses (Hall \& Ponton, 2005; Wheeler \& Montgomery, 2009). Hall and Ponton (2005) recommend that instructors use a combination of cognitive and meta-cognitive strategies. An instructional environment that combines cognitive and metacognitive strategies helps students develop a powerful sense of motivation to learn mathematics progressively through practicing self-regulation skills, enhancing self-efficacy, and promoting confidence in their success (Keisici \& Erdogan, 2009; Zimmerman 2002). 
Self-efficacy has a strong influence on individuals' decisions as they set goals and show persistence toward accomplishing them (Bandura, 1997; Hall \& Ponton, 2005). Consequently, students benefit from instruction that avoids monotonous and threatening learning environments, which ultimately undermine enhancing their self-efficacy. Learning experiences that are fulfilling as the result of teaching strategies and student effort boosts students' positive perceptions towards mathematics (Hall \& Ponton, 2005). However, successfully teaching students at different academic levels of mathematics implies using different teaching strategies (Hall \& Ponton, 2005). Hall and Ponton (2005) asserted that instructors in lower level mathematics courses can use strategies that make students improve their attitudes toward mathematics and become confident of their potential to solve mathematics problems. Hall and Ponton (2005) claim that students may become efficacious if instructional practices are designed to serve a diverse range of learning styles. These practices include assessing students in small increments and using applications of mathematics to other disciplines (Hall \& Ponton, 2005).

Positive experiences increase self-efficacy, which in turn strengthens attitudes and expectations to learn, and further impacts the decisions students make about their future. $\mathrm{Li}$, Lee, and Solmon (2005) studied the relationship between dispositional ability conceptions, intrinsic motivation, perceived competence, experience, and persistence. They found that students who are confident about their academic competence are naturally or intrinsically motivated to attain the academic task they are pursuing. $\mathrm{Li}$ et al. (2005) stressed that teachers need to use instructional activities that build a sense of competence in students, which in turns enhance active motivation. Consequently, understanding the extent of the effect of the classroom climate on self-efficacy and on 
students' attitudes and motivation to learn may serve as a reference for designing interventions that enhance students' experiences and that respond to their needs. Understanding the influence of teachers in students learning is a factor worth considering in research studies in mathematics education where instruction is delivered through different modalities.

Students may become efficacious if they are properly taught to function that way. For example, activities that people consider as hobbies are not innate conditions (Bandura, 1997). People feel pleasure when engaging in their hobbies because they are exposed to situations that enhance their interest in those activities. Unfortunately, students' satisfaction and success in mathematics is usually low as students usually perceive mathematics as a difficult academic discipline (Parker, 2004). Self-efficacy in mathematics is determinant for students' future educational engagement and career choice (Bandura, 1997). Many students do not see a purpose in pursuing a mathematicsrelated career because they do not feel competent in mathematics (Bandura, 1997). Selfefficacy in mathematics is an important indicator for college graduates applying to high ranked jobs. The accessibility of students to qualify for highly ranked positions in the labor market increases for those students who are efficacious in mathematics (U.S. Department of Education, 2009). Therefore, self-efficacy in mathematics is essential as an increasing demand of jobs require advanced mathematics and science related-skills. A vast range of majors in science, technology, engineering, and mathematics (or STEM) are now offered by colleges and universities nationwide (Munce \& Fraser, 2013). Despite the offering of STEM programs, it appears that these academic programs are not popular career choices (Munce \& Fraser, 2013). In a speech to the New England Board of 
Education in 2009, the Undersecretary of Education, Dr. Martha Kanter, expressed that American colleges and universities must graduate more students in STEM careers (U.S. Department of Education, 2009). Kanter added that the success in achieving this goal depends on the success that the growing population of students in higher education have in mathematics and science courses. Kanter further discussed the role online-based courses have in preparing students for college success. She also highlighted the importance of online-based college courses in guaranteeing equal access to higher achievement in mathematics, among other subjects; and to create a skillful labor force ready to face the challenges of globalization. At present, the demographics of students attending colleges and universities is more diverse than ever, and so is the need for varied modes of teaching to meet the demands of these students (NCES, 2015).

As the NCES (2015) reported, enrollment of students in colleges and universities has increased for several decades; however, graduation rates have not kept up with the increase in enrollment. One factor influencing completion of higher education degrees may be students' success in mathematics (Bargagliotti et al., 2012; Birgan, 2010; Brewer, 2009; Clutts, 2010; Hood, 2012). In a period of four years, from 2008 to 2012, the enrollment in higher education increased 8\% (NCES, 2014). The NCES (2015) further reported an increase of 46\% of enrollment in higher education from 1990 to 2013, from 12 million to 17.5 million. A projection of the NCES (2014) indicated that the enrollment of students will increase more than $14 \%$ between 2012 and 2020. Additionally, the enrollment of female students in higher education institutions has consistently increased since 1970, and it has steadily surpassed the enrollment of male students (NCES, 2014). It was predicted that this gender-related trend in postsecondary enrollment will follow the 
same pattern of increase in the future (NCES, 2014). Despite the increase, there is a gap between the number of students enrolled in higher education institutions and the number of STEM careers graduates the United States needs to stay in its global leading role (U.S. Department of Education, 2009). Several reasons contribute to enlarge this gap. In some cases, students find low incentives for enrolling in college. From those students who decide to enroll in college, not enough of them persevere in completing their academic programs. For example, from $2002-03$ to $2012-13$, there was an increase of only $59 \%$ in the number of associate's degrees awarded nationwide (NCES, 2015). In the same period, the increase in the number of students who earned a bachelor's degree was even lower with a pale 36\% (NCES, 2015). According to the NCES (2015), the U.S. occupied the $12^{\text {th }}$ place in 2012 in the number of students who have earned bachelor's or higher degrees between ages 25 and 34 years among the members of the Organization for Economic Cooperation and Development (OECD). Between 2001 and 2012, the U.S. had an increase from $28 \%$ to $33 \%$ of students who received bachelor's or higher degrees in the 25- to 64-year-old range, which placed the U.S. in the $18^{\text {th }}$ position among all the members in the organization (NCES, 2015). These facts indicate a breach between the number of students who enroll in college and the number of students who complete a degree.

Additionally, the ethnic and racial demographics of students attending higher education institutions and the instructional modalities available to serve this population have dramatically changed in the last several decades (NCES, 2014, 2015; Means, Toyama, Murphy, Bakia, \& Jones, 2009). As a common trend, the enrollment of White students has decreased as the enrollment of students from minority groups has increased 
(NCES, 2010; NCES, 2014; NCES, 2015). Particularly students from Hispanic and Black origins have become a significant portion of students feeding higher education institutions (Day \& Bauman, 2000; NCES, 2015). In fact, the two ethnic groups with the largest increase in college enrollment were Hispanics and Blacks. From 2000 to 2013, there was an increase from $25 \%$ to $31 \%$ of Black students and from $18 \%$ to $29 \%$ of Hispanic students (NCES, 2015). No other ethnic group has experienced a significant increase of enrollment, especially an increase of this magnitude, in the last decade. However, the number of students who have completed a bachelor's degree in these two ethnic groups does not seem to be keeping par with the enrollments. Apparently, Black and Hispanic students have not received enough support to be ready for college or to cope with the challenges associated with degree completion (Day \& Bauman, 2000; U.S. Means et al., 2009), which include demonstrating competence in mathematics. In 2013, the percentage of Black and Hispanic students between 25 and 29 years old who earned a bachelor's degree was significantly lower than that of other ethnic groups (NCES, 2015), as shown in Table 1. If these differences in degree attainment between ethnic groups are not resolved in time, the American society will suffer the consequences of a "tsunami that will devastate American productivity and competitiveness for generations to come" (U.S. Department of Education, 2009). 
Table 1

Percentage of 25 to 29-year-olds students who have completed a bachelor's or higher degree, by racelethnicity and gender: 2013.

\begin{tabular}{ccccccc}
\hline Race & White & Black & Hispanic & Asian & $\begin{array}{c}\text { Native } \\
\text { American }\end{array}$ & $\begin{array}{c}\text { Two or More } \\
\text { Races/Ethnicity }\end{array}$ \\
$\begin{array}{cccccc}\text { Gender } \\
\text { Female }\end{array}$ & 44 & 24 & 19 & 64 & 16 & 30 \\
Male & 37 & 17 & 13 & 55 & 16 & 29 \\
\hline
\end{tabular}

A pervasive deficit in the student enrollment in majors that require mathematics preparation is jeopardizing the stability of the American economy, as more occupations are requiring mathematics competency (Chen \& Soldner, 2013; Lora \& Ndum, 2013). The U.S. Department of Labor (Vilorio, 2014) predicts a growth of more than 9 million occupations in STEM fields between 2012 and 2022. If the labor trend persists, the number of qualified workers to take over the increasing demand of STEM jobs will not be sufficient. As a result, the U.S. will struggle to maintain its leading role in the world. Undoubtedly, there is an imperative need for analyzing the causes of such a negative trend. Zientek, Yetkiner, Fong, and Griffin (2013) note the urgency "of addressing student self-efficacy beliefs in various aspects of academic engagement" (p. 1005). The urgency for analyzing self-efficacy beliefs is even more concerning in populations underrepresented in research studies on the topic of self-efficacy. The study aimed to close the gap in the research that exists in self-efficacy in college students from minority groups, particularly students from African American and Hispanic origins.

Almost 20 years ago, Bandura (1997) expressed that the rate of students from minority groups, other than Asian students, enrolling in science related careers was 
steadily decreasing. Bandura further claimed that research studies had poorly addressed the efficacy of minority students to make early decisions about their professional future where education is a key factor. Still it is unclear how self-efficacy in mathematics manifests in students from minority groups. Furthermore, little is known about the influence of self-efficacy in mathematics on students' attitudes toward mathematics at the undergraduate level. Bandura (1997) has explicitly stated that "ethnicity delineates attributes that distinguish cultural grouping, but it does not explain how ethnic identities affect psychological functioning" (p. 437). A distinctive characteristic in students from minority groups is that they lack beliefs of success in mathematics. Besides, a low proportion of these students pursue science and mathematics related careers (Bandura, 1997; NCES, 2014). Research studies indicate that a significant relationship exists between demographic factors, particularly gender, and self-efficacy in mathematics (Clutts, 2010; Schunk, \& Pajares, 2002). Unfortunately, there are only a few attempts to study the relationship between other demographic factors such as ethnicity and selfefficacy in mathematics at the college level. Demographic factors such as ethnicity and gender may affect individuals' career choices and occupational decisions (Bandura, 1997).

In a meta-analytic study of attitude and achievement in mathematics, Ma and Kishor (1997) did not discuss the contribution that gender, ethnicity, and grade levels (academic levels) of students in mathematics had on their achievement because there was either missing information from the studies' demographics or because the studies had not analyzed demographic effects on attitudes and achievement. Ma and Kishor (1997) reviewed studies that used a varied range of instruments to assess attitudes toward 
mathematics. According to Ma and Kishor (1997), instruments measuring attitude need to be domain specific and academic level specific. Effective instruments are those that narrow down the scope of the research, reduce the confounding effects of aggregated variables, and add relevance to the findings when concrete meaning is given to the construct (or measure) under investigation (Bandura, 1997). One of the areas that needs further research in the academic literature is the relationship between self-efficacy and other beliefs-related constructs in undergraduate mathematics with minority students.

Along with changes in the demographics of students attending higher education institutions, the evolution of technology has played a key role in changing the dynamics of education. The Internet and other electronic resources provide students an opportunity to enroll in online-based courses with free access to course components (e.g., content resources, assessments, communication tools) which are adaptable to their needs of time and location (Means, Toyama, Murphy, Bakia, \& Jones, 2009). In online-based courses, interaction and collaboration with other peers and the teacher has reached higher levels (Means, Murphy, \& Baki, 2013). Still there are students who need the direct rapport faceto-face contacts provide that are often lacking in online-based courses. The use of technology has become a priority in colleges and universities as it supports instruction and responds to the challenges associated with the increase in enrollment (Allen, Mabry, Mattrey, Bourhis, Titsworth, Burrell, 2004; Bernard, Abrami, Lou, Borokhovsk, Wade, Wozney, \& Huang, 2004; Means et al., 2013; NCES, 2014; Simoson, Smaldino, Abright, Zvacek, 2012; Means et al., 2009). Colleges and universities have implemented different modalities of teaching and learning in each of their academic programs. These changes make education accessible to more students, meet more students' learning style demands, 
and provide equal learning opportunities without investing in expensive state of the art technological buildings (Means, et al. 2013; Simonson et al., 2012). Hybrid (blended) learning has emerged as an alternative to online instruction that gives access to education to non-traditional students (Means, et al. 2013). This development is happening amid the expansion of web-based learning along with the blend of novel applications in online education that is supported by face-to-face instruction. Simonson et al. (2012) established that hybrid learning is a form of distributed learning, which combines face-to-face and online instruction. Hybrid learning is an instructional modality that serves mainly adult students who cannot comply with an on-campus schedule or simply opt not to attend regular classes and enjoy using technology-based experiences to enhance their leaning (Means et al., 2013; Simonson et al., 2012).

Literature has commonly defined hybrid learning in terms of the instructional time used to deliver instruction in each of the modalities it combines: face-to-face or online-supported. Usually, in hybrid learning, $25 \%$ or more of the learning time is internet-based while assessment can be online or face-to-face (Means et al., 2013). Hybrid learning has become a popular choice of enrollment in higher education institutions (Means et al., 2013). According to Bargagliotti et al. (2012), blended courses are designed to increase interaction in a non-threatening environment and their implementation may produce better outcomes than traditional instruction. Furthermore, Bargagliotti et al. (2012) claim that blended courses allow efficient distribution of time for in classroom instruction and enhance active learning as students learn at their own pace. The discipline of mathematics has not been an exception in offering hybrid courses. The diversity of modes of teaching and learning at present has broadened the options for 
students to access education, as it has never been before (Allen, Bourhis, Burrell, Mabry; Means, 2013; Simonson et al, 2013). One of the reasons for an expansion of multiple modalities of learning in mathematics is that "traditional methods and techniques used to produce a specialized group of mathematics learners may no longer be sufficient" (Peters, 2013, p. 461). Such expansion of instructional modes has been accompanied with strategies intended to meet students' needs. Particularly the pedagogies educators utilize for instructional delivery are factors that influence students' beliefs beyond the boundaries of performance (Peters, 2013). Students receiving face-to-face instruction attend a regular on-campus schedule where they interact with teachers, other classmates, and the course content. A similar situation occurs in instructional modes that involve some type of separation and where technology is determinant in supporting teaching and learning. Strategies teachers use for students' learning and for providing feedback are important in enhancing students' experiences in both instructional domains (Allen et al., 2002; Means et al., 2013).

Postsecondary education poses similar challenges to mathematics education as previous education levels do. Students' success and retention in general education mathematics courses are far from what is expected in colleges and universities (Bargagliotti et al., 2012). College Algebra is an important course in general education mathematics because it serves as a terminal course for several disciplines (Bargagliotti et al., 2012), as well as a gateway course for STEM major students (Haver, Small, Ellington, Edwards, Kays, \& Haddock, 2007). College Algebra enrollment ranges from 650,000 to 750,000 students per year nationally (Harver et al., 2007). An average of more than $45 \%$ of these students do not complete the course, less than $10 \%$ of them plan to 
pursue a technical job, and "a much smaller percentage end up entering the workforce in technical fields" (Harver et al., 2007, p. 34). A study addressing the characteristics of students enrolled in College Algebra indicates that no more than $20 \%$ of these students will take Calculus, and at most $5 \%$ of these students will receive formal training in mathematics (Herriott \& Dunbar, 2009). These facts demonstrate the importance of College Algebra as a general education mathematics course in undergraduate education. A considerable number of students, most of them from disciplines other than STEM, need to take this course as an important requirement for their programs. Research indicates that there is an opposite relationship between enrollment and success rate in College Algebra (Bargagliotti et al., 2012; Herriott \& Dunbar, 2009). College Algebra is one of the undergraduate mathematics courses with the highest level of enrollment. However, success in this course is significantly lower than in other undergraduate mathematics courses (Herriott \& Dunbar, 2009). Such an inversely proportional relationship between these two important indicators, enrollment and success in mathematics, reveals a latent crisis in students' competency in College Algebra. This crisis may have roots in multiple factors, including self-efficacy in mathematics. A discussion on ways to improve students' success and retention in mathematics has focused on putting changes in the curriculum and pedagogies into practice (Bargagliotti et al., 2012). With this goal in mind, initiatives have been implemented to raise students' achievement in mathematics courses in post-secondary education, including College Algebra (Bargagliotti et al., 2012). The use of technology resources has become a common instrument in attaining success. Some of these initiatives have included mathematics instruction delivered in accelerated, pathway, and modular formats. 
While all these initiatives are commendable attempts for improving performance in mathematics, it takes time to make them beneficial instructional alternatives across institutions. When introducing Dr. John King Jr. as the Acting Secretary of Education, President Obama emphatically expressed that "one of the things about education is that it doesn't deliver results tomorrow or the next day" (Obama, 2015). President Obama (2015) added that a change in education represents "a decade-long or longer proposition."

A substantial body of the empirical studies designed to examine self-efficacy in mathematics and its causal relationship with other constructs has largely targeted the elementary and secondary school levels. Previous efforts to understand this phenomenon in postsecondary education and their impact on student's decisions for future educational endeavors have prioritized remedial courses, also known as developmental courses (Clutts, 2010; Hood, 2012; Nordstrom, 2012; Zientek et al. 2013). Nevertheless, problems in mathematics education are not over once students complete remedial courses. A comprehensive review of the literature presented in Chapter 2 demonstrates that research in mathematics education addressing self-efficacy in mathematics in multicultural post-secondary education institutions is lacking. Additionally, it is still uncertain how student's self-efficacy manifests in undergraduate level mathematics taught using a hybrid modality. At the same time, one of the modes of instruction that has received less attention in mathematics research is hybrid teaching and learning.

Lee (2011) states that research studies on teaching and learning mathematics in the virtual classroom were scarce in the last decade. Further, Lee claims, "the problems of retention and success in online mathematics have not been addressed as much as in 
other disciplines" (2011, p. 17). Research addressing hybrid learning in mathematics is even more critical because it is limited, practically non-existing. Online-based learning has not yet reached its maturity period. Technological advances in the area of communication point to a worldwide expansion of online-supported learning rather than its extinction. While virtual classrooms use technology as a replacement for in class instruction, blended learning is seen as an enhancement of face-to-face instruction (Means et al., 2013). According to Means et al., effective planning and use of the asynchronous resources of a course may maximize students' experiences. Hybrid instruction, supported by internet-based platforms, has become popular in postsecondary education because it includes the direct interaction that face-to-face instruction offers and the flexibility of online learning (Means et al., 2013). The popularity of hybrid courses is reflected on an increase in its offerings in higher education institutions, and suggests the need to understand students' beliefs regarding this mode of instruction in mathematics in comparison to face-to-face instruction. Consequently, the present study proposed to enrich the body of research in mathematics education as it aimed to shed light on the relationship between the constructs of teacher's effect, self-efficacy, modes of instruction, and attitude in mathematics courses in an institution mainly serving minority students. Particularly, it provides insight on an unexplored perspective of the dynamics of the relationship between the aforementioned constructs and demographic characteristics of students. The area of research addressed here could benefit the community of higher education mathematics practitioners.

The evidence presented above (Aldridge et al., 2012; Hall \& Ponton, 2005; Hackett and Betz, 1989; Hood; 2012; Keisici \& Erdogan, 2009; Li et al., 2005; Peters, 
2013; Wheeler \& Montgomery, 2009) supports the hypothesis that self-efficacy in mathematics is a key factor in enhancing students' attitudes toward the subject and their persistence in attaining learning. The study carried out an exploration of teacher effect, self-efficacy, and attitudes toward mathematics among college students in face-to-face and hybrid college algebra. The assessment the present study conducted becomes a framework for administrators, counselors, and educators to design interventions and mentoring programs that supports students in fostering positive attitudes toward mathematics and increases the completion of their academic programs.

\section{Statement of the Problem}

Institutions of higher education nationwide are focusing on improving academic program completion rates as a response to meet the challenges imposed by global competition (NCES, 2015). Proficiency in mathematics has been associated with program completion and a prerequisite for applying to highly demanding jobs (NCES, 2015). Research studies have firmly established self-efficacy as a factor for success in school (Bandura, 1997; Chemers, Hu, \& Garcia, 2001). At present, the number of graduate students from colleges and universities in the U.S. does not reach the required levels for the U.S. to maintain its global leadership (U.S. Department of Education, 2009). One of the factors impairing students from completing their higher education studies is their low level of competency in mathematics (Chen \& Soldner, 2013; Lorah \& Ndum, 2013; Ross et al., 2012). The hardship of students not completing their postsecondary studies has an even more pervasive negative outcome for students from minority groups (Day \& Bauman, 2000; NCES, 2010; NCES, 2014; Means, Toyama, Murphy, Bakia, \& Jones, 2009). 
Research on self-efficacy beliefs and attitudes toward mathematics, as well as the interplay between these constructs and the effect of self-efficacy on performance has been documented up to the remedial level in postsecondary education. Little is known about the effect of self-efficacy in mathematics at the undergraduate level, particularly beyond the remedial level. The shortage of research on the interplay of self-efficacy with school related factors such as teacher's effect and the effect of these two constructs on attitudes of students in mathematics beyond the remedial level is a fact. The academic literature has not addressed the magnitude of the interrelationship of these factors in urban institutions of higher education within undergraduate mathematics and across modes of instruction. Additionally, research on how both students' demographics and modes of teaching and learning affect self-efficacy in mathematics is limited.

\section{Purpose of the Study}

The quantitative study examined the relationship between type of instruction and the factors underlying students' attitudes toward College Algebra. Furthermore, this study analyzed the effect of factors underlying the constructs of teacher's effect and selfefficacy, as well as the demographic factors of gender and mode of instruction on factors underlying attitudes of students to learn mathematics in the context of College Algebra in face-to-face and hybrid learning courses at a minority-serving institution of higher education as described in the model shown in Figure 1. The analysis departed from the common trend that online-based learning research has focused on examining the superiority of an instructional modality with respect to the other. 


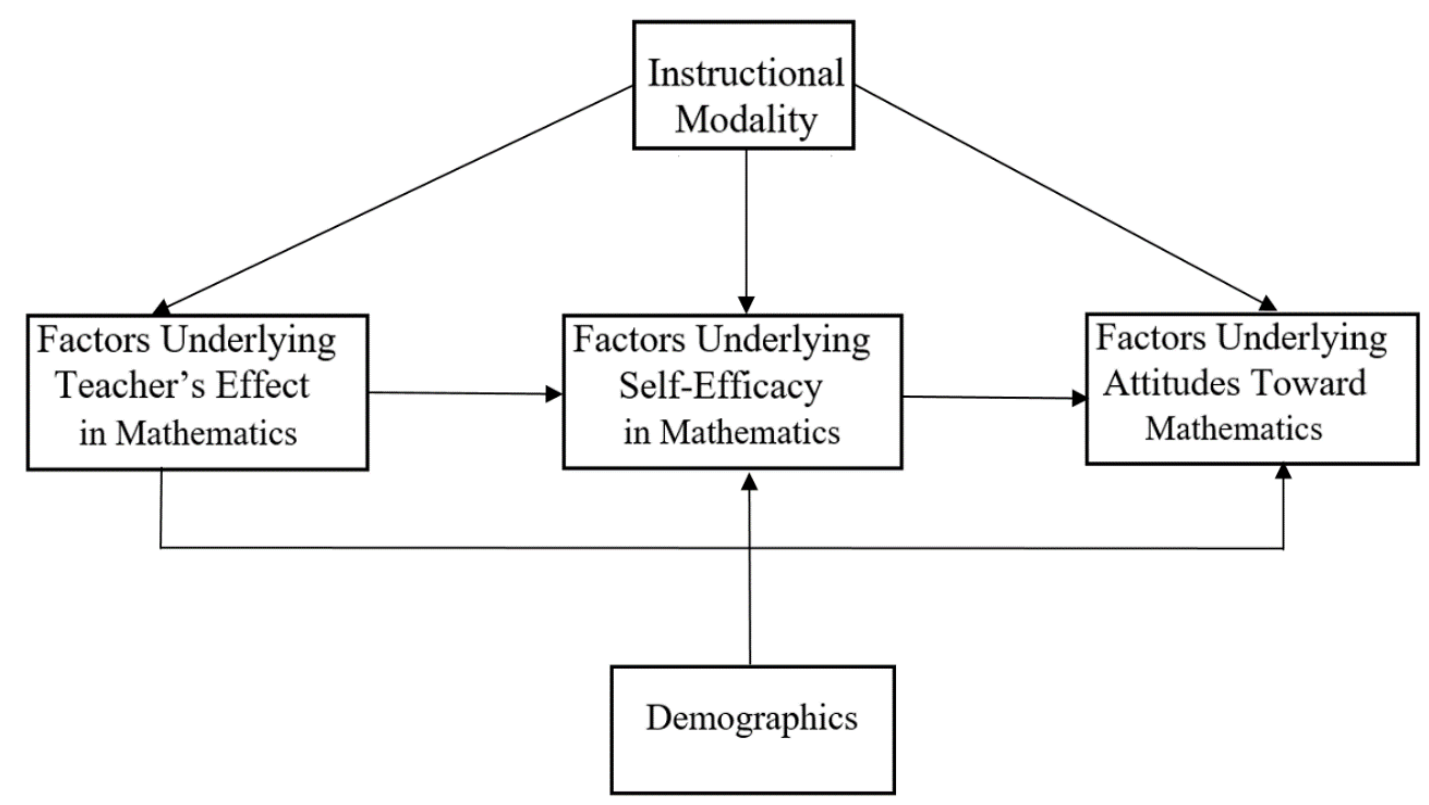

Figure 1. Model for the relationship between teacher effect, self-efficacy toward mathematics, demographics, instructional modalities, and attitudes toward mathematics.

\section{Research Questions}

Three research questions were used to guide this study:

Q1. Is there more than one reliable and interpretable factor underlying the constructs of teacher's effect in mathematics, self-efficacy toward mathematics, and attitudes toward mathematics in a sample of College Algebra students in a minorityserving College?

Q2. Is there a relationship between mode of instruction and the factors underlying the construct of attitude toward mathematics?

Q.3 How well does a model involving factors underlying teacher's effect in mathematics, self-efficacy in mathematics, instructional modality, gender, and factors 
underlying student's attitudes toward mathematics in undergraduate College Algebra delivered in face-to-face and hybrid learning modes fits the data?

\section{Theoretical Perspectives}

A significant bulk of the research on mathematics in postsecondary education has used performance as the main indicator of competency in the subject, yet performance itself accounts for a fraction of the capacity of an individual to function in an environment (Bandura, 1997). Performance gives an incomplete picture about an individual's capacity to complete a task or attain a goal. Bandura (1997) asserts that performance "alone does not provide sufficient information to judge one's level of capability, because many factors that have little to do with ability can affect performance" (p. 81). Bandura (1997) further stresses that individuals construct efficacy beliefs from factors that include perceived difficulty of the task being solved, the amount of external aid being received, the operational circumstances, and the temporal pattern of successes and failures. Perceived self-efficacy fits better than performance to explain the effect of the variability of the conditions under which an individual performs (Bandura, 1997).

Bandura's Social Cognitive Theory (SCT) (1986, 1989, 1993, 1997, and 1999) proposes that self-efficacy beliefs are the most determinant agent in infusing the confidence and the autonomy an individual requires to successfully complete an activity. According to Bandura (1993) "efficacy beliefs influence how people feel, think, motivate themselves, and behave" (p. 118). Bandura (1997) further emphasizes that beliefs shape the attitudes towards performing an activity and the values a person attributes to performing it. In the context of education, students' beliefs influence and stimulate their 
self-regulation to develop cognitive, emotional, and social skills that in turn affect their motivation, engagement, and capacity to be committed to educational endeavors they aim to pursue (Bandura, 1997; Hall \& Ponton, 2005). Strong beliefs in one’s self-efficacy expand the range of educational choices and strengthen the perseverance needed in attaining long-term goals (Bandura, 1997).

Bandura's Social Cognitive Theory (SCT) explains that human agency occurs through the interdependence of behaviors and both internal and external factors (Bandura, 1997). Similar to Bandura's SCT, Azjen (1988) asserts that the quality of a behavior does not depend only on the effect of the volition of an individual to commit the behavior. Individuals' capacities to perform a behavior vary according to the circumstances to which they are exposed (Bandura, 1997; Azjen, 1988). A person with strong attitudes and beliefs toward performing a behavior may be driven to fall short on the behavior. There may be instances where external factors, beyond an individual's control, deter or encourage the performance of a behavior (Azjen, 1988). These conditions may impact self-efficacy beliefs directly or indirectly. Consequently, beliefs of self-efficacy depend as well on the influence of agents where the volitional control of an individual is not sufficient to convert an intention into an action (Azjen, 1988).

Four major sources of information are found in building a sense of self-efficacy in an individual (Bandura, 1997). Enactive mastery experiences contribute to shape beliefs of self-efficacy as no other source because they instill judgements of competence based on interpretations of successes and failures (Bandura, 1997). Vicarious experiences refer to the capability of performance that individuals construct from referential comparisons with respect to achievement and failures of others. Verbal persuasions in the form of 
social influences from relatives, friends, and teachers serve to strengthen one's competence in reaching goals. Psychological and affective states involve somatic indicators of capabilities from which individuals build their competence to perform activities and accomplish outcomes. Negative emotional states such as apathy, anxiety, depression, and stress produce adverse outcomes in mathematics. As a result, emotional states regulate both psychological reactions and perceived vulnerability. Research studies have shown that self-efficacy sources are reliable in assessing the antecedents of selfefficacy (Joët \& Usher, 2011; Usher \& Pajares, 2009).

Research on self-efficacy in mathematics indicates that self-efficacy is an evolving quality that influences students' persistence and success. Students who perceive themselves as efficacious in mathematics do not feel stressed when performing mathematics tasks (Bandura, 1997; Kesici \& Erdogan, 2009). These students are confident about their skills and committed to succeed in accomplishing their goals (Bandura, 1997; Peters, 2013). Students with strong beliefs of their capabilities persevere in achieving the goals they have set for their future (Bandura, 1997). Poor performance usually does not deter these students from persevering in attaining their goals. These students foresee opportunities to improve their performance by deploying more effort and making use of available resources even if they fail in completing successfully a particular task as a part of attaining a goal (Bandura, 1997; Peters, 2013). According to the SCT, people who perceive value in the goals they envision and in their capabilities to achieve them find motivation to overcome substandard performances. Further, the SCT states that goals that demand significant effort and pose challenges pose a larger psychological reward. On the contrary, goals that are set without foundation on self-efficacy and lack 
commitment to be completed are eventually abandoned since there is no motivation to sustain them (Bandura, 1997). That is the case, for example, of those students who show negative beliefs toward mathematics, suffer from anxiety, and feel insecure about their capacity to carry out mathematics assignments. These students usually underperform in mathematics because of several causes. They doubt their capacity to solve mathematics problems, and they refrain from completing assignments, or even attempting to do them (Bandura, 1993; Kesici \& Erdogan, 2009). Besides, these students consider their deficit of skills a high hurdle. They usually anticipate failure as the potential outcome of their performance, and do not see opportunities for overcoming their deficiencies (Schunck \& Pajares, 2002). Students with low self-efficacy beliefs toward may get stuck under patterns of consistent failure, display poor social skills, and hold hostile attitudes that ultimately prevent them from attaining their goals (Schunck \& Pajares, 2002).

Perception of low self-efficacy can be changed if appropriate strategies are implemented (Bandura, 1997; Kesici \& Erdogan, 2009; Hall \& Ponton, 2005; Hodge \& Kim, 2013; Peters, 2013). Strategies that stimulate self-efficacy include providing frequent feedback that informs students about their progress (Peters, 2013), exposing students to learning environments that enhance and enrich their experiences in identifying ways that clarify conceptual gaps, and instilling a sense of confidence in students that it is possible to succeed in a mathematics course (Bandura, 1997). Learning environments that support students' participation and cooperation contribute to building high sense of selfefficacy. Students functioning under these conditions become self-efficacious in mathematics and attempt their best to attain their goals. Teaching and learning strategies that foster competitiveness inspire less sense of attainment and implicitly lead to isolation 
of those students who do not find appropriate assistance to overcome their weaknesses. The aforementioned framework underscores the role of self-efficacy as a mediator construct (Bandura, 1997; Hall \& Ponton, 2005).

\section{Operational Definitions of Terms and Variables}

The definitions of the terms and variables that are described as follows are relevant and limited to the context of this study.

Attitudes toward Mathematics. The composite of several theoretical aspects of the construct that includes value, anxiety, motivation, confidence, enjoyment, and adults' perspectives (Tapia, 1996).

Distance education (DE). Distance education is defined as the instructional mode that involves geographical and time separation between the instructor and the students. At present, technological resources such as the internet guarantee the connectivity in DE.

Hybrid instruction (Blended Instruction). It is an instructional modality that combines features of online and face to face instructions. The time allocated for online activities varies across institutions, usually from 30\% to $79 \%$ (Simonson, 2012).

Face to face instruction. It is a teaching and learning modality where $100 \%$ of the instruction occurs in a brick and mortar classroom.

Race/ethnicity. Defines sociocultural origins as reported by the participants. For the effects of this study race/ethnicity includes Hispanic, Black, White, Asian, Others.

Self-efficacy. Bandura (1997) defines self-efficacy as the judgments “in one's capabilities to organize and execute the courses of action required to produce given attainments" (Bandura, 1997, p. 3). The Hackett and Betz instrument (1982) was used to measure self-efficacy in mathematics. 
Teacher's Effect. Collection of “student's perceptions of their teacher's attitudes toward them as learners of mathematics. It includes the teacher's interest, encouragement, and confidence in the student's ability". (Fennema \& Sherman, 1976).

\section{Significance of the Study}

The interest on self-efficacy has grown over the years and solid theoretical frameworks have been established around it (Bandura, 1993, 1997; Lee, 2011; Nordstrom, 2012; Usher \& Pajares, 2009; Zimmerman, 2000). However, there is a surprising shortage of research addressing the relationship between self-efficacy in mathematics and other constructs at the undergraduate level (Peters, 2013). Research on mathematics education has overlooked examining the extent of the relationship between teacher effect, self-efficacy, attitudes toward mathematics, and demographic factors in undergraduate mathematics across modes of instruction. Academic literature urges conducting empirical work that fills the gap in the research on self-efficacy in higher education in undergraduate mathematics particularly in face-to-face and hybrid learning environments in underrepresented populations, as it is the case for minority groups.

Following the recommendations of Usher and Pajares (2009) to examine self-efficacy in populations with characteristics different from those used in prior studies, the present study was conducted in a minority-serving higher education institution.

The study represents a first attempt at examining the relationship of school-related factors such as teacher's effect, self-efficacy, attitudes as well as demographic characteristics of students in face-to-face and hybrid learning classes. Grounded in theory and research findings, this study became a unique effort to gather rich feedback from the point of view of students regarding the differences in attitudes toward mathematics across 
instructional modalities. Primarily, this study includes a comparison between face-to-face and hybrid learning in an urban college serving a majority of non-White students.

It was the primary goal of the research to add to the literature the missing knowledge about beliefs toward mathematics of students from non-traditional populations. The new knowledge this study produces may strengthen the theory and findings related to self-efficacy. Additionally, this study may serve as a scaffold for institutions of higher education when developing interventions that enhance students' experiences across teaching and learning modalities in mathematics and reduce patterns of unequal success in mathematics between racial groups.

\section{Delimitations}

The scope of this study is limited by the characteristics of the higher education institution where the sample was obtained. Most of the students attending this institution belong to minority groups, specifically Hispanic and Black students. Students in the sample self-selected the College Algebra courses that were used, either face-to-face or hybrid. Additionally, the context of the study was confined to College Algebra delivered through face-to-face and hybrid formats.

\section{Summary}

The present study proposed a model that explored the relationship among teacher's effect, self-efficacy, and attitudes in a sample of students in face-to-face and hybrid College Algebra classes. Additionally, the study was undertaken to analyze the effect of gender and mode of instruction on this relationship. Hybrid learning has become a popular means of instruction in today's colleges and universities. It represents a viable alternative for those individuals who are eager to attain their educational goals and either 
are not able to follow a regular on-site schedule or simply are willing to try a learning modality that offers a more flexible schedule. Administrators and professors nation-wide need to be aware of the particularities of implementing hybrid learning in higher education institutions. Hybrid instruction in mathematics is a growing area of research, albeit not new, that urges exploring what students think about learning mathematics in a non-traditional mode, where technology is used as a key resource to support learning, and comparing these students' thoughts with those of students in face to face mathematics classes. There is a significant shortage of self-efficacy studies and related constructs such as teacher's effect and attitudes in mathematics for minority students. The current study emerges as a response to fill this gap as it strives to provide insights on the minority students' beliefs toward mathematics, a sector of higher education population markedly underrepresented in research studies in mathematics education.

Chapter II provides a narrative of the review of the literature that includes further elaboration on a theoretical framework and the findings of prior studies relevant to building a case that supports the goal and directions of this investigation. Chapter III discusses the methodology and the research design of the study. Chapter IV presents the results of the study. Finally, Chapter V presents a discussion of the findings and implications. 


\section{CHAPTER II}

\section{REVIEW OF THE LITERATURE}

The review of the literature that follows presents empirical work that built a framework around the scope of this study. The chapter begins with an examination of research findings on teacher's effect, self-efficacy toward mathematics, and students' attitudes toward mathematics. Next, the chapter presents an overview of relevant research on instructional modalities. The overview on instructional modalities includes an examination of findings from meta-analyses studies and of relevant research on instructional modalities in mathematics. Finally, Chapter II examines the demographic factors of gender and ethnicity in mathematics.

\section{Teacher's Effect}

Wheeler and Montgomery (2009) explored students' views toward mathematics in redesigned mathematics courses, which included the application of the Standardsbased curricula (SBC). Redesigned courses in mathematics is an endeavor that pleads for the shifting of traditional lecture-oriented instruction to the use of pedagogies that facilitate self-learning throughout explorations and where technology plays a key role. Wheeler and Montgomery collected subjective views about mathematics from 74 students enrolled in remedial courses and basic statistics courses in two campuses of a small rural college. Wheeler and Montgomery selected students from these two courses to guarantee diversity of mathematics background in the study's sample.

Wheeler and Montgomery (2009) used the singular "Q methodologies" to analyze the data, a method that ranks individuals' statements or issues according to their beliefs. Three categories (factors) emerged from the participants' responses. The first category 
was active learners. Students from the active learners group expressed that they could perform well because of their potential, despite their previous negative experience and not being excited toward mathematics. These active learners thought that the combination of practice and good study habits were determinant ingredients for academic success. The active learning students viewed success as the result of arriving to the right answer in an assessment, which is the opposite mindset the SBC reform advocates for in mastery-oriented classrooms. In this regard, it appears that these students were most often taught using traditional techniques of instruction. The second category was that of the skeptical learners, which included students who viewed the instructor as the main factor for their success. Low achievement was a common issue in this group. Students in this group attributed their low achievement to instructors being rude and careless about their performance. The third category included confident learners, who reported to be mathematics-oriented students. These students believed the instructor's role was crucial in fostering meaningful learning experiences and nurturing their positive attitude toward mathematics. Most of these students were highly efficacious and performed at the higher level in mathematics. These findings indicate the key role of instructors in molding student's beliefs and self-efficacy in mathematics (Wheeler \& Montgomery, 2009). Moreover, Wheeler and Montgomery's findings are compelling evidence suggesting that instructors may have a positive impact in student's attitudes in mathematics independently of students' previous experiences.

Aldridge, Afari, and Fraser (2012) investigated the effect of learning environment on students' attitude in college mathematics. They developed a model to account for the direct and indirect effect of learning environment constructs (teacher's support and 
personal relevance) on attitude constructs (academic efficacy and enjoyment of mathematics lessons). The model included a path that showed a direct effect of academic self-efficacy on student enjoyment of mathematics. Three hundred and fifty-two students pursuing majors including primary-school teachers, engineering, and business responded to questionnaires addressing beliefs about each of the constructs. Aldridge et al. found that students pursuing engineering had the highest level of mastery in mathematics, while the business students had the least. Surprisingly teacher support was not a significant predictor of academic efficacy $(p>.05)$ but it did account for a significant amount of the variance of enjoyment of mathematics $(p<.001)$. Personal relevance was a significant predictor of both attitude constructs, academic efficacy $(p<.001)$ and enjoyment in mathematics $(p<.001)$. The strongest relationship in the model was that between academic efficacy and enjoyment of mathematics lessons $(p<.001)$. The combined effect of teacher support and personal relevance explained $9.4 \%$ of the variance of academic efficacy. Similarly, teacher support, personal relevance, and academic efficacy all together accounted for $49.3 \%$ of the variance of enjoyment of mathematics lessons. According to Aldridge et al. (2012), students who received more support from their instructors showed higher enjoyment when learning mathematics. At the same time, those students with higher personal relevance in mathematics were more efficacious academically.

Students enroll in colleges and universities with different mathematics experiences. For some students, their first mathematics class is a remedial course while other students are ready to enroll in college level mathematics courses (Dogbey, 2010; 
Hood, 2012). Still the effect of teachers' strategies on students' beliefs and success is critical in both cases (Hall \& Ponton, 2005; Wheeler \& Montgomery, 2009).

Feedback from instructors is an important source of fostering efficacy in students (Bandura 1997; Schunk \& Pajares, 2002). An instructor may change negative attitudes into positive attitudes through providing feedback that guides students to regulate discomfort or anxiety and inform them about their strengths and deficiencies (Bandura, 1997; Schunk \& Pajares, 2002; Schunk \& Meece, 2005). On the other hand, an instructor who exacerbates negative beliefs of students will in turn reinforce student's deficiencies and deter students from persisting in reaching their educational goals. Instructors' influence is a factor worth considering in mathematics education research as modes of instruction are becoming more diverse with technology as a key tool to support learning.

Rakoczy, Harks, Klieme, Blum, and Hochweber (2013) compared the effect of two forms of feedback in mathematics on the development of interest and achievement. A sample of 146 subjects divided in two groups received an intervention of either processoriented feedback or social comparative feedback while taking a mathematics assessment. Rakoczy et al. defined process-oriented feedback as the written feedback that informs students about their performance in mathematics to overcome challenges when working out problems in the subject. On the other hand, social comparative feedback refers to providing students feedback using on assessment grades. Rakoczy et al. assessed the comparison across forms of feedback through using two models. One of the models explored usefulness (perceived mindfulness) of feedback as a mediator between feedback and development of interest and achievement. Rakoczy et al. used another model to explore competence support (beliefs of competence from receiving feedback) as a 
mediator between feedback and development of interest and achievement on competence support. The findings from a structural equation modeling analysis indicated that there were not significant differences between forms of feedback. In other words, processoriented feedback was not a better form of feedback when compared to social comparative feedback in developing either interest or achievement in mathematics in any of the models. However, students saw process-oriented feedback as an effective strategy for competence support when compared to social comparative feedback that in turns enhanced their interest but not their achievement. Similarly, students perceived processoriented feedback as more useful than social comparative feedback in enhancing both their interest and achievement toward mathematics.

\section{Self-Efficacy in Mathematics}

Hall and Ponton (2005) compared differences in the mathematics self-efficacy between Intermediate Algebra and Calculus I in a sample of freshman students attending a southeastern university, wherein the demographic characteristics of the sample were not reported. Betz and Hackett Mathematics Self-Efficacy Scale (MSES) of 1983, an instrument with high internal consistency reliability $(\alpha>.90)$ and intended to measure self-efficacy in mathematics, served as the method for data collection. The comparison showed that Calculus I students were more self-efficacious in mathematics than Intermediate Algebra students $(t=8.902, p<.001)$.

Kesici and Erdogan (2009) sought to examine the role of motivational beliefs and self-regulated learning strategies on mathematics anxiety in a sample of college students taking a course on general mathematics in a Turkish university. These students were science-related education majors in disciplines such as physics, chemistry, computer and 
teaching technologies, and science education. Kesici and Erdogan used the Motivated Strategies for Learning Questionnaire (MSLQ), an instrument that includes the motivation scale and learning strategies scale, developed by Pintrich, Smith, Garcia, and McKeachie in 1991. The subscales of motivational beliefs included intrinsic goal orientation $(\alpha=.74)$, extrinsic goal orientation $(\alpha=.62)$, task value $(\alpha=.90)$, control of learning beliefs $(\alpha=.68)$, self-efficacy for learning and performance $(\alpha=.93)$, and test anxiety as subscales $(\alpha=.80)$. The learning strategies subscale included rehearsal ( $\alpha=.69)$, elaboration $(\alpha=.76)$, organization $(\alpha=.64)$, critical thinking $(\alpha=.80)$, metacognitive self-regulation $(\alpha=.79)$, time and study environment management $(\alpha=.76)$, effort regulation $(\alpha=.69)$, peer learning $(\alpha=.76)$, and help-seeking $(\alpha=.52)$. Kesici and Erdogan (2009) applied stepwise regression analysis to examine the effect of motivational beliefs and self-regulated learning strategies, as well as their subscales, in mathematics anxiety. Test anxiety and self-efficacy for learning and performance were the two subscales of motivational beliefs that accounted for a significant amount of the variance of mathematics anxiety (18\% and $22 \%$ respectively). Rehearsal and elaboration of cognitive learning strategies were the subscales of self-regulated learning strategies that significantly predicted mathematics anxiety, although in a smaller size, than the motivational beliefs subscales (3\% and $7 \%$ respectively).

Peters (2013) conducted a study that analyzed the relationship among classroom climate, self-efficacy, and achievement in a population that included College Algebra instructors and students from ten higher education institutions across the United States. In both groups, most of the participants were White women. Instructors completed a survey that collected their views about classroom climate at the beginning of the term. 
Classroom climate served as the reference for the type of teaching orientation instructors adopted in their courses, namely teacher-centered orientation or students-centered. At the end of the semester, students' responses on a survey that assessed their self-efficacy, as well as their score in the final exam, were used along with their instructor's survey.

Peters (2013) conducted an analysis using hierarchical linear modeling at two levels: student level and classroom level. The analysis at level 1 showed that male students were more efficacious in mathematics than female students $(\mathrm{t}=-2.57, p=.022)$. However, there were no significant differences in mathematics achievement with respect to gender $(p=.538)$. A one-way ANOVA with random effects showed significant differences in self-efficacy and achievement at the classroom level, $\left(\chi^{2}\right.$ classroom-selfefficacy $=37.94, p<.001 ; \chi^{2}$ classroom-achievement $\left.=57.07, p<.001\right)$. Classroom climate accounted for $40 \%$ of the differences in self-efficacy. The relationship between classroom climate and self-efficacy favored the classrooms where instructors used teacher-centered approaches. Contrasting previous studies results (Cheema \& Kitsantas, 2014; O'Reilly, 1975), Peters found that classroom climate was not a good predictor for achievement in College Algebra $(t=-1.23, p=.240)$ in terms of teacher-centered and student-centered modalities.

Peters stressed that the characteristics of the students' population might have been a reason for lack of the predicting effect of classroom climate. Participant students were late teenagers or young adults. In this regard, Peters hypothesized that these students may have been influenced from years of teacher-center approach in their previous mathematics classes. Additionally, Peters added that most of these students had previously taken mathematics courses at a level higher than College Algebra in high 
school, which could have accounted for the no differences in performance attributed to classroom climate. However, Peters suggested an implicit indirect effect of classroom climate on achievement mediated by self-efficacy, even though no direct effect was found. Path analysis is a statistical method that would have helped to clarify such an indirect effect. Furthermore, as Peters stated, other findings would have been likely obtained if the sample used in the study would have been different. A comprehensive study analyzing the same variables Peters used in her study requires a more diverse sample that truly resembles the composition of the population attending postsecondary institutions.

\section{Instructional Modalities}

\section{Meta-Analyses on Instructional Modalities}

Empirical evidence indicates that understanding how instructional modalities work contributes to identify areas for quality improvement of instruction (Allen, Mabry, Mattrey, Bourhis, Titsworth, \& Burrell, 2004; Bernard, Abrami, \& Lou, 2004). Comparing technology-based instruction modalities with traditional instruction is a line of research that has received significant attention from researchers in different disciplines across educational levels. Studies on technology-based instruction have primarily focused on determining the instructional mode that renders the highest academic standards. A research-based debate flared by Russel (1999) in No Significant Difference, showed mixed results about these two instructional modalities. On one hand, an important body of research studies has attempted to point out that the use of technology in the classroom has not produced better results in achievement of students when compared to traditional instructional settings (Paden, 2006; Russell, 1999; Thirunarayanan \& Perez-Prado, 2001). 
A perspective supporting the use of technology in the classroom has declared that onlinebased instruction is an equally effective instructional alternative (Allen, Bourhis, Burrell, and Mabry, 2002; Means, Toyama, Murphy, \& Baki, 2103; Phipps \& Merisotis, 1999; Means, Toyama, Murphy, Bakia, \& Jones, 2009) to traditional instruction. These two lines of research have concluded the same: students may learn in both instructional modalities.

The following section presents a synthesis of the findings of meta-analyses studies that have addressed several aspects of attitudes to learning and where online-based technologies plays a relevant role in teaching and learning.

\section{Synthesis of Findings of Meta-Analyses}

Allen et al. (2004) conducted a meta-analysis that compared students' achievement in distance education (DE) and classroom-based instruction. The study investigated the effect of moderator variables such as type the channel of delivery in DE, differences of course content in students' achievement, and differences between the synchronous DE and asynchronous DE in students learning.

Channel of delivery for course content dissemination included video, audio, and text. Channel of delivery as a variable was not a factor that affected student performance significantly in DE courses. Nevertheless, video was the communication channel producing the highest sensory levels and text produced the least. Instruction through video and written texts had just a slightly significant effect on student performance. Audio channel had an effect of similar magnitude. Allen et al. did not conduct an analysis on the effect of the combination of channel of delivery and student achievement, which may have produced additional conclusions. 
Allen et al. conducted an analysis on the relationship between discipline and role of technology. They included courses in the categories of natural sciences and engineering, social sciences, military training, foreign languages, education, and across content areas. Allen et al. observed that technology in DE favored foreign language courses with a higher effect on student learning as in no other discipline. Distance education in these foreign language courses used technology to promote conversation of learners with native speakers. The use of technology served as an effective strategy to mastering a foreign language. The result Allen et al. found regarding the positive effect of technology to promote conversation of learners with native speakers supports the claim that distance education is more effective in some disciplines than in others (Allen et al., 2004; Thirunarayanan \& Perez-Prado, 2001).

Achievement of students in DE courses that used either synchronous or asynchronous interaction was modestly higher than in traditional courses. An unexpected result was that using synchronous instruction showed no higher achievement of students in comparison to using asynchronous technologies in DE courses (Allen et al., 2004). New electronic devices (computer, tablet, and cell phone) and applications combined with enhanced internet connection, although still expensive, have opened additional opportunities to make instruction accessible to more people and facilitate its expansion beyond the local scope (Simonson et al., 2013). Any student working or living in a remote location with access to a computer and internet may interact with the content, the instructor, and other students. It is therefore important that instructors utilize modern technologies wisely to support instruction and instill a sense of self-efficacy among all students. 
Despite the overall comparison of instructional methods in Allen et al. study indicating that students enrolled in DE courses performed slightly higher than the students enrolled in the traditional instructional environments, the results were not quite reliable due to the very low value of the measure correlation of the sample. Type of instruction (DE/traditional) was not a factor that explained significant differences in achievement in such sample. A factor not considered in the Allen et al. study was students' demographic traits, which might have accounted for sample difference. Another limitation of the study was that it was not possible to carry out an analysis across DE formats (Allen et al., 20014). The DE courses differ in the type of technology used and the way it is used. Gathering feedback about what students believe of the functionality of channels of communication in facilitating their learning experiences; it is important to meet their needs and enhance the effectiveness of DE courses. Additionally, assessing the extent of students' attitudes and beliefs toward the subject and the instructional setting is important to design effective pedagogies across instructional modes.

Bernard et al. (2004) compared the achievement, attitudes, and retention between students in DE courses and students in classroom-based instruction. Bernard et al. found a small but significant effect of DE instruction on achievement with respect to classroombased instruction. Bernard et al. analyzed several facets of attitudes: attitudes toward courses, attitudes toward subject matter, attitudes toward technology, and attitudes toward instructor. The analysis produced no significant differences of attitudes across modes of instruction. Retention of students was significantly much higher in classroombased courses than in synchronous or asynchronous DE instructional settings. Bernard et al. examined the contribution of methodology of study research, type of pedagogy, and 
media to predict achievement, attitude, and retention. Furthermore, Bernard et al. (2004) analyzed differences between synchronous and asynchronous DE instruction. Pedagogy predicted attitude in asynchronous DE only (Bernard et al. 2004). Media, however, predicted attitude in both DE modalities. None of the indicators (methodology, pedagogy, and media) predicted retention. Methodology explained a higher proportion of the variance of achievement in synchronous DE than in asynchronous DE. Overall, synchronous and asynchronous instruction improved students' performance with a higher proportion accounted by the asynchronous mode. Both forms of DE instruction produced similar effect on student's attitude. However, the asynchronous mode produced a lower proportion of students' retention when compared to the synchronous mode, a distinction possibly accounted for by the empathy and sense of belonging that can seemingly be more pronounced in live-instruction.

In general, there was no sufficient evidence to conclude that the level of achievement, attitude, and retention was higher in DE classrooms and therefore to uncover the dilemma of what method works better. According to Bernard et al. the effectiveness of DE depends on the way it is applied because "there were instances which the DE group outperformed the traditional instruction group by more than $50 \%$, and there were instances in which the opposite occurred ... by $48 \%$ or more" (Bernard et al., p. 406). In this regard, Bernard et al. underscored that educational environment that combines peer collaboration and opportunities for communication are effective in fostering students' positive attitudes and in increasing their achievement.

Bernard et al. (2004) analyzed the strength and quality of the methodology sections of the studies used in the meta-analysis as essential factors affecting the findings 
of the studies in the meta-analysis. As an average, three out of five studies used in the meta-analysis did show weaknesses in the methodology they used. A common weakness was the poor descriptions about the conditions under which face-to-face instruction occurred, thus making the comparison between instructional modes challenging. This observation has wide implications for educational research. Bernard et al. warned that studies with weak research methodology (lack of internal validity) placed their external validity at risk, thereby leaving generalization of the findings more in question.

Allen, Bourhis, Burrell, and Mabry (2002) examined the level of satisfaction students experienced in both DE and traditional courses in postsecondary education. One of the examined aspects was the effect of the channels of communication to support interaction. The channels of communication included written, video, and audio channels. The overall analysis indicated that the more information a channel contained the more effective it was. As expected, Allen et al (2002) found that students preferred video channels of communications. Another aspect that served as a reference for satisfaction was the interaction with the instructor. Surprisingly, Allen et al. (2002) analysis indicated that interactivity of the media (resources and time used in DE courses to establish interaction with the instructors and for receiving feedback) was not a significant factor in affecting students' satisfaction. In other words, the frequency of students-instructor interaction did not influence experiences of students in DE courses. According to Allen et al. this result "is inconsistent with what most scholars would normally expect" (p. 91) as it is assumed that more interaction will produce better results if the interaction is effective in guiding students to succeed with clear feedback on progress status. 
Lou, Bernard, and Abrami (2006) compared achievement of undergraduate students in face-to-face and DE learning conditions. Lou et al. also addressed the relationship media versus pedagogy in $\mathrm{DE}$, as well as the role of this relationship in moderating achievement of undergraduate students. Specifically, the analysis aimed at identifying major types of media-supported DE pedagogies and understanding how media and pedagogy supported interaction, as well as its effect on student success. Additionally, the study attempted to identify variables affecting student' learning in DE.

Lou et al., 2006 found three types of pedagogies related to interaction in DE. They included

1. Instructor-Directed. It is the form of interaction between the instructor and students mediated by technology.

2. Independent. It is the form of interaction of students with the course content.

3. Discussion among Students. It is the form of interaction among students that includes collaboration in discussion forums.

The effect of these pedagogies in DE courses produced no significant differences in students' performance. Lou et al. found that students achieved at the same level in classrooms mediated by synchronous instructor-directed DE (a simulation of the traditional classroom where the learner can be in-site or out-of-site) independently of the learner location. Face-to-face meetings with the instructor and student-instructor activities were strategies that produced a significant positive effect in student learning in DE courses. Asynchronous DE learning in a remote site was not different to asynchronous DE learning in a host site (Lou et al., 2006). Media as a tool to reinforce student-content interaction in asynchronous DE settings (interaction that does not occur 
at the same time) was not a factor that influenced difference in students' learning in the DE and traditional instructional settings. However, DE students slightly outperformed those students in the traditional groups in some forms of student-content activities (media applications) that required students using self-regulation skills such as in tutorials, simulations, broadcast TV or video tape. Similarly, media as a tool to reinforce studentstudent collaboration and enhance students' discussion sessions in asynchronous DE settings was a significant factor that moderated students' success, favoring overall students' performance in DE with respect to the performance of face-to-face students. The significant role of using media in student's success indicates that learning through asynchronous collaboration that fosters rich conceptual discussions in small groups produces positive learning outcomes as students may share reflections and clarify doubts (Lou et al., 2006). Besides, the instructor's strategies played an important part in fostering student engagement and in making the asynchronous DE an effective learning mode.

As mentioned above, one of the goals of Lou et al. study was to identify factors affecting learning other than the effect of media and pedagogy. Readiness of students with respect to enrolling in DE courses was a significant moderator variable predicting DE students' performance. Distance education courses demand discipline to complete a significant amount of independent work. Those students who are not ready to work without direct instructor supervision as in face-to-face learning will struggle to succeed. They may experience frustration and disappointment as the course progress. Explicit information on the formulation of online courses regarding course content, assessments, 
and expectations provides students with concrete ideas about the dynamic of learning in online courses and their responsibility in attaining success.

Means, Toyama, Murphy, \& Baki (2013) compared achievement in online and blended instruction versus achievement in classroom-based instruction. Means et al. focused on studies that used practices (interventions) as moderators of effectiveness of online learning and that influenced student's achievement directly and on other measures of learning outcomes in disciplines that included medicine, computer science, teacher education, liberal arts, mathematics, and science. Additionally, Means et al. examined the conditions under which the practices/interventions took place, and teaching methods. Practice variables included instructional pedagogies, opportunity for online and face-toface interaction with the instructor and other peers, and opportunity for receiving feedback. Learner types (academic level) and subject matter were two of the conditions variables. The comparison of instructional modes showed that web-based learning instruction (pure online and blended) had a slight advantage to face-to-face learning with respect to achievement of students. Findings indicated that students learned more in blended learning than in pure online learning when compared to face-to-face instruction. Collaborative instruction and expository instruction in online learning were pedagogies that produced a positive effect on the achievement of students (Means et al., 2013). Conversely, online learning environments that adopted independent learning were not as effective. The lack of effectiveness Means et al., 2013 found in their study contrasts with findings of previous studies that declared that a shift from instructor-centered to independent or active learning is more effective learning mode (Means et al., 2013). Receiving feedback and opportunity for interaction with instructor and peers in 
asynchronous mode, as well as direct interaction with the instructor and peers during instruction produced significant positive differences. None of the condition variables moderated the effectiveness of online learning. It appears that online learning was superior to face-to-face, independently of the academic level of students and the subject matter they were taking (Means et al., 2013). Differences in curricular materials and instruction were significant moderators of online learning.

Means et al. cautioned readers when interpreting the findings from their metaanalysis. Undoubtedly, technology by itself does not propel dramatic changes in knowledge acquisition. Instead, the combination of technology with pedagogies is what may work as an effective pathway in supporting student learning. Blended learning involves a more complex dynamic than other modes of instruction because it involves "more learning time, additional instructional resources, and course elements that encourage interaction among learners" (Means et al., p. 36). According to Means et al., the confounding nature of these conditions bears better learning outcomes.

Means et al. remark that research studies on online learning, either pure online or blended, have failed in providing rich descriptions on the practices that enable students to learn such as instructors' pedagogies and online activities. Means et al. further added that "effective practices for learners with different levels of motivation and different senses of efficacy in the subject domain of the online experience need to be study as well" (p. 38). This research study pursues to contribute to the literature while addressing Means et al.'s concerns from the students' points of view. 


\section{A Reflection on the Findings of the Meta-Analyses}

The evolution of education at a distance from instruction by correspondence to online education has changed the dynamic of the interaction and collaboration in the classroom (Lou et al., 2006). The insertion of technology along with the advantages of the internet and novel electronic resources provide students who enroll in online-based courses free access to the course components (content resources, assessments, communication tools) which are adaptable to their needs of time and location (Means, Toyama, Murphy, Bakia, \& Jones, 2009). Online-based education is an instructional modality that serves a significant portion of the population of adult students for many several reasons. In some cases, students enroll in online-based courses because they cannot comply with a strict on-campus schedule (Lou et al., 2006; Means et al., 2009a) or simply choose not to attend school (Means et al., 2013). Other students choose to enroll in these courses because technology gives them the opportunity to learn in a more interactive environment. Nowadays applications of online-based instruction include resources to promote interaction of students with the instructors, other classmates, and course content. Students are required to complete assignments such as warm-up assignments, video reflection, discussion forums, conceptual homework, and unit projects. Students are allowed to submit their several times, prior the due date. When completing these assignments, students receive feedback not only from the instructors but from other classmates. Activities such as warm-up assignments, video reflection, discussion forums, conceptual homework, unit projects, and other activities students may build a sense of learning communities in students. 
The expansion of online-based education as a well-established instructional modality in higher education institutions has come together regardless of the gaps in the literature. These gaps include a comprehensive evaluation of factors that affect students' beliefs in academic disciplines such as in mathematics at undergraduate level. Studies addressing online teaching and learning in mathematics are scarce in the last decade (Lee, 2011). Lee (2011) claims that "the problems of retention and success in online mathematics have not been addressed as much as in other disciplines" (p. 17). However, retention and success are not tangible if the conditions to make them sustainable in the long term do not exist. One of these conditions is creating a sense of self-efficacy in students that help them reach academic success. Factors that affect self-efficacy in mathematics and how self-efficacy affects students' attitudes toward mathematics are areas not yet addressed in depth across instructional modes in post-secondary education. Further, studies in mathematics across learning environments have overlooked minority populations.

Detecting differences in achievement between students in DE courses and students in face-to-face courses have been the purpose of a significant portion of studies comparing instructional modalities. A common finding, briefly discussed above, indicates that student achievement in online-based (either pure online or blended) is similar to students' achievement in the traditional instructional mode. Additionally, findings from these studies have identified common themes that are significant to understand how the teaching and learning dynamic in online-based courses influence students' experiences. These areas include the effect of pedagogies to foster engagement in learning and commitment to completion. Application of media in DE instruction facilitates 
collaboration and enhance student's attitude (Allen, et al, 2002; Bernard et al., 2004; Lou et al., 2006). For example, Bernard et al. found that using asynchronous pedagogies effectively render positive students' attitudes in DE because the interactions in asynchronous modes produce systematic support and provide feedback to students at any time during the course.

Previous research has aimed to account for the effect of pedagogies in students' beliefs and behaviors toward achievement: the final product of learning (Allen, et al, 2002; Bernard et al., 2004; Lou et al., 2006; Means, 2013). An analysis that focuses only on achievement and obviates other aspects of the learning process becomes an incomplete effort (Bandura, 1997). Consequently, an examination of the effect of teacher's instructional strategies across modes of instruction may shed light on differences of beliefs toward mathematics particularly in underrepresented populations. Allen et al. (2004) noticed that online resources in DE foreign language courses favored students learning. At present, media platforms for mathematics online-based courses support a wide range of interactive applications such as online videos, animations, discussion forums, internal course messages, and collaborative workspace (e.g., wiki). These resources are accessible to students at all time. Effective use of media that provides systematic feedback on course progression, opportunities for supporting course content mastery, and facilitates interaction with classmates and the teacher in hybrid mathematics courses may contribute to enhancing student's experiences, foster self-efficacy in the subject, and ultimately boost student's attitudes. 


\section{Highlights of Prior Research on Instructional Modalities in Mathematics}

Clute (1984) explored mathematics anxiety, instructional method, and achievement with a group of 81 students enrolled in a survey course that covered problem solving and critical thinking in mathematics in two higher education institutions in California. The two instructional methods (treatments) Clute used were direct instruction discovery method and direct instruction expository. The direct instruction discovery method happens when students are at the center of learning and the teacher actively guides students to come up with the solution to problems. The direct instruction expository is an instructional method where the instructor is at the center of instruction. Students who participated in the study needed mathematics as part of their general education prerequisites either to graduate or to continue their education. Clute split the sample into three groups: (a) students enrolled in humanities or social sciences careers, (b) students pursuing an elementary school major, and (c) freshman and sophomore students. Clute used the Mathematics Anxiety Rating Scale (MARS) to gather information on students' anxiety and to assign students randomly to one of the treatment groups.

The administration of this assessment produced three levels of anxiety: low, medium, and high. Clute found no significant differences in the level of anxiety in students from both colleges. The MARS was administered at the beginning of the semester to avoid an effect on students' anxiety from the performance in the course (Clute, 1984). The University of California and California State University Mathematics Test (UC/CSU Mathematics Test) served to screen students' background in mathematics (Clute, 1984). With this test, Clute aimed to assess the computational competency of 
students and the equivalence between treatment groups and higher education institutions groups. Results from the UC/CSU Mathematics Test indicated no significant differences between colleges and treatments across levels of anxiety.

Subsequently, Clute administered a Mathematics Achievement Test at the end of the term to collect information of students' progression in mathematics. Results from an ANOVA test indicated that level of anxiety was a cause of success or failure $(F=10.11$, $p<.01)$. That is, students with a higher level of anxiety scored at the lowest level in the mathematics achievement test while students with less anxiety performed better in the achievement test. Students from both treatment groups performed at the same level $(F=.65, p>.05)$ in mathematics. However, there was a significant interaction between level of anxiety and instructional method. On average, students with low and medium level of anxiety performed better in mathematics in the direct instruction discovery group, while students with higher level of mathematics anxiety performed, as an average, better in the direct instruction expository method.

DePriter (2008) conducted a study on the role of collaborative learning as a tool to foster mathematics achievement in the virtual mathematics classroom. DePriter compared mathematics achievement of adult learners in an individual learning instructional setting (objectivism) versus mathematics achievement of adult learners in a cooperative learning instructional setting (constructivism). Both instructional settings followed a web-based design. Following a quantitative experimental design, the study used a pretest-posttest control-group because, as it appears, Depriter attributed more value to numerical results than to descriptive perceptions. The sample included 35 subjects enrolled in a remedial mathematics class. The data collection instrument included 25 multiple choice questions 
and three open-ended or free response questions resembling the structure of the General Education Development (GED) administered to a randomly selected sample.

Depriter's methodology followed a pretest-posttest control-group design. Depriter conducted a t-test on the results of the pretest scores to access the level of achievement in both groups. The t-test indicated that achievement in mathematics did not differ significantly between the students in the collaborative learning group and the students in the individual learning group $(p=.269)$. Similarly, results in both pretest and posttest produced the same level of achievement in the multiple-choice questions as well as in the open-ended questions. Depriter carried out an ANCOVA to determine the effect of the pretest score in the results of the posttest and to determine the extent of the free response questions as a measure of collaborative learning. For the ANCOVA, she used the pretest scores as the covariate, the type of instruction as the independent variable, and the posttest score as the dependent variable.

The ANCOVA showed an equivalent level in the mathematics achievement of students in both online instructional modalities $(F=.823, p=.371)$. Additionally, she found that the pretest was a good predictor of the posttest scores only in the individual learning setting. In other words, students who scored at the highest level in the pretest in the individual learning group were the same students who performed well in the posttest. Similarly, Depriter (2008) found that students who scored higher in the multiple-choice section of the posttest were those students who did better in the open-ended items of the posttest. However, most students in the individual learning group did not attempt to answer the free response problems. According to Depriter, this finding was a strong indication that those students who received collaborative learning instruction showed a 
higher disposition "to attempt advanced mathematics problems than those students taught using an individual learning approach" (p. 105). However, asserting that collaborative learning instruction influenced disposition of students to complete advanced mathematics problems is a conclusion not quite tangible to arrive at in a quantitative study that did not use a survey. Alternatively, through a qualitative analysis she would have been able to capture a better image of participant's perceptions. Depriter was not able to measure student's dispositions, as she did not use interviews and/or observations for data collection.

A goal of Depriter's study was to extend the results to other populations in postsecondary education in the United States. According to her study, a small sample of 33 cases was representative of all DE students in the nation. Random sampling occurs when any member from a population is likely to participate in an experiment (Hamburg, 1991; Triola, 2001), which was not the case of Depriter's study. Depriter's study was a case of judgment or convenience sampling because the sample was not random. Moreover, she did not explain randomization techniques and the criteria she followed to guarantee an equal representation in the sample's study of all students enrolled in the higher institution where she conducted the study. She vaguely described the characteristics of students and the postsecondary institution serving these students. Providing this valuable information would be imperative for generalizing the study's findings to other institutions serving higher education populations was DePriter's goal. Additionally, Depriter did not conducte an analysis on the effect of gender and ethnicity in her study. These demographic indicators have become important factors to consider 
when analyzing educational issues in an evolving and diverse society as that of the United States (Stevens, Olivarez, Lan, \& Tallent-Runnels, 2004).

Depriter cited plagiarism and students' low activity in the online course as issues that affect student success in DE courses and stated these as the two reasons for students failing in DE courses. However, the extensive case Depriter made on plagiarism failed to connect to the purpose of her study and with the findings nor did it establish a coherent relationship of plagiarism on the differences between constructivism and objectivism. Depriter expressed that "unlike in a face-to-face setting, a distance learning setting may make it difficult to ensure that students are still active members of the class" (p. 97) to justify student's low activity. Powerful online platforms have been providing close supervision on student's activities, including assessments, and attendance in DE courses for more than 10 years. Depriter should have stressed the role professors play in monitoring and facilitating interaction and in making sure that students are active users while enrolled in the curse. Professors need to contact students on a regular basis to encourage them in keeping track of course assignments deadlines as well as to set regular updates on students' academic status in the course. As such, Depriter should have explained the role of the instructor in student's learning, how the instruction occurred, and explicitly elaborated on the differences in instruction by using constructivism and objectivism.

Lee (2011) studied students' success in DE mathematics courses in two-year higher education institutions. Lee explored the relationship between the seven principles for good practice in undergraduate education and student success, the effect of tutoring services in student success, and the effect of technology proficiency in student success. 
Lee rooted her study in the low achievement of students taking online courses in mathematics compare to the students in face-to-face courses.

The seven principles for good practice in undergraduate education are

1. Good practice encourages contact between students and faculty

2. Good practice develops reciprocity and cooperation among students

3. Good practice uses active learning

4. Good practice uses prompt feedback

5. Good practice emphasizes time-on-task

6. Good practice communicates high expectations

7. Good practice respects diverse talents and ways of learning.

Lee administered an online survey (via email) to a convenience sample of 95 students who took an introductory statistics course at a community college. This form of data collection is an appropriate method when the research study does not include intervention (Gal \& Gal, 2007; Triola, 2001). One part of the survey included questions aimed to measure the use of online resources, student-instructor and student-student interactions, as well as tutoring services, which Lee called the Self-Assessment Questionnaire. The other part of the survey included questions about the demographic characteristics of students.

A regression analysis on the relationship of the seven principles of good practice in undergraduate education and student success in an online mathematics course showed that principle one, contact between students and faculty $(F=3.337, p<.05)$, and principle three, students use active learning $(F=2.373, p<.05)$, were good predictors of students' success. According to Lee, these findings indicated that interaction via 
electronic messages was associated with student achievement. Regarding to the effect of tutoring services on students' success Lee found that tutoring services explained a significant amount of the student's final grades $\left(F=6.218, p<.05, R^{2}=.26\right)$. To explore the impact of students' technology proficiency on their success in the introductory mathematics course Lee used computer requirements, student's proficiency with computer and calculators, ability to solve online homework, ability for taking online quizzes, and technology support as factors affecting success in mathematics. The combined effect of all these factors explained a significant amount of success in mathematics $(F=7.571, p<.05)$.

The efficacy of hybrid education in mathematics has been poorly addressed at college level. Research on hybrid teaching and learning has focused on comparing this instructional modality to traditional learning in terms of achievement in non-STEM disciplines. Additionally, research on hybrid instruction has examined the effect of the instructional features on student's satisfaction this modality offers in disciplines other than in mathematics. Calderon, Ginsberg, and Ciabocchi (2012) addressed the effect of feedback on student's satisfaction in blended courses in a private university. Students who participated in the study were enrolled in the Web Learning Project (WLP), a blended initiative developed for students majoring in health, information science, or computer science. Calderon et al. gathered data from two surveys administered in the fall of 2010 and the spring of 2011 terms. One of the surveys was the WLP Student Survey, a mixed quantitative and qualitative online questionnaire that collects demographic data from participants as well as about its experiences in blended courses. The second instrument was the WLP Faculty Survey, an online questionnaire that asks about the 
quality of online courses and includes questions on six categories. The categories are as follows: (1) Learner Support and Resources, (2) Online Organization and Design, (3) Instructional Design and Delivery, (4) Assessment and Evaluation of Student Learning, (5) Innovative Teaching with Technology, and (6) Faculty Use of Student Feedback (Calderon et al. 2012). One of the aspects the study focused on was students' experiences in blended learning compared to those of student in traditional courses (faceto-face).

In this regard, students identified flexibility to complete course assignments from anywhere and anytime as the main reason to enroll in hybrid course (Calderon et al., 2012). Student in the fall term expressed that their experiences in blended learning did not exceed their experiences in face-to-face. On the other hand, students in the spring term indicated that that blended courses demanded more work than face-to-face and did not provide sufficient opportunities for direct interaction with instructors (Calderon et al., 2012). Overall, students expressed their satisfaction with blended course as an alternative mode of instruction (Calderon et al., 2012).

Flexible schedules for students to learn at their own pace, communication with peer students, and the instructor meetings emerged as the most effective features of blended courses for students' preferences to enroll in blended courses. Additionally, students indicated that satisfaction in blended learning is a direct function of availability of resources to support instruction. In fact, sufficiency of resources for blended learning emerged as the best predictor of students' satisfaction, $p<.001$ (Calderon et al., 2012) "with $60 \%$ of the variability in students' satisfaction during the fall semester and for $38 \%$ of the variability" (Calderon et al., p. 31, 2012). Responses from the faculty survey 
reported as adequate that quality of the blended courses in both terms (Calderon et al., 2012, p. 31). All categories except innovative teaching with technology predicted quality of the blended course in the fall term. In this term, learner support and resources were the best predictor of course quality and student feedback the weakest. However, learner support and resources emerged, instructional design and delivery, and innovative teaching technology were only significant predictors of course quality in this order in the spring term.

Bargagliotti, Botelho, Gleason, Haddock, and Windsor (2012) studied the effect of blended instruction in postsecondary mathematics courses. The Memphis Mathematics Method (MMM), a blended mode of instruction that uses technology to deliver short lectures and traditional instruction in undergraduate mathematics was the intervention used to assess success and retention in mathematics in blended courses versus traditional instruction. Developmental Studies Program in Mathematics (DSPM), an instructional program designed to detect students' mathematics readiness and place them in remedial courses, delivered in both traditional and MMM format was another instructional mode in College Algebra and Foundation of Mathematics. The data from this study included students enrolled in mathematics courses such as College Algebra, Foundations of Mathematics, or Elementary Calculus delivered in MMM and traditional instructional modes from 2007 to 2010. Bargagliotti et al. found that MMM was a successful mode of instruction in increasing retention and student success. Students enrolled in blended courses showed higher success and less dropout rates as a norm across mathematics courses. The Memphis Mathematics Method proved to be a pedagogy that rendered better results in Elementary Calculus with $79 \%$ higher odds of success than traditional 
instruction. Similarly, the dropout rate in MMM was 10\% versus 13\% in traditional teaching and learning modality.

Furuto (2013) examined self-efficacy development of student in hybrid classroom model that combined traditional (independent) and cooperative instruction in College Algebra. Learning interaction was the main aspect that distinguished instructional differences between these two learning environments. The traditional learning setting fostered independent learning among students. On the other hand, students helped each other and collaborated in groups to work out problems in the collaborative instructional context. Following a mixed-method methodology, Furuto collected data from classroom observations, video recordings, interviews, surveys, and student journals in a sample of 10 students to provide a descriptive contrast of how students learn mathematics in traditional and cooperative instructional contexts. Additionally, Furuto used a pre-post survey to detect changes in self-efficacy. A preliminary analysis on self-efficacy changes via t-test of the pre-post surveys showed a significant increase in students' self-efficacy in College Algebra $(p<.001)$, regardless of the type of pedagogy used. Most importantly, an overwhelming response from students in the study emphasized the crucial role of the instructors in the increase of self-efficacy. The analysis of the qualitative data corroborated the findings from the t-test, the application of both instructional pedagogies in mathematics was an effective strategy for developing self-efficacy in students (Furuto, 2013). While some students expressed that working independently helped them focus on solving problems and developing strong mathematics skills, other students expressed that working with classmates to solve mathematics problems was an effective learning strategy. Students in Furuto's study further stated that both pedagogies have positive and 
negative characteristics. According to these students, individual learning encourages working at one's own pace and promotes the growth of abilities. On the other hand, in individual learning there is no room for clarifying learning gaps and sharing perspectives with others when solving problems as it is possible in cooperative learning (Furuto, 2013). The laudable effort of the study of Furuto to examine self-efficacy in undergraduate mathematics compromises the reliability of the results because of the small sample Furuto used given that the total course enrollment was of 424 students. As Furuto acknowledges, results from this analysis were seriously undermined because of the small sample size.

Smith and Suzuki (2015) used a sample of 56 students to compare learning experiences and satisfaction of instruction modality between blended and live-lecture classroom in a high school Algebra II course. Smith and Suzuki conducted this study under the assumption that embedded blended instruction would produce better outcomes. A group of students received live-lecture instruction while the other group received embedded multimedia lessons (in class and online access) in the form of edited videos of the teacher's recorded lectures, both for four weeks. Students who received embedded multimedia lessons seemed to have better learning experiences as more students in this group expressed that they learned the new material better than the live-lecture group students. In addition, they said that the teaching techniques were easy to follow. In fact, 8 out of 10 students who identified screen capture lectures (embedded hybrid learning) as a better learning strategy indicated their preference for online learning for future course enrollment. Smith and Suzuki summarized four reasons that emerged from students' preferences to blended learning: 
(a) Ability to control pacing of instruction

(b) New role of the classroom teacher

(c) Lack of distraction in the blended learning environment

(d) Accessibility to the embedded multimedia lessons outside the classroom.

Despite the students stating that accessing online lessons from anywhere was an advantage, most students indicated that watching the videos in the class was better for them than accessing the videos from home because they were able to receive real-time feedback from the teacher when they needed clarification in understanding concepts. Avoiding distraction was another reason students commented on for their preference for watching video lesson in the classroom. These findings stress results from other studies (Barkley, 2010) about the importance of face-to-face interaction.

In a study that investigated the effect of mode of instruction on student's achievement in mathematics, Czaplewski (2014) examined differences in knowledge acquisition in a blended pre-calculus class with respect to knowledge acquisition in a face-to-face pre-calculus class. The study used students not pursuing a mathematics major in a higher education institution with a population that included about of $88 \%$ of White students of its enrollment. According to Czaplewski, the study was conducted "to address the declining attitudes towards the subject by students" (p. 54). For the analysis, Czaplewski used a traditional face-to-face pre-calculus class and a blended precalculus class that run in different semesters. The comparative analysis of achievement across mode of instruction via ANOVA indicated that students in the blended courses performed significantly higher than students in face-to-face via the grades of a final 
exam. When comparing students' achievement with respect to the final grade in the course, students in blended courses outperformed students in the face-to-face courses.

Czaplewski (2014) further studied changes of attitudes of students under blended instruction. He addressed these changes from the perspective of what he called "two, sometimes related, objects of attitude,"- attitudes toward mathematics and attitudes toward blended learning (Czaplewski, 2014). The analysis of the attitudes toward mathematics included the two-time administration of the Attitude toward Mathematics (ATMI) questionnaire. Czaplewski studied the change of the score of each of the composite factors of the ATMI: Enjoyment of Mathematics, Motivation for Mathematics, Self-Confidence in Mathematics, and Value of Mathematics. Czaplewski reported significant differences in the responses of students between ATMI applications for the factors of Enjoyment and Value in a quantitative analysis conducted using $t$-test. According to Czaplewski, students in blended classes showed more enjoyment and value to learning mathematics at the end of the course when compared to the beginning of the term. Responses of students over time to the statement "I am happier in a math class than in any other class" indicated a remarkable change in student's attitude (Czaplewski, 2014).

Czaplewski gathered qualitative data from interviews of four students in the hybrid classes. Students expressed that they enjoyed learning mathematics in a blended setting as they had the chance to work in groups and share idea that led come up with a strategy to solve problems. Students testimony revealed that working in groups made learning mathematics more enjoyable, facilitate understanding while sharing ideas, and reduce anxiety (Czaplewski). Class format (combination of face-to-face and online 
instruction) emerged as a key factor for student's preferences in the hybrid group.

Students further expressed that reduction of face-to-face meetings, usefulness and flexible access to online resources, and work in small groups were advantages of blended instruction. Additionally, students perceived that instant feedback they received when completing an online task and opportunities to improve performance as effective tools to enhance concept understanding and motivation to learn mathematics. On the other hand, students indicated technical problems associated at the time of entering answers in the learning management system caused frustration in students. Besides, students stated that blended learning involve a significant increase of student's responsibility for assignment completion and commitment to learning.

\section{Demographics in Mathematics}

\section{Gender and Mathematics}

Research studies have reported the effect of demographic factors on student's motivation and engagement in mathematics and on their decisions to pursue future studies. Ma and Kishor (1997) studied the effect of gender and grade level in the relationship between attitude toward mathematics (ATM) and achievement in mathematics (AIM). Gender had a significant effect on the relationship between attitude toward mathematics and achievement in mathematics. In fact, the magnitude of the effect of male and female was comparable. Ma and Kishor used mixed gender for participants who did not report their gender. Conversely to the analysis of separate gender groups, mixed-gender had no significant effect on the relationship between ATM and AIM (Ma \& Kishor, 1997). Ma and Kishor's result indicates that mixed-gender did not explain the variability of the relationship ATM-AIM because information on gender was missing 
from a number subjects in the sample they used. Consequently, gender was not a good predictor on the relationship between ATM and AIM.

Hall and Ponton (2005) studied self-efficacy differences related to gender in Intermediate Algebra and Calculus. In this comparison, Hall and Ponton found no significant differences in self-efficacy between students in Intermediate Algebra and Calculus with respect to gender. Male and female students showed the same level of selfefficacy in the Calculus class $(t=.254, p=.80)$ as it was the case in the Intermediate Algebra class $(t=.337, p=.737)$. However, both male and female students in Calculus showed more self-efficacy in mathematics than Intermediate Algebra students $(F=$ 75.753, $p<.001$ ), which supports the fact that higher level mathematics students (Calculus students) exhibit higher self-efficacy, as previously described.

Aldridge et al. (2012) investigated the effect of the learning environment on students' attitude in college mathematics in a sample were more than $65 \%$ were female students. However, an analysis of gender differences was not conducted.

\section{Ethnicity and Mathematics}

Ma and Kishor (1997) studied the effect of ethnicity on the attitudes and achievement of students in mathematics. The methodology Ma and Kishor's used in their analysis revealed surprising and concerning facts. Ma and Kishor categorized ethnicity as White, Black, and Asian. Consequently, Ma and Kishor's study overlooked addressing attitudes toward mathematics and achievement in mathematics for Hispanic students, one of the most influential minority groups with an extensively reported population increase for more than five consecutive decades (NCES, 2015, NCES 2014, NCES, 2010). For the analysis on gender effect, Ma and Kishor used mixed ethnicity when participants reported 
no information on their ethnicity. Ma and Kishor found that ethnicity was not a significant predictor for students' attitudes and achievement in mathematics for White students. On the other hand, Ma and Kishor found a remarkable positive correlation between ethnicity and the relationship attitudes and achievement in mathematics has for Asian students. The relationship between attitudes and achievement in mathematics was also significant in Black students but of a lesser magnitude than for Asian students. Differences in the mixed ethnic group were not meaningful.

Hodges (2009) conducted a qualitative study about self-regulation techniques of students in an online-based mathematics course using a sample of seven all-White freshman students. Hodges collected data through field notes, guided journal, and one-onone interviews at different times of the semester. Overall, students expressed no fear to learning mathematics. Hodges' finding is congruent with NCES reports that indicate that Caucasian students hold positive attitudes toward learning mathematics. Hodges further found that most students had high expectation of succeeding in online mathematics courses. In fact, most students believed that they had the same probability of achieving success in online mathematics courses as in traditional face-to-face mathematics courses. According to participant responses, available resources supported mastery of course content. Specifically, resources such as practice quizzes and online lessons allowed them to practice the material effectively. Additionally, students expressed that they adopted new regulation techniques to succeed in the course because they were learning by themselves and without direct interaction with an instructor. For example, there was a strong sense of collaboration among these students since they helped one another when assistance to understand course topics was required. From a follow-up data collection 
event, most participants expressed positive beliefs toward online courses as well as they reported that their learning skills had improved for enrolling in this learning mode.

Bargagliotti et al. (2012) explored gender, race, and mathematics background as factors for success in blended mathematics. Bargagliotti's study indicated that blended courses may serve to close racial differences in mathematics achievement, as the gap in performance in MMM-Elementary Calculus was much lower between Blacks and Whites than in traditional instruction. According to Bargagliotti et al., Black students had $77.1 \%$ higher odds to succeed in MMM than in traditional courses. Similarly, the gap in overall course dropout was much lower in MMM courses than in any other teaching and learning mode. Additionally, gap of retention was much lower between Blacks and Whites in all MMM courses when compared to the traditional or DSPM courses. The analysis on race included only students from White and Black groups because a low representation from other racial groups ( $2 \%$ of Hispanic students). Therefore, this study was not able to explain any aspect of blended courses in emergent racial groups in American society such as in students from Hispanic roots.

Studies on mathematics education in higher education have not address the learning needs of students from minority groups, particularly from Hispanic origins. An analysis of the beliefs students hold about mathematics is even more deficient. It is imperative to address what students from minority groups think about learning mathematics and the repercussion for mastering mathematics brings to their life. It is assumed that a world of opportunity is to the disposal of those students with high marks in mathematics. Consequently, the present study addressed student's beliefs on mathematics-related factors as a fruitful way to help the increasing number of 
underrepresented students in research studies who attend colleges and universities reach their goals.

\section{Attitude toward Mathematics}

Ma and Kishor (1997) conducted a meta-analysis that examined the relationship between attitude toward mathematics (ATM) and achievement in mathematics (AIM), as well as the strength in the general relationship and the causal relationship of these constructs. Ma and Kishor's meta-analysis explored the relationship at the elementary and secondary levels. Such restriction of academic levels overlooked the extent the relationship ATM and AIM manifests in the higher education level where mathematics competence is an essential requirement for degree completion. The meta-analysis used studies that were conducted over a period of 27 years $(N=82,941, k=113)$, from 1966 to 1993. As Ma and Kishor remarked, data collection instruments (surveys/interviews) evolved dramatically over this period, which represents a limitation to the findings' interpretation because of the variability in the construction of the items measured in the instruments over the 27-year period. That is, there was lack of uniformity around the definition of ATM in the studies Ma and Kishor' used in the meta-analysis.

Ma and Kishor's (1997) analysis revealed a weak relationship between ATM and AIM, yet significant $(\mathrm{CI}=.12-.13)$. As previously mentioned, Ma and Kishor analyzed both directions of the relationship: the causal direction of the effect of attitude on achievement and the causal direction of the effect of achievement on attitude. Ma and Kishor found a significant relationship of attitude on achievement in the causal, but not strong enough to call the effect of attitude on achievement relevant $(\mathrm{CI}=.07-.09)$. The 
analysis of the second direction of the relationship indicated no significant effect of achievement on attitude $(\mathrm{CI}=-.01-.01)$.

Ma and Kishor reported that the effect of each of the grade levels on the relationship between attitude toward mathematics and achievement in mathematics produced similar outcomes as for the independent effect of male and female groups. Overall results underscored the effect of attitude on student success (Ma and Kishor, 1997). Ma and Kishor split the elementary and secondary levels into groups. One of the elementary subgroups included first through fourth grades while the other group included fifth and sixth grades. The groups in the secondary level included seventh through ninth grades and $10^{\text {th }}$ through $12^{\text {th }}$ grades. The split in academic groups produced significant differences across the four academic levels in the relationship under study. The differences in the relationship was also significant when Ma and Kishor compared elementary grade level (all students in grades one through six) and secondary grade level (all students in grades seven through 12), being the magnitude of the difference much greater in the secondary level. Particularly, Ma and Kishor found that attitudes toward mathematics of students in junior high grades affected achievement in mathematics at a higher rate than in other grades. Ma and Kishor citing results from previous studies claimed that students in junior grades start developing attitudes toward mathematics that can turn into negative feelings. Therefore, early interventions need to be in place when patterns of negative attitudes persist. Teachers are crucial to support students in the transition from having negative attitudes to experiencing positive attitudes toward mathematics (Ma and Kishor, 1997). 
Kim \& Keller (2010) studied the effect of motivation, volition and belief strategies embedded in personal and group email messages, on students' attitudes, study habits and achievement in a calculus course in a sample of 84 students pursuing nonmathematics major. The first group included emails containing motivation and volition change strategies (MV) while the second group included emails about belief changes strategies (B). MV emails contained mathematics situation aimed to elicit feelings that stimulate student's critical thinking (Kim \& Keller, 2010). Belief changes strategies emails (B) used mathematics situations aimed to foster positive attitudes about mathematics. Emails containing belief change strategies had two goals: to instill in students the idea that learning occurs progressively and that learning, even in mathematics, is an achievable goal. The third group was emails which content included a combination of both strategies (MVB).

Emails also differed with respect to the audience to receive the email. Personal emails $(\mathrm{P})$ were tailored to address individual needs of students. Group emails $(\mathrm{G})$ aimed at infusing motivation and volition in students. Students were randomly assigned to one of the email content groups (MV, G, or MVB) or to the control group (Kim \& Keller, 2010). Following this stage, students had the chance to select what type of message they would like to receive (P or G). Consequently, Kim and Keller's design produced a total of six groups (MV-P, MV-G, B-P, B-G, MVB-P, and MVB-G) and the control group. The content of emails to the control group included no strategy and was restricted to study habits. Kim \& Keller analyzed student's responses to the email messages as the strategies and design used in the emails aimed for students to develop empathy about 
what they were reading so that they would take to take concrete actions to solve the problem.

A one-way repeated measures ANOVA (with $\alpha=.10$ ) detected significant differences in the responses of participants to a pretest and a posttest assessing attitudes. Attitudes of participant students were a function of the time, which indicated significant differences over time $(p=.074)$. Only students who received personal emails with belief change strategies (BP) exhibited positive attitudes as it was reflected in an increase between the mean of the pretest $(M=3.52)$ and the mean of the posttest $(M=3.86)$. In general, negative attitudes of students increased as the course progressed. All other groups showed a decrease in negative attitudes as time passed. Kim and Keller (2010) attributed this result to the increase of the level of difficulty in the Calculus topics as the course progressed.

Kim and Keller (2010) also collected study habits data (number of hours students spent studying Calculus) using surveys administered at four different times during the course. The one-way repeated measures ANOVA $(\alpha=.10)$ that assessed the interaction between time and treatment was not significant $(p=.304)$. The analysis of changes of study habits over time showed a substantial decrease in the mean of the number of hours students spent for mastering course content, except for the group of students who received personal emails with motivational and volition and change of belief strategies. It appears that the messages combining all strategies were effective in engaging students in studying calculus.

According to Kim and Keller (2010), personal emails produced more favorable attitudes than the group emails perhaps because personal messages were significantly 
shorter in content. Conversely, to their expectations, motivation and volition did not affect study habits but the combination of beliefs and motivation and volition did. Kim and Keller found similar results for achievement. Type of email did not change student's achievement $(p=.348)$ over time. Besides, there were no significant changes in achievement across groups.

Hodges and Kim (2013) conducted a study that investigated course interest, student's attitudes and achievement in mathematics in a group of freshmen not pursuing mathematics majors. Forty-three students enrolled in emporium-based College Algebra course were assigned to an experimental or control group. The application of emporium in Hodges and Kim's study consisted of an informative face-to-face meeting on the first day of class. The rest of the course was fully delivered in virtual format. More than $74 \%$ of students in the sample were White and around $76 \%$ of them were female students. The intervention used in this study was a video available to the experimental group only. The video, aimed at increasing motivation and positive attitudes toward mathematics, presented situations where mathematics was a tool to solve simple problems in real life. Hodges and Kim administered a pretest and a post-test to assess levels of interest and attitudes in both groups before students in the experimental group watched the video. Both groups took a post-test once students in the treatment group received the intervention. Course Interest Survey (CIS) measured students' course interest while the Fennema-Sherman Mathematics Attitude (FSMAS, 1976) served to measure mathematics attitude. Hodges and Kim (2013) found no significant difference across groups regarding course interest toward mathematics through an ANCOVA on the CIS responses 
$(F(1,40)=.911, p=.346)$. However, results of an ANCOVA for the FSMAS survey indicated that students in the experimental group showed significantly better attitude toward mathematics than those students who were in the control group $(F(1,40)=8.601$, $p=.006)$. According to Hodges and Kim, the better attitudes of students in the treatment group indicate that implementing motivational strategies in the mathematics classroom may enhance students' attitudes.

Hodges and Kim (2013) found difficulties addressing negative attitudes toward mathematics in the online section because it included a single face-to-face meeting. However, the study did not explain how several ways to establish communication such as emails, discussion forums, and questions and answers forums in this emporium modality were used to minimize the effect of the separation and to gather substantial information on students' beliefs toward mathematics. Additionally, there was no justification for using the video only once through the duration of the course; furthermore, the study did not provide justification for why the first test was the only assessment that served as a reference to administer the pretest. Administering the video more than once in the semester as well as administering the surveys later during the course may have rendered different findings. As such, failing to address the effect of course resources on student's attitudes represents a limitation of the study that Hodge and Kim also observed.

Nunez-Pena, Suarez-Pelliconi, and Bono (2013) studied the effect of mathematics anxiety on student performance (measured by the final grade) in a sample of 193 psychology students in Spain. Besides, Nunez-Pena et al. (2013) examined the relationship between negative attitudes and feelings toward mathematics. Research Design, the course used to conduct the study, is not a formal mathematics course but 
involve a significant amount of quantitative work. Participants in this study responded to surveys that included questions about attitudes, motivation, confidence, and anxiety toward mathematics, as well as questions regarding to general anxiety. Congruent with Nunez-Pena et al. (2013) expectations, all measures of anxiety toward mathematics (mathematical anxiety, mathematics course anxiety, mathematics test anxiety, general anxiety), as well as enjoyment of mathematics and self-confidence in mathematics, were significant predictors of the course's final grade. Students with higher levels of anxiety toward mathematics showed the lowest confidence and motivation on the subject. As a result, these students struggled the most in the course. A contrasting finding pointed out that there was no relationship between course performance and numerical task anxiety in assessments that included daily life problems requiring mathematics computation.

\section{Summary}

The review of the literature presented empirical work on the constructs this study explored. The review examined research findings on teacher's effect, self-efficacy toward mathematics, and students' attitudes toward mathematics. The review included an overview of relevant research on instructional modalities. It presented a journey of findings from meta-analyses studies and of relevant research on instructional modalities in mathematics as well as student demographics in mathematics. The current research study departed from the common direction a significant bulk of research on instructional modes where technology has played a key role in instruction, specifically studies that have compared traditional classroom with computer-based instruction. 


\section{CHAPTER III \\ METHODOLOGY}

Research studies have identified mathematics competence as a determinant for student success in higher education and for later professional success (Bargagliotti et al., 2012; NCES, 2015). Self-efficacy in mathematics plays an indispensable role in strengthening attitudes toward mathematics and commitment for mathematics achievement. According to Dogbey (2010), attitude is a multi-dimensional construct that involves values, beliefs and behaviors. Dogbey remarks that attitude is expressed as the predisposition of an individual to perform a behavior rather than the behavior itself. Further Dogbey establishes that "performance of a particular behavior may lead to new beliefs about the object in turn influencing attitude" (p. 36). A primary goal of my study was to examine differences in students' attitudes toward mathematics in both face-to-face and hybrid learning to close the existing gap addressing attitudes in minority serving higher education institutions.

Research studies have also established the significant effect of self-efficacy of students in their progression in mathematics (Bandura 1997; Pajares, 2005; Pajares \& Miller, 1994; Pajares \& Kranzler, 1995). Nevertheless, research on the perceptions students have on the influence of the strategies and actions teachers perform (teacher's effect) to foster self-efficacy in mathematics has not explained the poor attitude toward learning mathematics a considerable number of students exhibit at the undergraduate level. The review of the literature presented in Chapter II reveals the importance of examining students' views about the influence of teachers' actions in supporting their learning and confidence, and the influence of teacher's effect on students' self-efficacy 
and attitudes in mathematics. The interplay of these constructs has not yet been explored in depth for undergraduate mathematics settings across modes of instruction.

Additionally, research studies on mathematics related beliefs in minority populations seem lacking. Consequently, this study was conducted to fill in the gap that exists among the relationship among teacher's effect, mathematics self-efficacy, instructional mode, gender, and attitudes about mathematics in undergraduate mathematics across instructional learning modes, namely face-to-face and hybrid learning.

The study was conducted at a minority-serving higher education institution. Previous research on self-efficacy toward mathematics has established a relationship between this construct and demographic factors such as gender of students in population of predominantly White students. Therefore, this study examined the effect of gender on self-efficacy toward mathematics to fill in the gap that exists in this line of research in underrepresented populations. This study used a model that investigated the relationship between teacher's effect, self-efficacy, instructional modalities, gender, and attitudes. The model shown in Figure 1 hypothesized a direct effect of teacher's effect on self-efficacy, a direct effect of self-efficacy on attitudes, a direct effect of mode of instruction on teacher's effect, self-efficacy, and attitudes, and a direct effect of gender on self-efficacy. The model also hypothesizes an indirect effect of teacher's effect, mode of instruction, and gender on attitudes through self-efficacy. The following section presents an overview of the methodological procedures this study used. It includes the research questions and hypotheses, operational definitions of variables, design of the research, population and sampling, instrumentation for data collection, procedure, and data analysis. This chapter concludes with a summary of its relevant points. 


\section{Research Questions and Hypotheses}

Three research questions were used to respond to the purpose of the study:

Q1. Is there more than one reliable and interpretable factor underlying the constructs of teacher's effect in mathematics, self-efficacy toward mathematics, and attitudes toward mathematics in a sample of College Algebra students in a minorityserving College?

$H_{1}$ : There is more than one reliable and interpretable factor underlying the constructs of teacher's effect in mathematics, self-efficacy toward mathematics, and attitudes toward mathematics.

$H_{1 a}$ : There is more than one reliable and interpretable factor underlying the construct of teacher's effect in mathematics.

$H_{1 b}$ : There is more than one reliable and interpretable factor underlying the construct of self-efficacy toward mathematics.

$H_{1 c}$ : There is more than one reliable and interpretable factor underlying the construct of attitudes toward mathematics.

Q2. Is there a relationship between mode of instruction and the factors underlying the construct of attitude toward mathematics? 
$\mathrm{H}_{2}$ : There are differences in the factors underlying the construct of attitudes toward mathematics across modes of instruction.

$H_{2 a}$ : There are differences in the level of Satisfaction across modes of instruction.

$H_{2 b}$ : There are differences in the level of Mathematics Apprehension across modes of instruction.

$H_{2 c}$ : There are differences in the level of Importance across modes of instruction.

Q.3 How well does a model involving factors underlying teacher's effect in mathematics, self-efficacy in mathematics, instructional modality, gender, and factors underlying student's attitudes toward mathematics in undergraduate College Algebra delivered in face-to-face and hybrid learning modes fits the data?

$H_{3}$ : The factors underlying the constructs of teacher's effect in mathematics, selfefficacy in mathematics, instructional modality, and gender account for a significant amount of the unique variance of student's attitudes toward mathematics delivered through face-to-face or hybrid learning modes. $H_{3 a}$ : There is a significant prediction of Satisfaction by the combined effect of Mathematical Procedures, Critical Thinking, Encouragement, Discouragement, and Mode of Instruction.

$H_{3 b}$ : There is a significant prediction of Mathematics Apprehension by the combined effect of Mathematical Procedures, Critical Thinking, Encouragement, Discouragement, and Mode of Instruction. 
$H_{3 c}$ : There is significant prediction of Importance by the combined effect of Mathematical Procedures, Critical Thinking, Encouragement, Discouragement, and Mode of Instruction.

$H_{3 d}$ : There is significant prediction of Mathematical Procedures by the combined effect of Encouragement, Discouragement, Gender, and Mode of Instruction.

$H_{3 e}$ : There is significant prediction of Critical thinking by the combined effect of Encouragement, Discouragement, Gender, and Mode of Instruction.

$H_{3 f}$ : There is significant prediction of Encouragement by Mode of Instruction.

$H_{3 g}$ : There is significant prediction of Discouragement by Mode of Instruction.

\section{Operational Definitions of Variables}

Building on the SLC theory (Bandura, 1986; Bandura, 1997), the following section defines the independent and dependent variables used in the context of this study. These variables include teacher's effect in mathematics, self-efficacy toward mathematics, modes of instruction, gender, and attitudes toward mathematics. Teacher's

effect, self-efficacy, and attitudes are continuous variables while modes of instruction and both demographic variables (mode of instruction and gender) are categorical variables. 


\section{Independent Variables}

Factors Underlying Teacher's effect in mathematics. Variates accounting for the judgement of students about the effect of the teacher in their learning of College Algebra, as reported by the participants.

Students' self-efficacy toward mathematics. Variates accounting for the personal judgment, beliefs, feelings regarding students' perceived capabilities to be efficacious in College Algebra.

Modes of Instruction. The variable includes face-to-face instruction and hybrid instruction.

Gender. Participants reported their gender (male/female).

\section{Dependent Variable}

Students' attitude toward College Algebra. Variates accounting for the opinions, beliefs, and feelings regarding the relevance, interest, motivation, and usefulness toward learning of mathematics.

\section{Research Design}

Grounded on Bandura's theoretical framework of self-efficacy and previous empirical findings presented in Chapter 2, the methodology of this non-intervention study followed an ex post facto, non-experimental, research design. An ex post facto research study is a form of causal-comparative research design where the variations between the independent and dependent variables are studied as they exist (Gall, Gall, \& Borg, 2007). For these reasons, randomization was not achieved, and independent variables were not manipulated in this study. 


\section{Setting and Sampling}

The study was conducted at Miami-Dade College, one of the largest 4-year colleges in the United States located in a metropolitan area of Miami-Dade County. Most students attending this institution of higher education in the southeast of the United States are from minority groups. The population for this study consisted of students enrolled in College Algebra courses delivered in face-to-face and hybrid instructional modalities. A convenience sample of students was selected to test the model presented in Chapter 1 following Bandura's theoretical framework.

The statistical analyses in this study tested hypothesis to detect differences in factors underlying students' attitudes, as it is customary in quantitative educational research. The relationship among statistical power, level of significance, effect size, and sample size to increase the chances of finding statistical significance was an important aspect this study considered (Gall et al., 2007; Hair, Black, Babin, \& Anderson 2010; Keith, 2006; Tabachnick \& Fidell, 2007). The complexity of the aforementioned relationship stems from the fact that the statistical power is a function of the effect size, the probability level to detect differences, and the sample size (Gall et al., 2007; Hair et al., 2010; Keith, 2006; Tabachnick \& Fidell, 2007). On the other hand, an adequate sample size depends on the desired power, the effect size, and the probability level to detect differences (Gall et al., 2007; Hair et al., 2010; Keith, 2006; Tabachnick \& Fidell, 2007). Consequently, early consideration on the sample requirements increases the ability to reject the null hypothesis. Tabachnick and Fidell (2007) states that "the cases-toIndependent Variable ratio has to be substantial" (p. 123) to achieving a meaningful solution. Gall et al. (2007) and Hair et al. (2010) indicate that a substantial sample size 
increases the statistical power, which in turn increases the probability that the sample represents the population characteristics.

Hair at al. (2010), Keith (2006), and Tabachnick and Fidell (2007) recommend a level of significance of .05 and a power level of 0.80 for multivariate statistics techniques, which are standard values used in behavioral sciences research studies. Hair at al. (2010) further advises using a sample of at least 100 for a small effect size in studies with 2 to 5 independent variables (IV). Tabachnick and Fidell (2007) provide rules of thumb for the number of cases to use in research studies, assuming medium effect size, for testing multiple correlations of $N \geq 50+8 m$ and for testing independent predictors of $N \geq 104+m$, where $N$ is the minimum sample and $m$ is the number of independent variables. The study used six independent variables. Following Tabachnick and Fidell (2007) recommendations, a six independent variables study will required a minimum of 98 cases for testing multiple correlations and 110 cases for testing independent predictors. Besides these important considerations, Gall et al. (2007) stress subgroup analysis, attrition, and reliability of measures as determinant factors to consider when selecting an adequate sample. Using a substantial sample size allows the researcher to conduct subgroup analysis not planned at earlier stages in the design of a study and reduces the effect of attrition (drop out) of subjects. Gall et al. (2007) defines attrition as "the loss of research participants from a sample over a period of time" (p. 633). Therefore, reducing the effect of attrition is important to capture perceptions that lead to detecting differences. Similarly, the sample size may help to minimize the negative effect of using measures with low reliability. Following all these recommendations, the six independent variable 
study used a sample of 390 participants to strengthen the power and minimize the chances of committing a Type II error.

\section{Instrumentation for Data Collection}

Three well-established instruments served as the method of data collection for the continuous variables this study. These instruments were used to explore the factors underlying three constructs: teacher's effect in mathematics, students' self-efficacy toward mathematics, and student's attitudes toward mathematics. Teacher's effect was measured with the Fennema and Sherman Mathematics Attitude Scales (FSMAS, 1976). Hackett and Betz's (1982) Mathematics Self-Efficacy Scale was used to measure selfefficacy toward mathematics. Attitude toward mathematics was measured with the Lim and Chapman (2013) shortened version of the Attitudes toward Mathematics Inventory (ATM). All these instruments have been used in previous research studies and their administration has undergone content validity and as well as they have reached high indexes of reliability as described in the following sections. As a result, a pilot study was not conducted in this study. The sections that follow discuss each of the scales.

\section{Teacher's Effect}

The Fennema-Sherman Mathematics Attitude Scales (FEMAS, Fennema \& Sherman, 1976) have been frequently used as an instrument to assess scales of affect toward mathematics in mathematics education studies. The FEMAS instrument used in the study measured attitudes toward mathematics through a 5-point Likert continuum from 1 (strongly disagree) to 5 (strongly agree). The FEMAS is an instrument that includes the subscales of attitudes toward success in mathematics, the mathematics as a male domain, mother/father, teacher, confidence in learning mathematics, mathematics 
anxiety, effectiveness, and mathematics usefulness. In this study, the factors underlying teacher's effect were measured with the teacher's scale from FSMAS' instrument as shown in Appendix B. The 12 items in the teacher's subscale of the FSMAS are “designed to measure students' perceptions of the teacher's attitudes toward them as learners of mathematics (Fennema \& Sherman, 1976, p. 326)". It includes the items addressing judgments from student's perspective "about teachers' interest, encouragement, and confidence in the student's ability" (Fennema \& Sherman, 1976, p. 326). Dogbey (2010) reported that the first administration of the teacher's scale of FEMAS instrument (Fennema \& Sherman, 1976) produced a split-half reliability value of .88. Other studies have confirmed the reliability of the FSMAS teacher's scale as well. In a study on attitudes of community college developmental mathematics students, Dogbey (2010) used the FEMAS teacher's scale and obtained a Cronbach alpha coefficient of .87, an acceptable value of internal consistency for this index.

\section{Self-Efficacy}

Self-efficacy has been a recurrent theme of research in mathematics education. Findings from research involving self-efficacy have played a determinant role in supporting educators to design interventions that increase student's achievement (Lagenfeld and Pajares, 1993). Self-efficacy predicts behavior to a greater extent than constructs such as performance and achievement (Bandura, 1997). Accordingly, instruments measuring the construct of self-efficacy have been widely used. In this regard, Bandura (1997) suggests that sound self-efficacy scales are those that collect perceptions of capabilities related to domain-specific functioning. Scales that evaluate self-efficacy in mathematics while students perform content specific tasks are likely to 
succeed in accomplishing the purpose of addressing this construct (Bandura, 1997;

Lagenfeld \& Pajares, 1993). Therefore, an all-purpose measure of perceived self-efficacy lacks the explanatory and predictive value as it fails to describe relevance to the specific domain of functioning (Bandura, 2006; Zimmerman, 2000).

Theory plays a crucial role in creating self-efficacy items. Bandura (2006) states that researchers need to distinguish self-efficacy from other constructs when developing items that accurately reflect self-efficacy beliefs. That is the case, for example, when using the confidence to describe the construct of self-efficacy. Bandura (1997) warns that "confidence is a nondescript term that refers to strength of belief but does not necessarily specify what the certainty is about" (p. 382). While confidence refers to general beliefs of preferences and disposition, beliefs of efficacy involve competence in specific tasks. Similarly, Bandura (1997) advises caution when misusing self-esteem to describe judgments of capabilities. Self-esteem refers to self-worth rather than capturing judgments of efficacy when functioning in a specific domain. Taking pride in one's accomplishments is not an expression of self-efficacy but self-esteem. However, selfdevaluation interferes in the development of self-efficacy. For example, the effect of stereotypes a mainstream culture dictates on other cultures may influence selfdevaluation of individuals from minorities in the form of discriminatory social practices that include gender and ethnicity (Bandura, 1997). Besides, self-devaluation may stem from suffering systematic episodes of failure. External factors such as teacher's effect are important in developing confidence in one's efficacy and satisfaction in accomplishment (Bandura, 1997; Peters, 2013). Success in mathematics is usually low in postsecondary education (Bargagliotti et al., 2012). Therefore, mathematics is an appropriate discipline 
to measure self-efficacy without the confounding effect of self-confidence and selfesteem (Bandura, 1997).

Hackett and Betz (1982) measured gender differences in self-efficacy expectations toward mathematics in college students. In their study, Hackett and Betz (1982) administered the Mathematics Self-Efficacy Scale (MSES) to psychology students. The MSES contained 52 items broken down into three scales: 18 items covering mathematics tasks, 16 items covering mathematics-related college courses, and 18 items covering mathematics problems. The items in the mathematics tasks scale included daily life tasks that require basic mathematics skills such as applying order of operations. The mathematics problems scale included items like the problems covered in aptitude toward mathematics tests. The mathematics-related college courses scale was comprised of items addressing perceptions of capabilities to succeed in mathematics, science, and liberal arts courses that required certain levels of self-efficacy. Each item on the MSES used a 9-point Likert-type scale where a 0 indicated no confidence at all and a 9 indicated complete confidence (Hackett \& Betz, 1982). Cronbach's alpha for the composite MSES was .96 while it was $.90, .93, .92$ for the independent scales of mathematics tasks, mathrelated college courses, and mathematics problems, respectively, indicating high internal consistency reliabilities. Hackett and Betz (1982) found that self-efficacy was significantly related to mathematics attitudes and mathematics performance. Particularly, males showed higher perceptions of self-efficacy than females in each subscale of the MSES.

Hackett and Betz (1989) examined the interplay between self-efficacy, performance and achievement, and attitudes toward mathematics in a sample of 
introductory psychology courses. Hackett and Betz (1989) used the MSES they developed in 1983 to measure self-efficacy and performance with the Performance subscale developed by Dowling in 1978. The American College Test (ACT) Mathematics was used to measure achievement. A short version of the FSMAS was used to assess the relationship between self-efficacy, performance and achievement, and attitudes toward mathematics. Hackett and Betz (1989) found that self-efficacy expectation was a much stronger predictive effect on attitudes toward mathematics than the other two measures (performance and achievement) combined. Brewer (2009) used the MSES to explore differences of self-efficacy in mathematics between students that were assigned onlinebased homework and students who did textbook-based homework in College Algebra courses. Brewer's exploration showed a similar level of student's self-efficacy across groups. Clutts (2010) also applied the MSES to examine the predictive effect of age, gender, developmental mathematics course, and developmental mathematics grade on mathematics self-efficacy in developmental mathematics students. None of the factors Clutts considered was significantly related to self-efficacy in mathematics.

Hackett and Betz (1989) emphasized that "mathematics self-efficacy can be distinguished from other measures of attitudes toward mathematics in that mathematics self-efficacy is a situational or problem- specific assessment of an individual's confidence in her or his ability to successfully perform or accomplish a particular task or problem" (p. 262). They further claimed that "self-efficacy theory calls for the assessment of confidence in performance expectations for specific tasks" (p. 264). The societal context on which the MSES was developed has dramatically changed (Langenfeld \& Pajares, 1993). Technology has shaped most facets of life. Some of the items in the mathematics 
tasks subscale of the MSES are obsolete and no longer respond to assessments of selfefficacy in mathematics (Langenfeld \& Pajares, 1993). Adding on inconsistencies of the MSES, Langenfeld and Pajares (1993) expressed that "it is not especially useful to compare self-efficacy judgments regarding accomplishing mathematics-related tasks or successfully completing mathematics related courses with a performance measure that requires the solving of mathematics problems" (p. 15). Besides, some of the courses the MSES uses in the college course scale such as Algebra I and Algebra II are not college mathematics courses.

College Algebra is a college undergraduate mathematics course that requires strong foundations of critical thinking, arithmetic and pre-algebra skills. Consequently, being efficacious in these mathematics areas is crucial to develop and strengthen confidence in solving mathematics problems that require these skills to be successful in College Algebra.

Distance between categories (scale points) in psychometric instruments is a critical aspect of the quality of a measure, and in its reliability and validity (Krosnick \& Fabrigar, 1997; Wakita, Ueshima, and Noguchi, 2012). Lissitz and Green (1975) studied the optimal number of scale points in a rating scale on reliability. Lissitz and Green emphatically reported that 5 scale points was the cutting point where reliability leveled off. That is, Lissitz and Green found little effect in using scales with more than 5 points in reliability. Lagenfeld and Pajares (1993) modified the Mathematics Confidence Scale (MCS), a version of the mathematics problems scale of the MSES, from 10-point Likert scale to a 5-point Likert scale. Lagenfeld and Pajares measured the internal consistency for this version of the MSES and obtained a .90 score. 
Krosnick and Fabrigar (1997) argue that scales with few options (less than 3 scale points) gives room for ambiguous responses on perceptions/preferences about performing an activity. On the other hand, scales with a larger number of options may become less precise for those respondents doubtful of the meaning of specific points (Krosnick \& Fabrigar, 1997). Further, Krosnick and Fabrigar cautiously stressed that including too many response options may discourage participants for willing to express their genuine thoughts. Consequently, Krosnick and Fabrigar recommend surveys with items with 4-7 points in the scale.

Dawes (2012) studied whether data characteristics were a function of the number of scale points used in a survey. Dawes analyzed the effect of 5-point, 7-point or 10-point format survey response categories on the mean, skewness, and kurtosis of the data. Dawes found that the 10-point scale produced a lower mean when compared to the other scales. However, indexes of standard variation, skewness or kurtosis were not significantly different across point scale formats. As a result, Dawes concluded that independently of the scale points, any of the surveys under analysis produced similar results when sophisticated statistical techniques are used. Lee and Paek (2014) examined the optimal number of response categories in Likert-type rating scales. In generated categorical datasets, Lee and Paek found that survey items that ranged between 4 and 6 points produced comparable outcomes with small differences with respect to measures of reliability, validity, and correlations. Lee and Paek recommend that the optimal number of response categories should include between 4 and 6 points.

Building on the recommendations of Bandura, (1997, 2006), Betz and Hackett, (1982, 1989), Langenfeld and Pajares (1993), and Zimmerman (2000) for the application 
of effective self-efficacy scales, my study used the modified version of the Hackett and Betz (1982) scale for mathematics problems self-efficacy used by Langenfeld and Pajares in 1993 to assess the factors underlying self-efficacy toward mathematics. The current study used a 5-point Likert scale metric for the MSES, where 1 represented "No Confidence at All" while a 5 represented "Complete Confidence." Appendix C shows the scale used in this research study as the means to collect expectations of self-efficacy toward College Algebra.

\section{Attitude toward Mathematics}

Factors underlying attitudes toward mathematics were measured using the shortened version of the Tapia (1996) Attitude Instrument to measure student's attitudes toward mathematics (ATMI) developed by Lim and Chapman (2013) and shown in Appendix D. The ATMI is a relatively new instrument for which strong validity and reliability estimates have been established. According to Majeed, Darmawan, and Lynch (2013) the ATMI is a "more cohesive" instrument than previously created instruments to measure attitudes toward mathematics. Tapia (1996) created the ATMI to explore attitudes toward mathematics in a predominantly Hispanic sample of middle and high school students. The initial assessment included 49 items in a 5-point Likert scale continuum from 1 (strongly disagree) to 5 (strongly agree). Nine items assessing teacher/parents effect were eliminated to increase the reliability and internal consistency of the instrument from a Cronbach alpha of .96 to .97 . A principal component analysis with a varimax rotation analysis produced a 4-factors (4-subscales) optimal solution. The subscales were self-confidence, value, motivation, and enjoyment with Cronbach .95, .86, .89 , and .89 , respectively. The final ATMI instrument included 40 items (Tapia, 1996). 
Tapia and Marsh (2002) applied the ATMI in a majority White sample of mathematics students. A confirmatory factor analysis indicated a 4-factors model. Reliability and validity was confirmed via Cronbach alpha coefficients for each subscale: .96 for selfconfidence, .93 for value, .88 for enjoyment, and .87 for motivation (Tapia \& Marsh, 2002). Tapia and Marsh (2004) replicated their 2002 instrument in a group of high school mathematics students and found high internal consistencies across subscales. Lim and Chapman (2013) created a shorter version of the ATMI because their goal was to develop an alternative instrument that would assess mathematics attitudes of non-Western students. They also wanted the instrument to have fewer items. Lim and Chapman (2013) conducted confirmatory factor analyses on the ATMI and a reduced 4-factor model from 40 to 19 items was achieved. Each subscale of the shortened version of the ATMI showed high correlations with the corresponding original subscales in the ATMI. The overall internal consistency $\alpha$ for the full shortened scale was 0.93 , and the mean value for individual subscales was 0.87 .

\section{Validity of the Instruments in the Study}

Psychometric properties of the instruments used in the study was an important aspect to consider. The provision of considering the psychometric properties of the instruments included addressing the validity and reliability of each measure. Validity of an instrument refers to the accuracy of an instrument to effectively measure the dimension it was designed to measure and where the quality of items to capture the dimension under study is essential (Gall et al., 2007). All instruments used in the study had been validated in previous studies as they were written to explicitly address the dimensions (constructs) they were designed to measure as well as they had served to 
measure the same dimensions this study intended to investigate: teacher's effect in mathematics, self-efficacy in mathematics, and attitudes toward mathematics, respectively. Ruseffendi (1986) stated that one of the strategies Fennema and Sherman used to achieve validity in their instrument was to define the dimension of teacher. Fennema and Sherman created items so that they reflected various aspects of the teacher's dimension. Similarly, Hackett and Betz (1982) addressed validity of their instrument to measure mathematics self-efficacy. It included items addressing mathematics problems in three different areas of mathematics: arithmetic, algebra, and geometry. As a result, Hackett and Betz' mathematics problems instrument encompasses a comprehensive range of the dimension self-efficacy toward mathematics. Lim and Chapman (2013) assessed validity of the shortened version of the ATMI by examining the correlation between ATMI subscales and theoretically related constructs such as mathematics anxiety and performance. According to Lim and Chapman, "the strong relationships found between the various domains of mathematics attitudes and achievement further attested to the robust relationships amongst these constructs" (p. 161) and becomes an evidence of construct validity of the ATMI instrument. Reliability refers to degree to which items in an instrument produces consistent results. Previous studies obtained high values of internal consistency through Cronbach alpha indexes for each of the instruments this study used. Previous sections that explained the instruments used in this study addressed the analysis of reliability prior studies conducted which included the specific score of the Cronbach alpha index for each of the instrument. Chapter IV includes an analysis of the reliability of each instrument used in this study. 


\section{Procedures}

\section{Data Collection}

This section describes the methodology for conducting this study. This study followed guidelines Gall, Gall, and Borg (2007) established when administering a research questionnaire. These steps were considered when envisioning the purpose of this study and developing the research questions. Gall et al. stated that research objectives are defined when researchers clarify the research problem. These provisions help in testing the hypotheses so that the survey items respond to the study's purpose. Gall et al. added that selecting a sample pursues to identify the population of interest for which the questionnaire items are highly salient. Permission to conduct the study was requested from Florida International University Institutional Review Board (IRB). Once IRB permission was granted (Approval \#: IRB-16-0354, Reference \#: 104708), the researcher requested permission to conduct the study in the higher education institution serving the population of interest for this study. After IRB permission was secured, the researcher contacted instructors teaching College Algebra courses delivered in both face-to-face and hybrid instructional modalities to collect survey data from their students.

The researcher met with the volunteer instructors to explain the nature, purpose, and significance of the study. During this meeting, the researcher addressed the instructors' concerns about benefit/danger from their participation and time of administration of the instruments. Furthermore, the researcher oversaw addressing student concerns at the time of recruiting volunteer students as well as administering the survey, as the researcher was the only individual administering the instruments to students. Consequently, instructors did not need to receive any training to participate in 
the study. Volunteer instructors who taught College Algebra at the higher education site used in this study were highly qualified as stipulated by the Department of Education of the State (FLDOE). They have met the requirements of the FLDOE as either they have a Master's Degree in Mathematics or a Master's Degree in a discipline related to mathematics plus 18 graduate credits in higher-level mathematics courses. Additionally, these instructors have a vast experience teaching this course as they receive pedagogical training every year in workshops and seminars. These workshops and seminars exposed instructors on techniques of analysis of teaching that includes implementation of strategies to improve students' success. As explained above, this study used wellestablished scales. Gall et al. (2007) describe the advantages of using scales for which validity and reliability have been previously established. It was expected that participants would be encouraged to complete the surveys as the current study used questionnaires that contained succinct and friendly-written items. Using well-established subscales enhanced the strength of the study (Gall et al., 2007).

Gall et al. (2007) advises that pre-contacting the sample is an important initial step so that the researcher can inform participants about the purpose of the study and can directly request participation. To comply with this guideline, students who attended the classes from the participating instructors were contacted two weeks prior to the beginning of the study and were informed about the purpose of the study at that time. The researcher informed these students about the goal of the study and the importance of their participation in the completion of the study. The three instruments discussed in previous sections were administered to a sample of 390 students in 12 College Algebra classes. Students in six of these sections received instruction in face-to-face form while students 
in the other six sections learned mathematics in a hybrid instructional setting. The instruments were administered in the second half of the academic terms Fall-2016 and Spring-2017 before the last day to drop courses or withdraw. The rationale behind this decision was to collect as much data as possible (Gall et al. 2007). Both terms, Fall-2016 and Spring-2017, comprised 16 weeks of academic instruction. Most students were still enrolled in each semester at the time of administering the survey. Administering the instrument prior to the last day to drop courses or withdraw was an effort to reduce the effect of attrition (Gal et al. 2007) in the data collection process.

Both the face-to-face and the hybrid classes that participated in this study used the same instructional material and the same assessment system. Since the institution where the study was conducted advocates for the use of technology and electronic resources, College Algebra classes under both instructional modalities used the same e-book and students in all participant classes were assigned online mandatory homework on the same online platform as well as e-book-based optional homework. In addition to the homework assignments, the assessment system included 4 in class exams and an optional final exam. One of the differences between the face-to-face and hybrid classes was that students in the hybrid classes were assigned weekly online warm-up quizzes. These quizzes had the goal of preparing hybrid students for in-class discussion during the face-to-face meetings. The warm-up quizzes included conceptual and application problems and students had 75 minutes to complete it. Prior taking the warm-up quizzes, hybrid students had to complete reading assignments via e-book and summarize information that they would need know when completing the warm-up quizzes. 
A remarkable difference between face-to-face and hybrid courses was the time allocated for in-class interaction (direct contact with the instructor and peer students). Students in the face-to-face courses met twice a week in in-class meetings that lasted 75 minutes each. Students in hybrid courses met once a week for 75 minutes as well. Students in the hybrid courses were assigned 75 minutes to complete online assignments. In the face-to-face classes, the instructor lectured every meeting. The in-class meetings in the hybrid classes were used to discuss and clarify the content areas students were not able to master by themselves when taking the warm-up quizzes. Meetings between participant instructors in the study were regularly held to keep uniformity of instruction and assessments and minimize the effect of collecting data from different instructors. The researcher participated in these meetings as well. Additionally, students used a syllabus that included the same course pacing, use of instructional materials, and course content to be covered.

The researcher read an adult verbal consent at the time of the instrument administration. A signed copy of this consent was required as consent for participating in the study prior to the completion of the instruments. The consent also informed the participants about the relevance of the study and the importance of students' completion as an appeal for students to complete the instruments. The survey was administered during the last 30 minutes of a regular meeting in the face-to-face classes and in the last 30 minutes in the in-class meeting in the hybrid classes. The researcher expressed to students that the participation in the study was strictly voluntary. The researcher also informed that those students who did not wish to participate in the survey had the 
opportunity to leave the room before the survey was administered. Students under 18 years of age were not allowed to participate in the study.

Finally, statistical analyses were conducted to explore the relationship among the variables used in this study. The students did not need to provide any personal information in their responses to the surveys. Therefore, a student's identity was not traceable. Students' participation in this project was strictly voluntary and the confidentiality of their responses was warranted. As such, students could choose not to participate in the study at any point. Data from the instrument were collected and secured in a locked filing cabinet in an office with researcher-access only. Data will be destroyed three years upon the completion of the study.

\section{Data Analysis}

The use of the Social Cognitive Theory (SCT) as a theoretical framework and the use of findings from previous research studies served as tools for developing the model depicted in Figure 1 in Chapter 1. In this model, it was hypothesized that factors underlying teacher's effect and self-efficacy, and the demographic factor of mode of instruction would have a direct effect on factors underlying students' attitudes towards mathematics. The model also hypothesized that factors underlying teacher's effect and the demographic factors of gender and modes of instruction would have a direct effect on self-efficacy. The construct teacher's effect, self-efficacy, and attitudes were latent constructs, not directly measured variables. The model was used to evaluate the extent of the interrelationship among factors of the constructs and the demographics factors in face-to-face College Algebra and hybrid College Algebra. The study also addressed the 
differences of factors underlying attitudes toward College Algebra with respect to learning modes.

An analysis of the data via descriptive statistics (percentage, frequency distribution, mean and standard deviation) and t-tests of homogeneity was conducted for demographics to assess responders' characteristics. Exploratory factor analysis was used to extract the factors underlying the constructs of teacher's effect, self-efficacy in mathematics, and attitudes toward mathematics. Path analysis was the statistical method used to assess the relationship among the variables in the model. Path analysis is an appropriate statistical method in this context since the model tested the validity of a theoretical framework (Bandura's SCT) and the causal relationship between the factors underlying the constructs of teacher's effect, self-efficacy, and attitudes toward mathematics. Additionally, path analysis evaluated the strength of the causal relationship among the constructs across modes of instruction. A MANOVA was conducted to analyze differences of the factors underlying attitudes toward College Algebra in terms of instructional modes. All variables, except for gender and modes of instructions were continuous. Statistical analysis was conducted using SPSS (20.0 version for Microsoft Windows).

\section{Summary}

Chapter 3 discussed the methodology of the study including the research questions, the research design, population and sample, instrumentation, and procedures for data collection and analysis. The statistical technique chosen to respond to the research questions was also addressed in this chapter. 


\section{CHAPTER IV}

\section{RESEARCH FINDINGS}

This chapter presents the findings of the study. The chapter starts with a descriptive analysis of the sample used in the study. It also includes the results from applying the statistical procedures to respond to the research questions. The purpose of this study was to examine the effect of factors underlying the dimension of teacher's effect, self-efficacy, and the demographic factors of gender and mode of instruction on the factors underlying attitudes of students to learn mathematics in the context of College Algebra in face-to-face and hybrid learning courses at a minority-serving institution of higher education. The study also examined the differences of factors underlying students' attitudes toward College Algebra with respect to both instructional modalities (face-toface and hybrid learning).

\section{Analysis on Demographic Indicators}

This study was conducted in a 4-year college in a metropolitan area of South Florida during the Fall term of 2016 and the Spring term of 2017. A total of 510 students enrolled in College Algebra delivered in hybrid and face to face modalities were reached to request their voluntary participation in the study. Several factors led to excluding some of the students invited to participate in this study. One of the factors was that some students were absent at the time the instrument was administered. In addition, responses of those students who did not complete each of the item in the instrument (missing values) were not included in this study. Finally, there were instances where students were not able to sign the consent form because they were less than 18 years old. As a result, the final sample in this study consisted of 390 students. 
The first part of the survey included a battery of demographic questions to collect relevant information about the participants. The demographic information collected is shown in Table 2. One hundred and eighty-five students were enrolled in hybrid courses while 205 were enrolled in face to face courses. Most of the participants in this study, 327 students (83.85\%), were from Hispanic origin followed by students from White heritage with a representation of 30 students (7.69\%). Twenty-one students identified themselves as African American or Black (5.38\%), only 7 (1.79\%) students indicated that they were Asian or Asian Americas, and 5 (1.29\%) students belonged to other ethnic/racial groups. One hundred and sixty-one students (41.28\%) were male and 229 students (58.72\%) were female. Three hundred and sixty-two students $(92.82 \%)$ were 25 years or less, followed by $21(5.38 \%)$ students in the range $26-40$ years, $5(1.28 \%)$ students between $41-54$ years, and $2(0.52 \%)$ students were older than 54 years. More than one-half of students had not taken a remedial mathematics class. Around 30\% of these students had previously taken a hybrid mathematics class and almost $60 \%$ of them pursued an STEM career. 
Table 2

Demographic Indicators of Students Participants in the Study.

\begin{tabular}{|c|c|c|}
\hline Indicator & $n$ & $\%$ \\
\hline \multicolumn{3}{|l|}{ Instructional Modality } \\
\hline Hybrid & 185 & 47.44 \\
\hline Face to Face & 205 & 52.56 \\
\hline \multicolumn{3}{|l|}{ Race/Ethnicity } \\
\hline African American/Black & 21 & 5.38 \\
\hline Asian American/Asian & 7 & 1.79 \\
\hline White & 30 & 7.69 \\
\hline Hispanic/Latino & 327 & 83.85 \\
\hline Other & 5 & 1.29 \\
\hline \multicolumn{3}{|l|}{ Gender } \\
\hline Male & 161 & 41.28 \\
\hline Female & 229 & 58.72 \\
\hline \multicolumn{3}{|l|}{ Age } \\
\hline 25 or under & 362 & 92.82 \\
\hline $26-40$ & 21 & 5.38 \\
\hline $41-55$ & 5 & 1.28 \\
\hline More than 55 & 2 & 0.52 \\
\hline \multicolumn{3}{|l|}{ Hybrid Math Class Before } \\
\hline Yes & 116 & 29.74 \\
\hline No & 274 & 70.26 \\
\hline \multicolumn{3}{|l|}{ Remedial Math Classes Taken } \\
\hline 0 & 214 & 54.87 \\
\hline 1 & 119 & 30.51 \\
\hline 2 & 45 & 11.54 \\
\hline 3 or more & 12 & 3.08 \\
\hline
\end{tabular}


Area of Future Studies

STEM

232

59.49

Non-STEM

158

40.51

Out of the 390 students who participated in the study, 185 students received Hybrid instruction in College Algebra. The demographic description of the data in terms of Hybrid learning modality is shown in Table 3. More than $83 \%$ of students in this group (154 students) were from Hispanic origin. A total of 13 students were White, 4 students Black or African American, and 3 students were from another ethnic/racial group. In this group, 67 of these students were male and 118 were female. Most students in the hybrid instruction group, 172 students $(92.97 \%)$, were 25 years old or less. Other demographic indicators are shown in Table 3 as well. 
Table 3

Demographic Indicators for Students in the Hybrid Group.

\begin{tabular}{|c|c|c|}
\hline Indicator & $n$ & $\%$ \\
\hline \multicolumn{3}{|l|}{ Race/Ethnicity } \\
\hline African American/Black & 11 & 5.95 \\
\hline Asian American/Asian & 4 & 2.16 \\
\hline White & 13 & 7.03 \\
\hline Hispanic/Latino & 154 & 83.24 \\
\hline Other & 3 & 1.62 \\
\hline \multicolumn{3}{|l|}{ Gender } \\
\hline Male & 67 & 36.22 \\
\hline Female & 118 & 63.78 \\
\hline \multicolumn{3}{|l|}{ Age } \\
\hline 25 or under & 172 & 92.97 \\
\hline $26-40$ & 10 & 5.41 \\
\hline $41-55$ & 2 & 1.08 \\
\hline More than 55 & 1 & 0.54 \\
\hline \multicolumn{3}{|l|}{ Hybrid Math Class Before } \\
\hline Yes & 71 & 38.38 \\
\hline No & 114 & 61.62 \\
\hline \multicolumn{3}{|l|}{ Remedial Math Classes Taken } \\
\hline 0 & 94 & 50.81 \\
\hline 1 & 63 & 34.05 \\
\hline 2 & 21 & 11.35 \\
\hline 3 or more & 7 & 3.79 \\
\hline \multicolumn{3}{|l|}{ Area of Future Studies } \\
\hline STEM & 112 & 60.54 \\
\hline Non-STEM & 73 & 39.46 \\
\hline
\end{tabular}


The group of students that received face-to-face instruction in College Algebra included 205 students and the description of the demographic indicators for students in this group is shown in Table 4. One hundred and seventy-three students (84.39\%) were Hispanic, 17 students were White, 10 African American or Black, 3 were Asian, and 2 from other ethnic/racial origins. A total of $111(54.15 \%)$ students were female. The age distribution in the face-to-face group was 190 (92.68\%) students 25 years old or younger, 11 of these students had ages between 26 and 40, 3 students between 41-55 years, and one student was 55 years old or older. Table 4 also includes other demographic factors. 
Table 4

Demographic Indicators for Students in the Face-to-Face Group.

\begin{tabular}{|c|c|c|}
\hline Indicator & $n$ & $\%$ \\
\hline \multicolumn{3}{|l|}{ Race/Ethnicity } \\
\hline African American/Black & 10 & 4.88 \\
\hline Asian American/Asian & 3 & 1.46 \\
\hline White & 17 & 8.29 \\
\hline Hispanic/Latino & 173 & 84.39 \\
\hline Other & 2 & 0.98 \\
\hline \multicolumn{3}{|l|}{ Gender } \\
\hline Male & 94 & 45.85 \\
\hline Female & 111 & 54.15 \\
\hline \multicolumn{3}{|l|}{ Age } \\
\hline 25 or under & 190 & 92.68 \\
\hline $26-40$ & 11 & 5.37 \\
\hline $41-55$ & 3 & 1.46 \\
\hline More than 55 & 1 & 0.49 \\
\hline \multicolumn{3}{|l|}{ Hybrid Math Class Before } \\
\hline Yes & 45 & 21.95 \\
\hline No & 160 & 78.05 \\
\hline \multicolumn{3}{|l|}{ Remedial Math Classes Taken } \\
\hline 0 & 120 & 58.54 \\
\hline 1 & 56 & 27.32 \\
\hline 2 & 24 & 11.71 \\
\hline 3 or more & 5 & 2.43 \\
\hline \multicolumn{3}{|l|}{ Area of Future Studies } \\
\hline STEM & 120 & 58.54 \\
\hline Non-STEM & 85 & 41.46 \\
\hline
\end{tabular}


Screening of demographic indicators included conducting independent $t$-tests to evaluate homogeneity between groups. Table 5 shows the results for each $t$-test for each of the indicators. Results of the independent samples $t$-tests indicated that the hybrid and face to face groups were not different in terms of ethnicity/race, gender, age, remedial math classes taken, area of future studies as each of those $t$-tests for these demographic indicators was not statistically significant $(p>.05)$. On the other hand, the $t$-test for the demographic indicator of number of hybrid mathematics class taken before produced significant differences between students in the hybrid and face-to-face learning modalities. This result is to some extent expected because the difference between the number of students who had previously taken a hybrid mathematics class and the students who had not in the face-to-face group was more than twice of the difference between the number of students who had taken hybrid mathematics class and the students who had not in the hybrid group. Table 3 shows that 71 students out of 185 in the hybrid group had taken a hybrid mathematics class before enrolling in College Algebra. Table 4 shows that only 45 students out of 205 had taken a hybrid mathematics class in the past. Therefore, the difference in the number of students who had taken a mathematics hybrid class between groups could have been related to a significant difference between groups with respect to the indicator hybrid mathematics class before. 
Table 5

Independent-Samples t-Test Results for Demographics Differences of Indicators in Hybrid and Face to Face Groups

\begin{tabular}{lcccccc}
\hline \multicolumn{1}{c}{$\begin{array}{c}\text { Demographic } \\
\text { Indicators }\end{array}$} & \multicolumn{2}{c}{ Hybrid } & Face-to-Face & \multicolumn{3}{c}{$\begin{array}{c}\text { t-test for } \\
\text { Equality of } \\
\text { means }\end{array}$} \\
\hline & $M$ & $S D$ & $M$ & $S D$ & $t(388)$ & $p$ \\
\hline $\begin{array}{l}\text { Ethnicity/Race } \\
\text { Gender }\end{array}$ & 3.72 & .80 & 3.75 & .73 & 0.73 & .728 \\
$\begin{array}{l}\text { Age } \\
\text { Hybrid Math Class }\end{array}$ & 1.64 & .48 & 1.54 & .50 & 1.94 & .054 \\
$\begin{array}{l}\text { Before } \\
\text { Remedial Math } \\
\text { Hybrid Classes } \\
\text { Taken Before } \\
\begin{array}{l}\text { Area of Future } \\
\text { Studies }\end{array}\end{array}$ & 1.09 & .37 & 1.10 & .38 & -.148 & .883 \\
\hline
\end{tabular}

\section{Statistical Analysis Conducted to Respond to Research Question 1}

Q1. Is there more than one reliable and interpretable factor underlying the constructs of teacher's effect in mathematics, self-efficacy toward mathematics, and attitudes toward mathematics in a sample of College Algebra students in a minorityserving College?

$H_{1}$ : There is more than one reliable and interpretable factor underlying the constructs of teacher's effect in mathematics, self-efficacy toward mathematics, and attitudes toward mathematics. 


\section{Dimensionality of the Variables}

This study used three well-known instruments as sources of data collection. The dimensionality of the teacher's effect construct was assessed with the Fennema and Sherman Mathematics Attitude Scales (Fennema \& Sherman, 1976), an instrument composed of 12 items. The Hackett and Betz (1982) Mathematics Self-Efficacy Scale, which contains 18 items, served to assess dimensionality of the self-efficacy toward mathematics construct. The dimensionality of the attitude toward mathematics construct was assessed with the Lim and Chapman (2013) instrument, a 19-item version of the Attitudes toward Mathematics Inventory (ATM). A 5-point scale was used as the metric for each observed variable (item). Screening for outliers showed that all values were in the range expected for each variable. Items Teacher7 through Teacher12 in the teacher's effect scale and items Attitude10 through Attitude15 in the attitudes toward mathematics scale were negatively worded items. That is, these items were worded in such a way that the numerical scoring scale run in the opposite direction the teacher's effect and attitudes toward mathematics dimensions were intended to assess respectively. High values on these items reflected low levels of the constructs and vice versa. For these reasons, all these items were reversed-scale.

A preliminary analysis of reliability via Cronbach's coefficient alpha was conducted for each independent instrument and for the 3 instruments combined. The preliminary analysis produced the values presented in Table 6 . As Table 6 shows, each of the Cronbach Alpha indexes exceeded by far the lower limit of acceptability of .70 according to Hair, Black, Babin, and Anderson, (2010) and Meyers, Gamst, and Guarino (2013). In fact, each of the values of the Cronbach index was either very good (values 
ranging $.85-.89$ ) or outstanding (values $>.90$ ), according to the guidelines recommended by Field (2009) and Meyers et al. (2013) when interpreting this index of reliability.

Table 6

Cronbach alpha coefficient for individual and combined instruments in the study.

\begin{tabular}{lc}
\hline \multicolumn{1}{c}{ Instrument } & Cronbach Alpha \\
Teacher's Effect & .868 \\
Self-Efficacy & .923 \\
Attitudes toward Mathematics & .917 \\
All Instruments Combined & .941 \\
\hline
\end{tabular}

Creating a composite measure (new variables) that would reflect the underlying dimensions (constructs) of teacher's effect, self-efficacy in mathematics, and attitudes toward mathematics was the next step. Hair et al. (2010) advices carrying out exploratory factor analysis (EFA) prior to creating new composite variables. Otherwise, the unidimensionality of the scale would not be properly addressed. In other words, not a single factor but several independent factors may represent the structure of the dimension under study. The goal of this study was to analyze the causal relationship between the factors underlying the measures. Congruent to this purpose, this study used exploratory factor analysis as the means "to reduce a set of variables to a smaller number of variables while retaining as much of the original variance as possible" (Ren, Green, \& Smith, 2016, p. 313). 
Exploratory factor analysis (EFA) using the Principal Axis Factoring (PAF) extraction method of estimation and a Promax rotation (oblique) of the teacher's effect measure, the self-efficacy toward mathematics measure, and the attitudes toward mathematics measure was performed on the data of 390 College Algebra students. Social science researchers commonly use EFA when they study variables that cannot be directly measured (Field, 2009). Field claims that EFA eases the inconvenient effect of multicollinearity in multiple regression. Therefore, "factor analysis can be used to solve this problem by combining variables that are collinear" (Field, 2009, p. 628). The analysis in this study focused on assessing the dimensionality of each of the three measures used. Sample size is an aspect of concern before conducting an EFA. According to Field, "the reliability of factor analysis is also dependent on sample size" (p. 645). Field added that previous research has come up with a different array of relationships between sample size and factor interpretation. As a rule, a sample size of at least 300 cases is required to produce a potential stable solution (Field, 2009) Meyers et al. (2013). The sample in the study $(N=390)$ satisfied the minimum sample recommended for EFA. The section that follows describes the EFA conducted to assess the structure of each of the scale.

$H_{l a}$ : There is more than one reliable and interpretable factor underlying the construct of teacher's effect in mathematics. 


\section{Exploratory Factor Analysis of the Teacher's Effect Measure}

Correlations between items of the teacher's effect scale were assessed prior to conducting the EFA. These correlations are shown in Table 7. An observation of Table 7 suggests a strong positive correlation between items 1 through 6 except for item 4 which correlation with other items in this group was somewhat weaker. Table 7 also indicates a positive moderate and significant correlation between items 8 through 12 except for item 7 which correlation with other items in this group was not as strong. From this pattern, it was expected to extract 2 factors. All correlations except for items 4 and 7 were significant for $p<.001$.

Table 7

Intercorrelations for Scores on the 12 items of Teacher's Effect measure

\begin{tabular}{|c|c|c|c|c|c|c|c|c|c|c|c|c|}
\hline & $\mathrm{T} 1$ & $\mathrm{~T} 2$ & $\mathrm{~T} 3$ & $\mathrm{~T} 4$ & T5 & T6 & $\mathrm{T} 7$ & T8 & T9 & $\mathrm{T} 10$ & $\mathrm{~T} 11$ & T12 \\
\hline $\mathrm{T} 1$ & - & & & & & & & & & & & \\
\hline $\mathrm{T} 2$ & $.70 * *$ & - & & & & & & & & & & \\
\hline T3 & $.65 * *$ & $.67 * *$ & - & & & & & & & & & \\
\hline $\mathrm{T} 4$ & $.30 * *$ & $.33 * *$ & $.34 * *$ & - & & & & & & & & \\
\hline T5 & $.60 * *$ & $.60 * *$ & $.61 * *$ & $.40 * *$ & - & & & & & & & \\
\hline T6 & $.60 * *$ & $.60 * *$ & $.62 * *$ & $.37 * *$ & $.71 * *$ & - & & & & & & \\
\hline T7 & $.18 * *$ & .09 & $.20 * *$ & $.11 *$ & $.17 * *$ & $.21 * *$ & - & & & & & \\
\hline T8 & $.22 * *$ & $.18 * *$ & $.21 * *$ & $.22 * *$ & $.24 * *$ & $.28 * *$ & $.35 * *$ & - & & & & \\
\hline T9 & $.24 * *$ & $.19 * *$ & $.22 * *$ & $.13 * *$ & $.28 * *$ & $.23 * *$ & $.42 * *$ & $.51 * *$ & - & & & \\
\hline T10 & $.26 * *$ & $.23 * *$ & $.22 * *$ & $.13 * *$ & $.26 * *$ & $.28 * *$ & $.38 * *$ & $.50 * *$ & $.60 * *$ & - & & \\
\hline T11 & $.25 * *$ & $.25 * *$ & $.30 * *$ & $.18 * *$ & $.26 * *$ & $23 * *$ & $.39 * *$ & $.53 * *$ & $.63 * *$ & $.60 * *$ & - & \\
\hline $\mathrm{T} 12$ & $.28 * *$ & $.26 * *$ & $.27 * *$ & $.12 *$ & $.26 * *$ & $.26 * *$ & $.44 * *$ & $.47 * *$ & $.63 * *$ & $.57 * *$ & $.815^{* *}$ & - \\
\hline
\end{tabular}

As is customary before conducting an EFA, the suitability of the data for this analysis was examined (Field, 2009; Hair et al., 2010; Meyers et al., 2013). The KaiserMeyer-Olkin measure of sampling adequacy was 0.879 , indicating that the present data 
was suitable for factor analysis. Similarly, the Barlett's chi-square test of sphericity was significant $\left(\chi^{2}=2434.53, \mathrm{p}<.001\right)$, granting sufficient correlation between the variables to proceed with the analysis. An initial EFA was conducted to analyze the domains of the teacher's effect measure. Table 8 shows the result of this analysis. A two-factor solution produced eigenvalues greater than 1.00 , cumulatively accounting for $55.08 \%$ of the total variance. The first factor (eigenvalue $=5.04$ ) accounted for $38.62 \%$ of the variance and included items 1 through 6 of the measure. The wording of items 1 through 6 stresses inspiration and stimulation to learn mathematics. As a result, factor 1 was named as Encouragement. The second factor (eigenvalue $=2.38$ ), accounted for $16.46 \%$ of the variance and included items 7 through 12 of the measure. Items 7 through 12 stress lack of support from the teacher. Factor 2 was named as Discouragement. The communality of each of the items were above 0.5 , except for the items 4,7 , and 8 with very low communalities. For all items except for items 4, 7, and 8 loading in their respective factors exceeded the desired value of 0.7 . For this reason, items 4,7 , and 8 were considered as candidates for removal from the analysis. Results of this preliminary EFA appear in Table 8 . 
Table 8

Summary of the initial Solution from an Exploratory Factor Analysis Results on 12 Items of the Teacher's Effect Measure Using Principal Axis Factoring Estimation and Promax Rotation $(N=390)$.

Factor Loadings $\quad$ Communality

Item Encouragement Discouragement

1. My teachers have .79

encouraged me to study more mathematics

2. My teachers think I'm the kind of person who could do well in mathematics.

3. My mathematics teachers have been interested in my progress in mathematics.

4. I would talk to my mathematics teachers about a career which uses math.

5. Mathematics teachers have made me feel I have the ability to go on in mathematics.

7. When it comes to anything serious, I have felt ignored when talking to mathematics teachers.

8. My teachers think advanced for me.

9. Getting a mathematics teacher to take me seriously has usually been a problem.

10. My teachers would think I wasn't serious if I told them I was interested in a career in science and mathematics. 
11. I have found it hard to win the respect of mathematics teachers.

12. I have had a hard time getting teachers to talk seriously with me about mathematics.

Eigenvalues

$\%$ of variance

Note: Factor loadings are those from the Pattern Matrix.

Additional EFAs were run eliminating one item at a time. As a result, items 4, 7, and 8 were removed from the analysis in this order due to poor loading in their respective factors. The final two-factor solution, after removing items 4,7 , and 8 , is shown in Table 9. The final solution explained much more variance than the first solution (64.22\%) with a moderate inter-factor correlation coefficient of 0.38 . An analysis of the reliability via Cronbach alpha for each factor was performed after achieving the final solution. Factor 1 (with items $1,2,3,5,6$ ) reached a Cronbach alpha value of 0.873 . The Cronbach alpha value for factor 1 would not have increased if another item was removed. Factor 2 (with items 9 through 12 included) reached a Cronbach alpha value of 0.867 . The value of this index of reliability did not increase after removing an item in this factor. 
Table 9

Summary of the Final Solution from an Exploratory Factor Analysis Results after

removing Items 4, 7, and 8 of the Teacher's Effect Measure Using Principal Axis

Factoring Estimation and Promax Rotation $(N=390)$.

Factor Loadings

Communality

Item Encouragement Discouragement

1. My teachers have encouraged

.80

.65

me to study more mathematics

2. My teachers think I'm the

kind of person who could do

well in mathematics.

3. My mathematics teachers

have been interested in my

progress in mathematics.

5. Mathematics teachers have

made me feel I have the ability

to go on in mathematics.

6. My mathematics teachers

encourage me to take the entire mathematics I can.

9. Getting a mathematics teacher

to take me seriously has usually been a problem.

10. My teachers would think I wasn't serious if I told them I was interested in a career in science and mathematics.

11. I have found it hard to win the respect of mathematics teachers. 
12. I have had a hard time

with me about mathematics.
Eigenvalues
4.39
2.08
$\%$ of variance
44.90
19.32

Note: Factor loadings are those from the Pattern Matrix.

$H_{1 b}$ : There is more than one reliable and interpretable factor underlying the constructs of self-efficacy toward mathematics.

\section{Exploratory Factor Analysis of the Self-Efficacy Measure}

Most correlations between the items of the self-efficacy measure were significant in the range from weak to high as shown in Table 10. The correlation analysis of items in this measure revealed no underlying relationship between items. That is, no clear pattern emerged from the inspection of the correlation between items. 
Table 10

Intercorrelations for Scores on the 18 items of Self-Efficacy in Mathematics measure

\begin{tabular}{|c|c|c|c|c|c|c|c|c|c|c|c|c|c|c|c|c|c|c|}
\hline & 1 & 2 & 3 & 4 & 5 & 6 & 7 & 8 & 9 & 10 & 11 & 12 & 13 & 14 & 15 & 16 & 17 & 18 \\
\hline Self1 & 1 & $.431^{* *}$ & $.352^{* *}$ & $.342^{* *}$ & $.321^{* *}$ & $.376^{* *}$ & $.355^{* *}$ & $.323^{* *}$ & $.295^{* *}$ & $.317^{* *}$ & $.285^{* *}$ & $.321^{* *}$ & $.272^{* *}$ & $.333^{* *}$ & $.321^{* *}$ & $.254^{* *}$ & $.171^{* *}$ & $.205^{* *}$ \\
\hline Self2 & $.431^{* *}$ & 1 & $.516^{* * *}$ & $453^{* *}$ & $.378^{* * *}$ & $.423^{* * *}$ & $.412^{* *}$ & $.468^{* *}$ & $.346^{* *}$ & $.424^{* *}$ & $.374^{* *}$ & $.390^{* *}$ & $.338^{* *}$ & $.440^{* *}$ & $.394^{* *}$ & $.341^{* *}$ & $.238^{* *}$ & $.256^{* * *}$ \\
\hline Seelf3 & $.352^{* *}$ & $.516^{* *}$ & 1 & $.493^{* *}$ & $.363^{*}$ & $.393^{\prime}$ & $.490^{* *}$ & $.417^{* *}$ & $.346^{* *}$ & $.445^{* *}$ & $.411^{* *}$ & $.336^{* *}$ & $.359^{* *}$ & $.359^{* *}$ & $.250^{* *}$ & $.427^{* *}$ & $.371^{* * *}$ & $.322^{* *}$ \\
\hline Self4 & $.342^{* *}$ & $.453^{* *}$ & $.493^{* * *}$ & 1 & $.403^{* * *}$ & $.353^{* *}$ & $.442^{* * *}$ & $.454^{* *}$ & $.328^{* *}$ & $.432^{* *}$ & $.384^{* *}$ & $.356^{* *}$ & $.342^{* *}$ & $.396^{* *}$ & $.398^{* *}$ & $.393^{* *}$ & $.310^{* *}$ & $.346^{* *}$ \\
\hline Self5 & $.321^{* *}$ & $.378^{* * *}$ & $.363^{* *}$ & $.403^{* *}$ & 1 & $.483^{* *}$ & $.405^{* *}$ & $.413^{* *}$ & $.433^{* *}$ & $.410^{* *}$ & $.405^{\text {** }}$ & $.396^{* *}$ & $.325^{* *}$ & $.349^{* *}$ & $.335^{* *}$ & $.374^{* *}$ & $.345^{* *}$ & $.265^{* *}$ \\
\hline Self6 & $.376^{* *}$ & $.423^{* *}$ & $.393^{* *}$ & $.353^{* *}$ & $.483^{* *}$ & 1 & $.421^{* *}$ & $.410^{* *}$ & $.419^{* *}$ & $.354^{* *}$ & $.315^{\text {** }}$ & $.345^{\text {** }}$ & $.345^{\text {** }}$ & $.382^{* *}$ & $.401^{* *}$ & $.296^{* *}$ & $.263^{* *}$ & $.218^{* *}$ \\
\hline Self7 & $.355^{* *}$ & $.412^{* * *}$ & $.490^{* * *}$ & $.442^{* *}$ & $.405^{* * *}$ & $.421^{* *}$ & 1 & $.623^{* *}$ & $.452^{* *}$ & $.582^{* *}$ & $.542^{* *}$ & $.458^{* *}$ & $.474^{* *}$ & $.390^{* *}$ & $.430^{* *}$ & $.440^{* *}$ & $.436^{* *}$ & $.465^{\text {** }}$ \\
\hline Self8 & $.323^{* *}$ & $.468^{* *}$ & $.417^{* *}$ & $.454^{* *}$ & $.413^{* * *}$ & $.410^{* * *}$ & $.623^{* *}$ & 1 & $.483^{* *}$ & $.516^{* *}$ & $.498^{* *}$ & $.520^{* *}$ & $.525^{* *}$ & $.371^{* *}$ & $.441^{* *}$ & $.432^{* *}$ & $.418^{* *}$ & $.419^{* *}$ \\
\hline Self9 & $.295^{* *}$ & $.346^{* *}$ & $.346^{* * *}$ & $.328^{* *}$ & $.433^{* * *}$ & $.419^{* * *}$ & $.452^{* *}$ & $.483^{* *}$ & 1 & $.535^{\text {** }}$ & $.421^{\text {** }}$ & $.362^{* *}$ & $.428^{* *}$ & $.233^{* *}$ & $.338^{* *}$ & $.399^{* *}$ & $.511^{\text {** }}$ & $.455^{\text {** }}$ \\
\hline Self10 & $.317^{* *}$ & $.424^{* * *}$ & $.445^{* * *}$ & $.432^{* *}$ & $.410^{* * *}$ & $.354^{* * *}$ & $.582^{* * *}$ & $.516^{* *}$ & $.535^{* *}$ & 1 & $.664^{* *}$ & $.416^{\text {** }}$ & $.470^{* *}$ & $.434^{* *}$ & $.432^{* *}$ & $.512^{* *}$ & $.476^{* *}$ & $.502^{* *}$ \\
\hline Self11 & $.285^{* *}$ & $.374^{* * *}$ & $.411^{* * *}$ & $.384^{* *}$ & $.405^{* * *}$ & $.315^{* *}$ & $.542^{* * *}$ & $.498^{* *}$ & $.421^{* *}$ & $.664^{* *}$ & 1 & $.512^{* *}$ & $.484^{* *}$ & $.465^{* *}$ & $.494^{* *}$ & $.548^{* *}$ & $.513^{* *}$ & $.532^{* *}$ \\
\hline Self12 & $.321^{* *}$ & $.390^{* *}$ & $.336^{* *}$ & $.356^{* *}$ & $.396^{* *}$ & $.345^{* *}$ & $.458^{* *}$ & $.520^{* *}$ & $.362^{* *}$ & $.416^{* *}$ & $.512^{* *}$ & 1 & $.563^{* *}$ & $.380^{* *}$ & $.443^{* *}$ & $.403^{* *}$ & $.375^{* *}$ & $.394^{* *}$ \\
\hline Self13 & $.272^{* *}$ & $.338^{* *}$ & $.359^{* *}$ & $.342^{* *}$ & $.325^{* *}$ & $.345^{* *}$ & $.474^{* *}$ & $.525^{* *}$ & $.428^{* *}$ & $.470^{* *}$ & $.484^{* *}$ & $.563^{* *}$ & 1 & $.366^{* *}$ & $.446^{* *}$ & $.482^{* *}$ & $.494^{* *}$ & $.448^{* *}$ \\
\hline Self14 & $.333^{* *}$ & $.440^{* *}$ & $.359^{* * *}$ & $.396^{* *}$ & $.349^{* *}$ & $.382^{* *}$ & $.390^{* *}$ & $.371^{* *}$ & $.233^{* *}$ & $.434^{* *}$ & $.465^{* *}$ & $.380^{* *}$ & $.366^{* *}$ & 1 & $.558^{* *}$ & $.446^{* *}$ & $.224^{* *}$ & $.221^{* * *}$ \\
\hline Self15 & $.321^{* *}$ & $.394^{* *}$ & $.250^{* *}$ & $.398^{* *}$ & $.335^{* *}$ & $.401^{* *}$ & $.430^{* *}$ & $.441^{* *}$ & $.338^{* *}$ & $.432^{* *}$ & $.494^{* *}$ & $.443^{* *}$ & $.446^{* *}$ & $.558^{* *}$ & 1 & $.507^{* *}$ & $.408^{* *}$ & $.353^{* *}$ \\
\hline Self16 & $.254^{* *}$ & $.341^{* *}$ & $.427^{* *}$ & $.393^{* *}$ & $.374^{* *}$ & $.296^{* *}$ & $.440^{* *}$ & $.432^{* *}$ & $.399^{* *}$ & $.512^{* *}$ & $.548^{* *}$ & $.403^{* *}$ & $.482^{* *}$ & $.446^{* *}$ & $.507^{* *}$ & 1 & $.657^{* *}$ & $.561^{* *}$ \\
\hline Self17 & $.171^{* *}$ & $.238^{* *}$ & $.371^{* *}$ & $.310^{* *}$ & $.345^{* *}$ & $.263^{* *}$ & $.436^{* *}$ & $.418^{* *}$ & $.511^{* *}$ & $.476^{* *}$ & $.513^{* *}$ & $.375^{* *}$ & $.494^{* *}$ & $.224^{* *}$ & $.408^{* *}$ & $.657^{* *}$ & 1 & $.701^{* *}$ \\
\hline Self18 & $.205^{* *}$ & $.256^{* *}$ & $.322^{* *}$ & $.346^{* *}$ & $.265^{* *}$ & $.218^{* *}$ & $.465^{* *}$ & $.419^{* *}$ & $.455^{* *}$ & $.502^{* *}$ & $.532^{* *}$ & $.394^{* *}$ & $.448^{* *}$ & $.221^{* *}$ & $.353^{* *}$ & $.561^{* *}$ & $.701^{* *}$ & 1 \\
\hline
\end{tabular}

**. Correlation is significant at the 0.01 level (2-tailed). 
Results of the Kaiser-Meyer-Olkin measure of sampling adequacy was 0.934 granting the suitability of the data for EFA. There was sufficient correlation between the variables to proceed with the analysis as the Barlett's chi-square test of sphericity was

significant $\left(\chi^{2}=3398.7, \mathrm{p}<.001\right)$. A two-factor solution with eigenvalues greater than 1.00 was obtained from an EFA. Results of this analysis are shown in Table 11. These two-factors combined explained $47.22 \%$ of the total variance. Factor 1 (eigenvalue $=$ 7.971) accounted for $41.42 \%$ of the variance and included items $2,6,1,14,4,3,5,8,7$, 15 , and 12 , in order of loading in the factor. Items loading in this factor addressed problems from different areas in mathematics. The second factor (eigenvalue $=1.51$ ), accounted for $5.80 \%$ of the variance and included items $7,15,12,17,18,16,11,13,10$, 9 in order of loading in the factor. As for Factor 1, the items loading in Factor 2 presented mathematics problems from different areas of the subject. Only the communality of items $7,8,10,11,16,17,18$ were above 0.5 . Loadings of most items in both factors, except for item 6 in factor 1 and items 17 and 18 in factor 2, were below the rule of thumb value of 0.7. Additionally, item 7 cross-loaded with both factors with a difference of less than 0.2 and item 17 loaded in factor 2 with a value higher than 1. Items with both communalities below 0.5 and factor loading less than 0.7 were considered as candidates for removal from the analysis. 
Table 11

Summary of the initial Solution from an Exploratory Factor Analysis Results on

18 Items of the Self-Efficacy in Mathematics Measure Using Principal Axis Factoring

Estimation and Promax Rotation $(N=390)$.

Factor $\quad$ Communality
Loadings

Item $\quad$ Factor $1 \quad$ Factor 2

1. In Starville, an operation ${ }^{\circ}$ on any numbers $\mathrm{a}$ and $\mathrm{b}$ is defined by $\mathrm{a}^{\circ} \mathrm{b}=\mathrm{a}$

$\mathrm{x}(\mathrm{a}+\mathrm{b})$. Then $2^{\circ} 3$ equals ?

2. Sally needs three pieces of poster board for a class project. If the boards are represented by rectangles A, B, C, arrange their areas in increasing order. (assume $b>a$ )

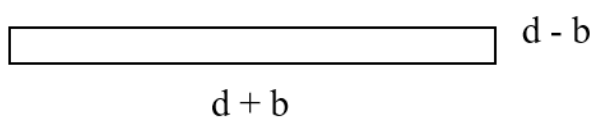

A

B

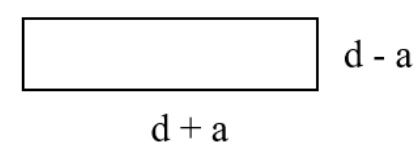

$\mathrm{C}$

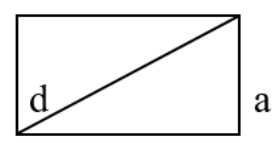

b

The fourth number is at least 10 . What is the smallest average of the four numbers? 
4 pieces of wood 2.5 feet long for the legs. She wants to determine how much wood she will need for five tables. She reasons: $5 \times(4 \times 2.5)=(5$ $x 4) \times 2.5$. Which number principle is she using?

5. The opposite angles of a

parallelogram are?

6. Five points are on a line. $\mathrm{T}$ is next to $\mathrm{G}$. $\mathrm{K}$ is next to $\mathrm{H}$. C is next to T. $\mathrm{H}$ is next to $\mathrm{G}$. Determine the relative positions of the points along the line.

7. There are three numbers. The one-third of the other number. Their sum is 48 . Find the largest number.

8. In a certain triangle, the shortest side is 6 inches, the longest side is twice as long as the shortest side and the third side is 3.4 inches shorter than the longest side. What is the sum of the three sides in inches?

9. The hands of a clock form an obtuse angle at o'clock.

10. Bridget buys a packet containing 9 -cent and 13-cent stamps for $\$ 2.65$. If there are 25 stamps in the packet, how many are 13-cent stamps?

11. A living room set consisting of one sofa and one chair is priced at $\$ 200$. If the price of the-sofa is $50 \%$ more than the price of the chair, find the price of the sofa. 12. Write an equation which expresses the condition that "The product of two numbers $\mathrm{R}$ and $\mathrm{S}$ is one less than twice their sum."

13. Set up the problem to be done to

find the number asked for in the expression "six less than twice 4?" 
14. On a certain map, $7 / 8$ inch

Note: Factor loadings are those from the Pattern Matrix.

Consequently, additional EFAs were run eliminating one item at a time and aiming to retain as many items as possible to come up with a plausible structure. An intermediate solution is shown in Table 12. As observed in the intermediate solution in Table 21 few items meet the limit values recommended for both communalities (0.5) and loadings (0.7). Further EFAs were run to analyze the impact of excluding one of these items at a time. The EFAs were conducted with the goal of retaining the maximum number of items in the factors that explain the highest possible variance at the same time of achieving fair levels of communalities and loading. The intermediate solution shown in Table 12 retained items, 2, 3, 4, 5, 6, 8, 11, 14, 16, 17, and 18 as their loadings were captured by one of the factors. The two-factor solution explained $58.03 \%$ of the variance. 
Table 12

Summary of the Intermediate Solution from an Exploratory Factor Analysis Results on

18 Items of the Self-Efficacy in Mathematics Measure Using Principal Axis Factoring

Estimation and Promax Rotation $(N=390)$.

Factor Loadings

Communality

Item

Factor $1 \quad$ Factor 2

2. Sally needs three pieces of poster

.79

.42

board for a class project. If the boards

are represented by rectangles $\mathrm{A}, \mathrm{B}, \mathrm{C}$,

arrange their areas in

increasing order. (assume $b>a$ )

A

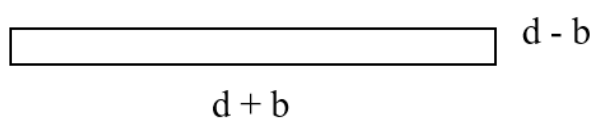

B

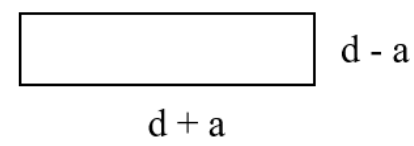

C

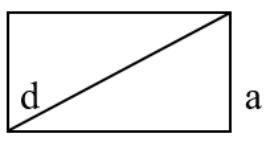

b

The fourth number is at least 10 . What

is the smallest average of the four

numbers?

4. To construct a table, Michele needs 4

pieces of wood 2.5 feet long for the

legs. She wants to determine how much

wood she will need for five tables. She

reasons: $5 \times(4 \times 2.5)=(5 \times 4) \times 2.5$.

Which number principle is she using?

5. The opposite angles of a

parallelogram are $?$

6. Five points are on a line. $\mathrm{T}$ is next to

G. $\mathrm{K}$ is next to H. C is next to T. $\mathrm{H}$ is next to $\mathrm{G}$. Determine the relative positions of the points along the line. 
8. In a certain triangle, the shortest side

is 6 inches, the longest side is twice as

long as the shortest side and the third

side is 3.4 inches shorter than the

longest side. What is the sum of the

three sides in inches?

11. A living room set consisting of one sofa and one chair is priced at $\$ 200$. If the price of the-sofa is $50 \%$ more than the price of the chair, find the price of the sofa.

14. On a certain map, 7/8 inch

represents 200 miles. How far apart are

two towns whose distance apart on the map is $3 \frac{1}{2}$ inches?

16. $33 / 4-1 / 2=$

17. If $3 x-2=16$, what does $x$ equal?

18. Fred's bill for some household

supplies was $\$ 13.64$. If he paid for the items with a $\$ 20$, how much change should he receive?

Eigenvalues

Note: Factor loadings are those from the Pattern Matrix.

The final solution that would attain the highest possible variance explained and retaining the highest possible number of items was accomplished. This solution included items 16, 17, 18 loading in factor 1 and items 2, 3, 4, 6, and 14 loading in factor 2 and explained $62.78 \%$ of the variance. This final solution appears in Table 13. The total variance explained for these two factors increased by 4.75 percentage points. As Table 13 shows, some of the items had a loading less than the minimum recommended value of 0.7. However, these items were retained in a factor as their loading average did not depart substantially from 0.7 . Items 17,18 , and 16 addressed mathematics problems that involves applying where applying several mathematical procedures was a crucial tool to 
solve them. This observation led to name Factor 1 Mathematical Procedures. Items 2, 3, 4, 6, and 14 involved solving problems that required some level of abstraction. Factor 2 was named Critical Thinking. An analysis of the reliability via Cronbach alpha was performed for each factor. Factor 1, Mathematical Procedures, reached a Cronbach alpha value of 0.836 . Removing any item from this factor would have not produced a higher Cronbach value. Factor 2, Critical Thinking, reached an acceptable Cronbach alpha value of 0.72 . If any item would have been removed in this factor, the Cronbach alpha value would have not increased.

Table 13

Summary of the Final Solution from an Exploratory Factor Analysis Results on 18 Items of the Self-Efficacy in Mathematics Measure Using Principal Axis Factoring Estimation and Promax Rotation.

\begin{tabular}{lccc}
\hline & Loading & Communality \\
\hline Item & Arithmetic & $\begin{array}{c}\text { Critical } \\
\text { Thinking }\end{array}$ & \\
\hline $16.33 / 4-1 / 2=$ & .61 & .55 \\
$\begin{array}{l}17 . \text { If } 3 \mathrm{x}-2=16, \text { what does x equal? } \\
\begin{array}{l}\text { 18. Fred's bill for some household } \\
\text { supplies was } \$ 13.64 \text {. If he paid for the }\end{array}\end{array}$ & .97 & .61 \\
$\begin{array}{l}\text { items with a } \$ 20, \text { how much change } \\
\text { should he receive? }\end{array}$ & & & .52
\end{tabular}



arrange their areas in increasing order. (assume $b>a$ )

A

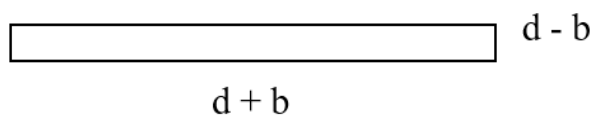

B

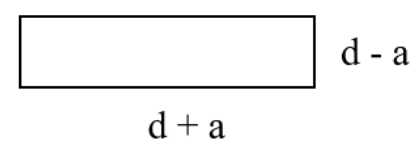

C

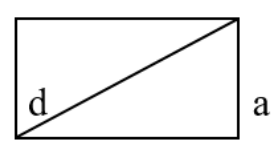

$b$

3. The average of three numbers is 30 .

The fourth number is at least 10 . What is the smallest average of the four numbers?

4. To construct a table, Michele needs 4 pieces of wood 2.5 feet long for the legs. She wants to determine how much wood she will need for five tables. She reasons: $5 \times(4 \times 2.5)=(5 \times 4) \times 2.5$.

Which number principle is she using?

6. Five points are on a line. $\mathrm{T}$ is next to

G. $\mathrm{K}$ is next to $\mathrm{H}$. C is next to T. H is next to G. Determine the relative positions of the points along the line.

14. On a certain map, $7 / 8$ inch map is $3 \frac{1}{2}$ inches?

Eigenvalues 
$H_{l c}$ : There is more than one reliable and interpretable factors underlying the constructs of attitudes toward mathematics.

\section{Exploratory Factor Analysis of the Attitudes toward Mathematics Measure}

Three well-defined clusters of items emerged from the inter-correlation assessment of items in the attitudes toward mathematics scale (Table 14). The analysis indicated an association between items 1 through 9 in one of the clusters with correlation values that ranged from moderate to very high. Items 10 through 14 clustered in a second cluster with a relatively moderate correlation. The third cluster included items 15 through 19 with strong correlation between these items. 
Table 14

Intercorrelations for Scores on the 19 items of Attitudes toward Mathematics Measure

\begin{tabular}{|c|c|c|c|c|c|c|c|c|c|c|c|c|c|c|c|c|c|c|c|}
\hline & 1 & 2 & 3 & $T$ & & 0 & & & 3 & 10 & & & & & 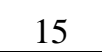 & & 17 & & 19 \\
\hline t1 & 1 & & & & & & & & & 1 & & & & & & & & & 78 \\
\hline $\mathrm{tt} 2$ & & & $.800^{* *}$ & 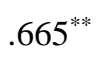 & & & & $69^{* *}$ & $28^{* *}$ & -.050 & 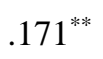 & & & & & & & & 142 \\
\hline $\mathrm{tt} 3$ & 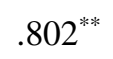 & & 1 & .181 & $.765^{* *}$ & & & $48^{* *}$ & $.656^{* *}$ & -.016 & & & & & & & & & .358 \\
\hline $\mathrm{tt} 4$ & & & & 1 & & & & & & -.009 & & & & & & & & & .272 \\
\hline $\mathrm{tt5}$ & 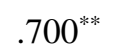 & 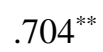 & & & 1 & $.697^{* *}$ & & & $.644^{* *}$ & -.037 & & & & & & & & & .45 \\
\hline tt6 & & 02 & $.706^{* *}$ & & .091 & 1 & & $.629^{* *}$ & $.652^{* *}$ & -.024 & & & & & & & & & .400 \\
\hline tt7 & $601^{* *}$ & $621^{* *}$ & $.681^{* *}$ & $.706^{* *}$ & $.649^{* * *}$ & .673 & 1 & $.784^{* *}$ & & -.044 & & & & & & & & & .29 \\
\hline $\mathrm{tt} 8$ & & .509 & .64 & .68 & $.579^{* * *}$ & $.629^{* *}$ & & 1 & $.532^{* *}$ & -.027 & & & $.147^{* *}$ & & & $.317^{* *}$ & & & .372 \\
\hline tt9 & -0 & .628 & & .61 & $.644^{* * *}$ & & & & 1 & -.0 & & & & & & & & & .367 \\
\hline $\mathrm{tt} 10$ & -.031 & -.050 & 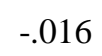 & -.0 & 7 & -. & &.-( & & 1 & & .34 & $.201^{* * *}$ & .28 & & & & & -.03 \\
\hline $\mathrm{tt} 1$ & & & & & & & & & & & 1 & & & & & & & & 162 \\
\hline $\mathrm{tt} 12$ & .22, & .20 & .239 & .19 & .16 & .27 & * & .11 & $.136^{* * *}$ & $.341^{* *}$ & $.577^{* * *}$ & 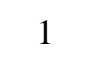 & $.475^{* * *}$ & .57 & & & & & .14 \\
\hline t1 & 20 & .207 & & & & & & & & .20 & .47 & & 1 & & & & & & .175 \\
\hline 114 & & & & & & & & & & & & & & & & & & & 20 \\
\hline $\mathrm{t} 15$ & & 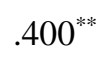 & $.289^{* *}$ & & 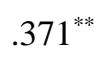 & & & * & *** & -.0 & & & & & & 676 & & & 58 \\
\hline $\mathrm{tt} 16$ & .414 & $.453^{* *}$ & $.358^{* *}$ & 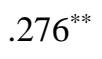 & $.427^{* *}$ & & & $.317^{* *}$ & $.316^{* *}$ & -.040 & & .10 & & .13 & & 1 & .801 & & 660 \\
\hline $\mathrm{tt} 17$ & $453^{* *}$ & $.493^{* *}$ & $.423^{* *}$ & $370^{* * *}$ & $.500^{* *}$ & $.434^{* *}$ & $.321^{* *}$ & $.384^{* *}$ & $.352^{* *}$ & -.016 & 21 & $124^{*}$ & $.197^{* *}$ & $.147^{* *}$ & $.650^{* *}$ & .801 & & $.704^{* *}$ & $65 \varepsilon$ \\
\hline तार & & $.487^{* *}$ & $.407^{* *}$ & .310 & $.444^{* *}$ & $.459^{* *}$ & .301 & .363 & $.359^{* * *}$ & -.045 & & & & $.180^{* *}$ & & $.694^{* *}$ & & & 72 \\
\hline $\mathrm{t} 19$ & $78^{* *}$ & $.442^{* *}$ & $.358^{* *}$ & $.272^{* *}$ & $438^{* * *}$ & $.400^{* *}$ & $299^{* *}$ & $.372^{* *}$ & $.367^{* *}$ & -.037 & $.164^{* *}$ & $.149^{* * *}$ & $.175^{* *}$ & $.200^{* *}$ & $.583^{* * *}$ & $.660^{* * *}$ & $.658^{* *}$ & $.726^{* *}$ & 1 \\
\hline
\end{tabular}

**. Correlation is significant at the 0.01 level (2-tailed);

*. Correlation is significant at the 0.05 level (2-tailed). 
The data was suitable for factor analysis as the Kaiser-Meyer-Olkin measure of sampling adequacy was 0.926 . Similarly, the Barlett's chi-square test of sphericity was significant $\left(\chi^{2}=5248.26, \mathrm{p}<.001\right)$, granting sufficient correlation between the variables to proceed with the analysis. Consistent with the correlation analysis, an initial EFA produced a three-factor solution with eigenvalues greater than 1.00. The three-factor solution accounted for $64.11 \%$ of the total variance. The first factor (eigenvalue $=8.15$ ) accounted for $42.88 \%$ of the variance and included items 1 through 9 of the measure. The second factor (eigenvalue $=2.54$ ), accounted for $10.80 \%$ of the variance and included items 15 through 19 of the measure. The third factor (eigenvalue $=2.31$ ) accounted for $10.43 \%$ of the variance and included items 10 through 14 of the measure. Results in this stage of the analysis are shown in Table 15. As Table 15 shows, communalities were greater than 0.3 and loadings were greater than 0.7 for all items except for items 10 and 13 . 
Table 15

Summary of the Initial Solution from an Exploratory Factor Analysis Results on

19 Items of the Attitudes toward Mathematics Measure Using Principal Axis Factoring

Estimation and Promax Rotation $(N=390)$.

Factor Loadings

Communality

$\begin{array}{llll}\text { Item } & \text { Factor } 1 & \text { Factor } 2 & \text { Factor } 3\end{array}$

1. I have usually enjoyed $\quad .78$

studying mathematics in school.

2. I like to solve new problems

in mathematics

4. I am happier in a mathematics

class than in any other class

5. Mathematics is a very

interesting subject.

6. I am confident that I could learn advanced mathematics.

7. I am willing to take more

than the required amount of mathematics

8. I plan to take as much

mathematics as I can during my education.

9. The challenge of mathematics appeals to me.

10. Studying mathematics makes me feel nervous.

11. I am always under a terrible strain in a mathematics class.

think about having to do a mathematics problem.

13. I am always confused in my mathematics class. 
most important subjects for people to study.

18. College mathematics lessons

background could help me in my professional life.
Eigenvalues
8.15
2.54
2.31
$\%$ of variance
42.88
10.80
10.43

Note: Factor loadings are those from the Pattern Matrix.

An additional EFA was conducted as an attempt to increase the explained variance. This analysis consisted of removing items 10 and 13, one at a time, as these items had the lowest communality and loading values. This solution explained $72.11 \%$ of cumulative variance and included the three factors of the previous solution. The first factor (eigenvalue $=8.04$ ) accounted for $47.29 \%$ of the variance and included items 1 through 9 of the measure. The second factor (eigenvalue $=2.31$ ), accounted for $13.60 \%$ of the variance and included items 15 through 19 of the measure. The third factor (eigenvalue $=1.91)$, accounted for $11.22 \%$ of the variance and included items 11,12 , and 14 of the measure. The wording of items 1 through 9 addresses feelings of satisfaction, fulfillment, and enjoyment from working with mathematics. As a result, factor 1 was named as Satisfaction. The second factor included items 15 through 19 of the measure. Items 15 through 19 remark the importance of learning mathematics in life. 
Consequently, factor 2 was named Importance. Finally, items in factor 3 stress anxiety and suffering when learning mathematics. Factor 3 was named Mathematics Apprehension. An analysis of the reliability via Cronbach alpha for each factor was performed. Factor 1 (with items 1 through 9 included) reached a Cronbach alpha value of 0.948. The Cronbach alpha value for this factor would not have increased if any of the items would have been removed. Factor 2 (with items 15 through 19) reached a Cronbach alpha value of 0.913 . Removing any item in this factor would not have increased the value of Cronbach alpha. Factor 3 (with items 11, 12, and 14) reached an acceptable Cronbach alpha value of .783. This Cronbach alpha value would not have increased if any of the items in this factor would have been removed. Table 16 shows this final solution.

Table 16

Summary of Final Solution from an Exploratory Factor Analysis Results on 19 Items of the Attitudes toward Mathematics Measure Using Principal Axis Factoring Estimation and Promax Rotation.

$\begin{array}{llll}\text { Item } & \text { Factor 1 } & \text { Factor 2 } & \text { Factor } 3\end{array}$

1. I have usually enjoyed .78 studying mathematics in school. 2. I like to solve new problems .76 in mathematics

3. I really like mathematics. 


\begin{tabular}{|c|c|c|c|c|}
\hline $\begin{array}{l}\text { 5. Mathematics is a very } \\
\text { interesting subject. }\end{array}$ & .77 & & & .69 \\
\hline $\begin{array}{l}\text { 6. I am confident that I could } \\
\text { learn advanced mathematics. }\end{array}$ & .74 & & & .67 \\
\hline $\begin{array}{l}\text { 7. I am willing to take more } \\
\text { than the required amount of } \\
\text { mathematics }\end{array}$ & .88 & & & .71 \\
\hline $\begin{array}{l}\text { 8. I plan to take as much } \\
\text { mathematics as I can during my } \\
\text { education. }\end{array}$ & .77 & & & .68 \\
\hline $\begin{array}{l}\text { 9. The challenge of mathematics } \\
\text { appeals to me. }\end{array}$ & .74 & & & .55 \\
\hline $\begin{array}{l}\text { 11. I am always under a terrible } \\
\text { strain in a mathematics class. }\end{array}$ & & & .71 & .41 \\
\hline $\begin{array}{l}\text { 12. It makes me nervous to even } \\
\text { think about having to do a } \\
\text { mathematics problem. }\end{array}$ & & & .83 & .46 \\
\hline $\begin{array}{l}\text { 14. I feel a sense of insecurity } \\
\text { when attempting mathematics. }\end{array}$ & & & .69 & .40 \\
\hline $\begin{array}{l}\text { 15. Mathematics is a very } \\
\text { worthwhile and necessary } \\
\text { subject. }\end{array}$ & & .80 & & .58 \\
\hline $\begin{array}{l}\text { 16. Mathematics is important in } \\
\text { everyday life. }\end{array}$ & & .90 & & .76 \\
\hline $\begin{array}{l}\text { 17. Mathematics is one of the } \\
\text { most important subjects for } \\
\text { people to study. }\end{array}$ & & .85 & & .75 \\
\hline $\begin{array}{l}\text { 18. College mathematics lessons } \\
\text { would be very helpful no matter } \\
\text { what I decide to study in future. }\end{array}$ & & .80 & & .70 \\
\hline $\begin{array}{l}\text { 19. A strong mathematics } \\
\text { background could help me in } \\
\text { my professional life. }\end{array}$ & & .76 & & .62 \\
\hline Eigenvalues & 8.04 & 2.31 & 1.91 & \\
\hline$\%$ of variance & 47.29 & 13.60 & 11.22 & \\
\hline
\end{tabular}

Note: Factor loadings are those from the Pattern Matrix. 


\section{Exploratory Factor Analysis of the Retained Items}

Substantive theoretical research and empirical findings built the framework of this study. As the model in Figure 1 indicates, it was hypothesized that the underlying dimensions from teacher's effect would have a direct impact on the underlying dimensions of self-efficacy in mathematics as well as a direct and indirect impact on the underlying dimensions of attitudes toward mathematics. The model also hypothesized a direct effect of the underlying dimensions of self-efficacy in mathematics on the underlying of attitudes toward mathematics. Consequently, it was expected that observed variables (items) Teacher1 through Teacher12 would measure the factors from teacher's effect, the variables Self1 through Self18 would measure the factors from self-efficacy in mathematics; and that Attitude1 through Attitude19 would measure the factors from attitude toward mathematics. Therefore, it was expected that all observed variables, Teacher1 though Teacher12, would load only in the dimension teacher's effect. Similarly, it was expected that all observed variables, Self1 through Self18, would load on the dimension self-efficacy in mathematics, and that all observed variables, Attitude1 through Attitude19, would load on the dimension of attitudes toward mathematics. These assumptions imply that the relationships among the observed variables were not accounted for by a factor other than the factor they were expected to load at.

An EFA was conducted on the retained items from each of the instruments to prevent strong cross loading of items across factors, item redundancy, as well as to establish the underlying structure of the instruments aligned to the theoretical framework of this study and results from prior empirical studies. Items 1, 2, 3, 5, 6, 9, 10, 11, 12 from the teacher's effect, items 2, 3, 4, 6, 14, 16,17, and 18 from self-efficacy in 
mathematics, and items, 1 through 9, 11,12,14, and 15 through 19 from attitudes toward mathematics were entered in an EFA on the data of 390 College Algebra students. The Kaiser-Meyer-Olkin measure of sampling adequacy was 0.908 , indicating that the present data was suitable for principal component analysis. Similarly, the Barlett's chi-square test of sphericity was significant $\left(\chi^{2}=8576.016, \mathrm{p}<.001\right)$, granting sufficient correlation between the variables to proceed with the analysis. This EFA produced the same number of factors as each separate EFA. Results of this EFA appears in Table 17. A reliability analysis including all items reached the value of 0.930 , implying a good standing. 
Table 17

Summary of the Exploratory Factor Analysis Results on the Retained Items of the Teacher's Effect, Self-Efficacy in Mathematics, and Attitudes toward Mathematics Measure Using Principal Axis Factoring Estimation and Promax Rotation.

\section{Factor Loadings}

Item
F1

F3

T5. Mathematics teachers

have made me feel I have the ability to go on in

mathematics.

T6. My mathematics teachers encourage me to take the entire mathematics I can.

T9. Getting a mathematics teacher to take me seriously has usually been a problem.

Communality

F4 $\quad$ F5 $\quad$ F6 $\quad$ F7


T10. My teachers would think

I wasn't serious if I told them

I was interested in a career in

science and mathematics

T11. I have found it hard to

in the respect of

mathematics teachers.

T12. I have had a hard time

getting teachers to talk

seriously with me about

mathematics. 
Self2. Sally needs three pieces

of poster board for a class

project. If the boards are

represented by rectangles $\mathrm{A}$,

$\mathrm{B}, \mathrm{C}$, arrange their areas in

increasing order. (assume b >

a)

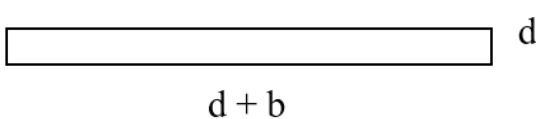

A

B

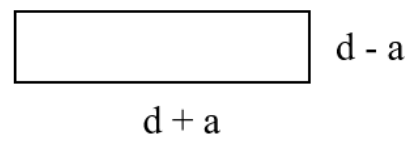

C

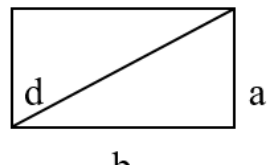

$b$

Self 3 . The average of three

numbers is 30 . The fourth

number is at least 10 . What is

the smallest average of the

four numbers? 
Self 4 . To construct a table,

Michele needs 4 pieces of wood 2.5 feet long for the legs. She wants to determine how much wood she will need for five tables. She reasons: 5 $\mathrm{x}(4 \times 2.5)=(5 \times 4) \times 2.5$.

Which number principle is she using?

Self 6 . Five points are on a

line. $T$ is next to $G$. $K$ is next

to $\mathrm{H}$. $\mathrm{C}$ is next to T. $\mathrm{H}$ is next to $\mathrm{G}$. Determine the relative positions of the points along the line.

Self 14 . On a certain map, $7 / 8$

inch represents 200 miles.

How far apart are two towns whose distance apart on the map is $3 \frac{1}{2}$ inches?

Self $16.33 / 4-1 / 2$

$=$

Self 17 . If $3 x-2=16$, what 
Self 18. Fred's bill for some

items with a $\$ 20$, how much

change should he

Att1. I have usually enjoyed

studying mathematics in

school.

Att2. I like to solve new

problems in mathematics.

Att3. I really like

mathematics.

mathematics class than in any other class.

Att5. Mathematics is a very

interesting subject.

Att6. I am confident that I

could learn advanced

mathematics.

Att7. I am willing to take

more than the required

amount of mathematics.

Att8. I plan to take as much

my education.

Att9. The challenge of 
Att11. I am always under a

terrible strain in a

mathematics class.

Att12. It makes me nervous to

even think about having to do a mathematics problem.

Att14. I feel a sense of

insecurity when attempting mathematics.

Att15. Mathematics is a very

worthwhile and necessary

subject.

Att16. Mathematics is

important in everyday life.

Att17. Mathematics is one of

the most important subjects

for people to study.

Att18. College mathematics

lessons would be very helpful no matter what I decide to study in future.

Att19. A strong mathematics background could help me in my professional life.

\begin{tabular}{lcccccccc} 
Eigenvalues & 10.66 & 3.20 & 2.79 & 2.22 & 2.16 & 1.63 & 1.26 \\
\hline \% of variance & 31.34 & 9.40 & 8.21 & 6.54 & 6.35 & 4.78 & 3.72
\end{tabular}


The model in Figure 2 arises, based on the results from this final assessment and previous EFAs. The model in Figure 2 synthesizes the results from the EFAs and the relationship hypothesized in the model depicted Figure 1. As shown in Figure 2, factors underlying teacher's effect in mathematics (Encouragement and Discouragement) have a direct effect on the factors underlying self-efficacy toward mathematics (Critical Thinking and Mathematical Procedures) and the factors underlying attitudes toward mathematics (Satisfaction, Mathematics Apprehension, and Importance). Similarly, the model depicts a direct effect of the factors underlying self-efficacy toward mathematics on the factors underlying attitudes toward mathematics. As previously hypothesized, the model includes indirect effects from the factors underlying teacher's effect to the factors underlying attitudes toward mathematics. Additionally, the model includes the direct effect of gender on the factors underlying self-efficacy toward mathematics and the effect of instructional modality on the factors underlying teacher's effect, self-efficacy in mathematics, and on the factors underlying attitudes toward mathematics. 


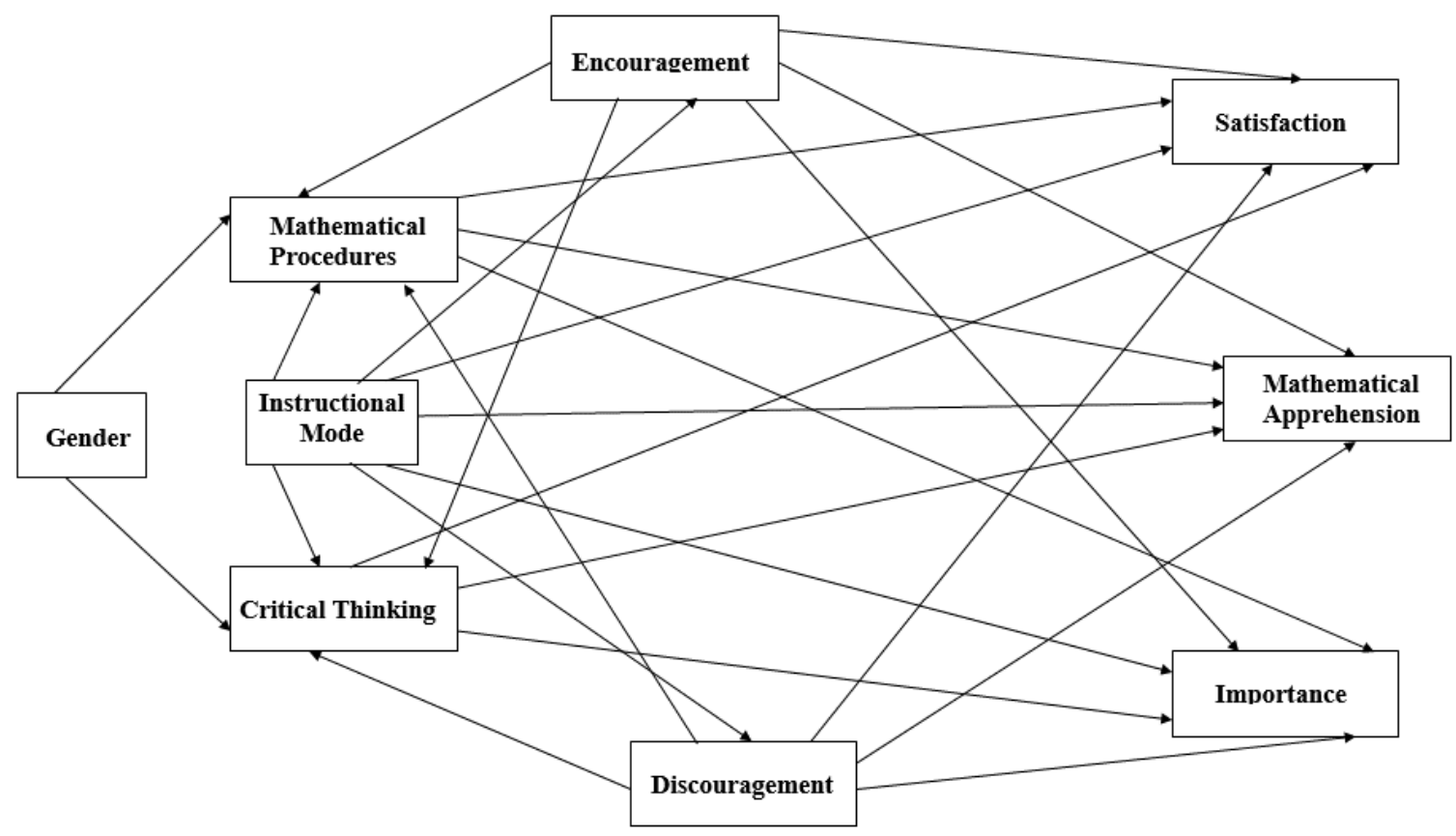

Figure 2. Model Synthesizing Results of EFAs and Hypothesis in Model 1

\section{Composite Variables}

Seven subscales or composite variables representing the factors extracted were computed following the structure shown in Table 18. These variables were created as summated scales by adding the score of each of the items loading in the corresponding factor. Items 1 through 9 from the attitudes toward mathematics formed Factor 1 . The sum of these items was used to compute the Satisfaction variable. Items 15, 16, 17, 18, and 19 from the attitudes toward mathematics scale loaded in Factor 2. Therefore, the sum of these items was used to create the Importance variable. Variable Encouragement represented Factor 3 and includes items 1, 2, 3, 5, and 6 of the teacher's effect scale. The sum of items $1,2,3,5$, and 6 of the teacher's effect measure were used to compute variable Encouragement. Variable Discouragement represented Factor 4 and included items $9,10,11$, and 12 from the teacher's effect scale and the sum of these items were 
used to compute this variable. Items 2, 3, 4, 6, and 14 loaded in Factor 5 extracted from the self-efficacy instrument and the sum of these items was used to compute the Critical Thinking variable. Mathematics Apprehension variable that represented Factor 6 was computed using the sum of the items 11,12 , and 14 of the attitudes toward mathematics scale. Items 16, 17, and 18 loaded in Factor 6 from the self-efficacy instrument and the sum of these 7 items were used to compute the Mathematical Procedures variable. Therefore, the sum of these items was used to create the Importance variable. The rationale behind using the summated scales as the variable in the model was to reduce the effect of measurement error. The technique of using summated variables as the form of creating composite variables is recommended when multiple linear regression is the statistical methodology proposed to analyze the data collected (Hair et al., 2010). 
Table 18

Distribution of Items per Factor after Performing the Exploratory Factor Analysis.

\begin{tabular}{|c|c|c|}
\hline Instrument & Factor & Item Number and Exact Wording \\
\hline Teacher's Effect & Encouragement & $\begin{array}{l}\text { 1. My teachers have encouraged } \\
\text { me to study more mathematics. } \\
\text { 2. My teachers think I'm the kind } \\
\text { of person who could } \\
\text { do well in mathematics. } \\
\text { 3. My mathematics teachers have } \\
\text { been interested in } \\
\text { my progress in mathematics. } \\
\text { 5. Mathematics teachers have } \\
\text { made me feel I have } \\
\text { the ability to go on in mathematics. } \\
\text { 6. My mathematics teachers } \\
\text { encourage me to take } \\
\text { the entire mathematics I can. }\end{array}$ \\
\hline & Discouragement & $\begin{array}{l}\text { 9. Getting a mathematics teacher to } \\
\text { take me seriously } \\
\text { has usually been a problem. } \\
10 . \text { My teachers would think I } \\
\text { wasn't serious if I told them I was } \\
\text { interested in a career in science } \\
\text { and mathematics. } \\
\text { 11. I have found it hard to win the } \\
\text { respect of mathematics teachers. } \\
\text { 12. I have had a hard time getting } \\
\text { teachers to talk seriously with me } \\
\text { about mathematics. }\end{array}$ \\
\hline Self-efficacy & Critical Thinking & $\begin{array}{l}\text { 2. Sally needs three pieces of } \\
\text { poster board for a class project. If } \\
\text { the boards are represented by } \\
\text { rectangles } A, B, C \text {, arrange their } \\
\text { areas in increasing order. (assume } \\
b>\text { a) }\end{array}$ \\
\hline
\end{tabular}

A 
B

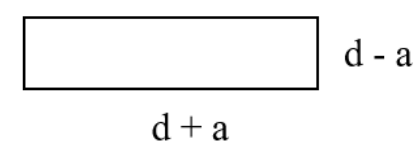

C

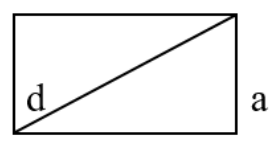

b

3. The average of three numbers is 30. The fourth number is at least 10. What is the smallest average of the four numbers?

4. To construct a table, Michele needs 4 pieces of wood 2.5 feet long for the legs. She wants to determine how much wood she will need for five tables. She reasons: $5 \times(4 \times 2.5)=(5 \times 4) \times$ 2.5. Which number principle is she using?

6. Five points are on a line. $\mathrm{T}$ is next to $\mathrm{G}$. $\mathrm{K}$ is next to $\mathrm{H}$. $\mathrm{C}$ is next to $\mathrm{T}$.

$\mathrm{H}$ is next to $\mathrm{G}$. Determine the relative positions of the points along the line.

14. On a certain map, $7 / 8$ inch represents 200 miles. How far apart are two towns whose distance

Mathematical Procedures

Attitudes toward Mathematics

Satisfaction apart on the map is $3 \frac{1}{2}$ inches?

16. $33 / 4-1 / 2=$ 17. If $3 x-2=16$, what does $x$ equal?

18. Fred's bill for some household supplies was $\$ 13.64$. If he paid for the items with a $\$ 20$, how much change should 1. I have usually enjoyed studying mathematics in school.

2. I like to solve new problems in mathematics.

3. I really like mathematics. 
Mathematics

Apprehension

Importance
4. I am happier in a mathematics class than in any other class. 5. Mathematics is a very interesting subject.

6. I am confident that I could learn advanced mathematics.

7. I am willing to take more than the required amount of mathematics.

8. I plan to take as much mathematics as I can during my education.

9. The challenge of mathematics appeals to me.

11. I am always under a terrible strain in a mathematics class.

12. It makes me nervous to even think about having to do a mathematics problem.

14. I feel a sense of insecurity when attempting mathematics. 15 . Mathematics is a very worthwhile and necessary subject. 16. Mathematics is important in everyday life.

17. Mathematics is one of the most important subjects for people to study.

18. College mathematics lessons would be very helpful no matter what I decide to study in future. 19. A strong mathematics background could help me in my professional life.

\section{Statistical Analysis Conducted to Respond to Research Question 2}

Q2. Is there a relationship between mode of instruction and the factors underlying the construct of attitude toward mathematics? 
$\mathrm{H}_{2}$ : There are differences in the factors underlying the construct of attitudes toward mathematics across modes of instruction.

$H_{2 a}:$ There are differences in the level of Satisfaction across modes of instruction.

$H_{2 b}$ : There are differences in the level of Mathematics Apprehension across modes of instruction.

$H_{2 c}$ : There are differences in the level of Importance across modes of instruction.

Inspection of the Pearson product moment correlations coefficient for the dependent variables in Table 19 showed statistically significant inter correlation between variables, which granted performing the two-group between-subject multivariate analysis of variance (MANOVA). A two-group between subjects MANOVA is a multivariate analysis of variance for the case where there are more than one continuous dependent variable and the independent variable is categorical. The hypothesis the MANOVA tested was that the population means for the dependent variable of Attitudes toward Mathematics (measured by indexes of Satisfaction, Mathematics Apprehension, and Importance) are the same for the two levels or groups of the factor Mode of Instruction (face-to-face or hybrid). Additionally, it examined the hypothesis that the means of the linear combinations of the dependent variables were equal across groups of the factor. 
Table 19

Pearson Correlations, Means, and Standard Deviation Associated with Subscales that Emerged from the EFAs.

\begin{tabular}{|c|c|c|c|c|c|c|c|c|}
\hline & 1 & 2 & 3 & 4 & 5 & 6 & $\bar{M}$ & $S D$ \\
\hline $\begin{array}{l}1 . \\
\text { Encouragement }\end{array}$ & -- & & & & & & 17.69 & 5.02 \\
\hline $\begin{array}{l}2 . \\
\text { Discouragement }\end{array}$ & $.368 * *$ & -- & & & & & 17.04 & 3.14 \\
\hline $\begin{array}{l}\text { 3. Mathematics } \\
\text { Procedures }\end{array}$ & $.298 * *$ & $.238 * *$ & -- & & & & 17.43 & 4.48 \\
\hline $\begin{array}{l}\text { 4. Critical } \\
\text { Thinking }\end{array}$ & $.237 * *$ & $.170 * *$ & $.508 * *$ & -- & & & 13.29 & 2.46 \\
\hline 5. Importance & $.398 * *$ & $.260 * *$ & $.389 * *$ & $.284 * *$ & -- & & 27.90 & 10.21 \\
\hline $\begin{array}{l}\text { 6. Mathematics } \\
\text { Apprehension }\end{array}$ & $.198 * *$ & $.299 * *$ & $.175^{* *}$ & $.128 * *$ & $.256^{* *}$ & -- & 11.65 & 2.78 \\
\hline 7. Satisfaction & $.371 * *$ & $.273 * *$ & $.223 * *$ & $.208 * *$ & $.515 * *$ & $.223^{* *}$ & 18.65 & 5.04 \\
\hline
\end{tabular}

The multivariate test for homogeneity of dispersion, Box's Test, evaluated whether the variances and covariance among the Importance and Satisfaction were the same for all levels of the independent variables of mode of instruction (Table 20). The test was not significant, $F(6,1038046)=1.298, p=.254$. This finding indicated that the dependent variable covariance matrices are equal across the levels of the independent variables. Bartlett's Test of Sphericity was statistically significant (approximate chi square $=739.988, p<.001)$, meaning that there was sufficient correlation between 
Importance, Mathematics Apprehension, and Satisfaction. Consequently, Wilk's lambda index was used to evaluate the multivariate effect.

The Wilks's $\Lambda$ criterion of .984 was significant, $F(2,383)=3.033, p<.05$, indicating a rejection of the null hypothesis that the population means on the dependent variables (Importance, Mathematics Apprehension, and Satisfaction) are the same for the two modes of instruction (face to face/hybrid). The multivariate effect size $\eta^{2}=.022$, based on Wilks's $\Lambda$, was weak, which indicates that a poor $2.2 \%$ of multivariate variance of the dependent variables was associated with Mode of Instruction.

Table 20

One- way MANOVAs with Satisfaction, Mathematics Apprehension, and Importance as Subscales of Attitudes toward mathematics and Mode of Instruction as Independent Variables.

\begin{tabular}{|c|c|c|c|c|c|c|c|c|}
\hline \multicolumn{2}{|c|}{$\begin{array}{l}\text { Mode of } \\
\text { Instruction }\end{array}$} & \multicolumn{2}{|l|}{$\begin{array}{l}\text { Box's Test } \\
\text { (Equality of } \\
\text { Covariance }\end{array}$} & \multicolumn{2}{|c|}{$\begin{array}{c}\text { Bartlett's Test of } \\
\text { Sphericity }\end{array}$} & \multicolumn{3}{|c|}{ Multivariate Tests } \\
\hline Hybrid & $\overline{F T F}$ & $\begin{array}{l}F \\
(6,1038046)\end{array}$ & $\bar{p}$ & $\overline{\chi^{2}(5)}$ & $P$ & $\begin{array}{l}\text { Wilks' } \\
\text { Lambda } \\
\Lambda\end{array}$ & $p$ & $\begin{array}{l}\text { Partial } \\
\eta^{2}\end{array}$ \\
\hline 183 & 203 & 1.298 & .254 & 739.998 & $<.001$ & .978 & $<.05$ & .022 \\
\hline
\end{tabular}

Univariate ANOVAs were conducted on each of the outcome variables to determine the locus of the statistically significant multivariate test (Table 21). There was only statistically significant effect associated to Importance, $F(1,384)=6.059$, p <.017; 
students enrolled in hybrid instruction showed higher importance toward learning mathematics $[M=19.31, S D=4.72]$ than students in the face to face instructional modality $[\mathrm{M}=18.05, \mathrm{SD}=5.26]$.

Table 21

One-way ANOVAs with Satisfaction, Mathematics Apprehension, and Importance as Subscales of Attitudes toward mathematics and Mode of Instruction as Independent Variables.

\begin{tabular}{|c|c|c|c|c|c|c|c|c|c|}
\hline & \multicolumn{2}{|l|}{ Levene's } & \multicolumn{3}{|l|}{ ANOVAs } & \multicolumn{2}{|c|}{ Hybrid } & \multicolumn{2}{|c|}{ Face-to-Face } \\
\hline & $F(1,384)$ & $p$ & $F(1,384)$ & $p$ & $\eta^{2}$ & $M$ & $S D$ & $M$ & $S D$ \\
\hline Satisfaction & 2.36 & .126 & 1.93 & .165 & .005 & 28.66 & 9.85 & 27.22 & 10.50 \\
\hline $\begin{array}{l}\text { Mathematics } \\
\text { Apprehension }\end{array}$ & .333 & .564 & .910 & .341 & .002 & 11.50 & 2.80 & 11.77 & 2.77 \\
\hline Importance & 2.27 & .133 & 6.06 & .014 & .016 & 19.31 & 4.72 & 18.05 & 5.26 \\
\hline
\end{tabular}

\section{Statistical Analysis Conducted to Respond to Research Question 3}

Q.3 How well does a model involving factors underlying teacher's effect in mathematics, self-efficacy in mathematics, instructional modality, gender, and factors underlying student's attitudes toward mathematics in undergraduate College Algebra delivered in face-to-face and hybrid learning modes fits the data? 


\section{Model Fit Analysis}

An analysis of multiple regression assumptions was conducted prior to assessing the fitting of the model. Indexes of skewness and kurtosis as well as well as results of both Kolmogorov-Smirnov and Shapiro-Wilk tests were inspected to assess normality assumptions. Skewness and kurtosis values for Encouragement, Discouragement, Critical Thinking, Satisfaction, Mathematics Apprehension, and Importance were between -1 and 1 (Table 22), tentatively a range to consider these variables as normal (Meyers et al., 2013). The values of skewness and kurtosis for arithmetic were not inside this range. Kolmogorov-Smirnov and Shapiro-Wilk tests were significant (Table 22) which suggested departure from normality in the distribution of each variable. Several transformations were unsuccessfully performed on each variable to achieve normality. Tabachnick and Fidell (2007) claim that there are variables "that are not expected to be normally distributed in the population" (p. 683). Hair et al. remarks that the effect of nonnormality in a distribution of a variable diminishes as the sample size increases. On this regard, Hair et al. (2010) recommend using a sample size greater than 200 cases. Consequently, the effect of non-normality in the variables of this study was deemed as minimum as the sample size was 390 cases. 
Table 22

Skewness, Kurtosis, Kolmogorov-Smirnov test, and Shapiro-Wilk test.

\begin{tabular}{|c|c|c|c|c|c|}
\hline Variable & Mean & Kurtosis & Skewness & $\begin{array}{l}\text { Kolmogorov- } \\
\text { Smirnov }\end{array}$ & $\begin{array}{l}\text { Shapiro- } \\
\text { Wilk }\end{array}$ \\
\hline Encouragement & 17.69 & -.18 & -.54 & .00 & .00 \\
\hline Discouragement & 17.04 & -.013 & -.85 & .00 & .00 \\
\hline $\begin{array}{l}\text { Mathematics } \\
\text { Procedures }\end{array}$ & 17.43 & -.33 & -.38 & .00 & .00 \\
\hline $\begin{array}{l}\text { Critical } \\
\text { Thinking }\end{array}$ & 13.29 & 3.73 & -1.89 & .00 & .00 \\
\hline Importance & 27.90 & -.88 & -.15 & .01 & .00 \\
\hline $\begin{array}{l}\text { Mathematics } \\
\text { Apprehension }\end{array}$ & 11.65 & -1.3 & .37 & .00 & .00 \\
\hline Satisfaction & 18.65 & -.05 & -.74 & .00 & .00 \\
\hline
\end{tabular}

Examination of multivariate outliers among the quantitative variables led to remove 4 cases. This assumption was examined using the Mahalanobis distance for each case which measure the difference between the value of a case from the average of all cases (Meyers et al., 2013). For this purpose, a variable for the Mahalanobis distances was created and their extreme values were compared with the critical value $\chi^{2}(7)=24.32$ $(p<.001)$. The comparison produced 4 multivariate outliers which all were removed. Removing these 4 outliers reduced the sample to 386 cases.

The examination of the shape of the bivariate scatter plots revealed an overall random scatter pattern, with lack of defined relationship, and no curvilinear relationship of each of the combinations (Figure 3). Additionally, the graph of the regression standardized predicted values versus the regression standardized residuals values for the three predicted variables in Figure 4 (Satisfaction), Figure 5 (Mathematics 
Apprehension), and Figure 6 (Importance) indicate that there was a random distribution of positive and negative values across the entire range of variables plotted on the horizontal axis reinforcing the thesis that no clear pattern emerged from the graph. As a result, pair-wise linearity was deemed satisfactory.

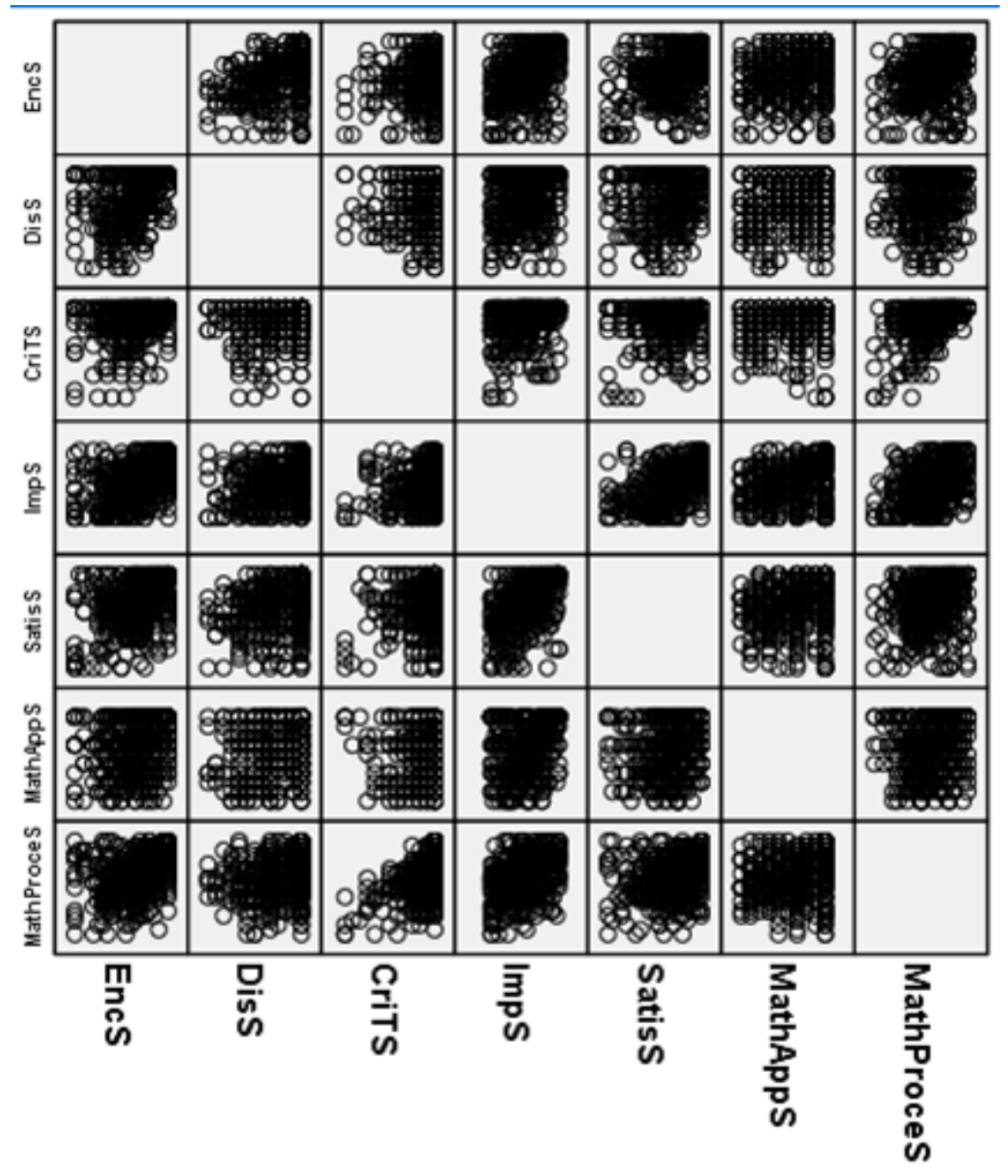

Figure 3. Bivariate Scatter Plot 


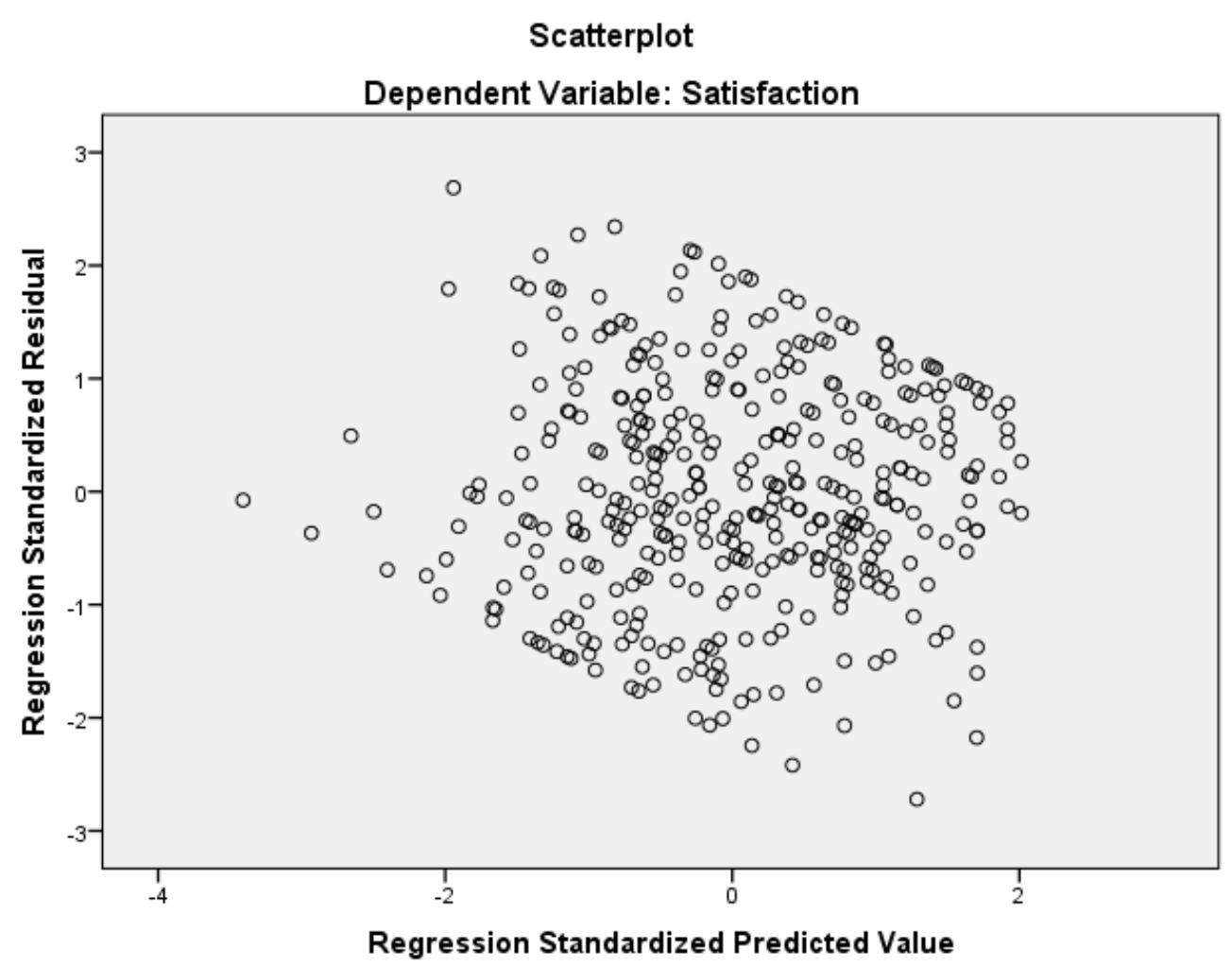

Figure 4.Regression Standardized Predicted Values versus the Regression Standardized Residuals Values for Satisfaction. 


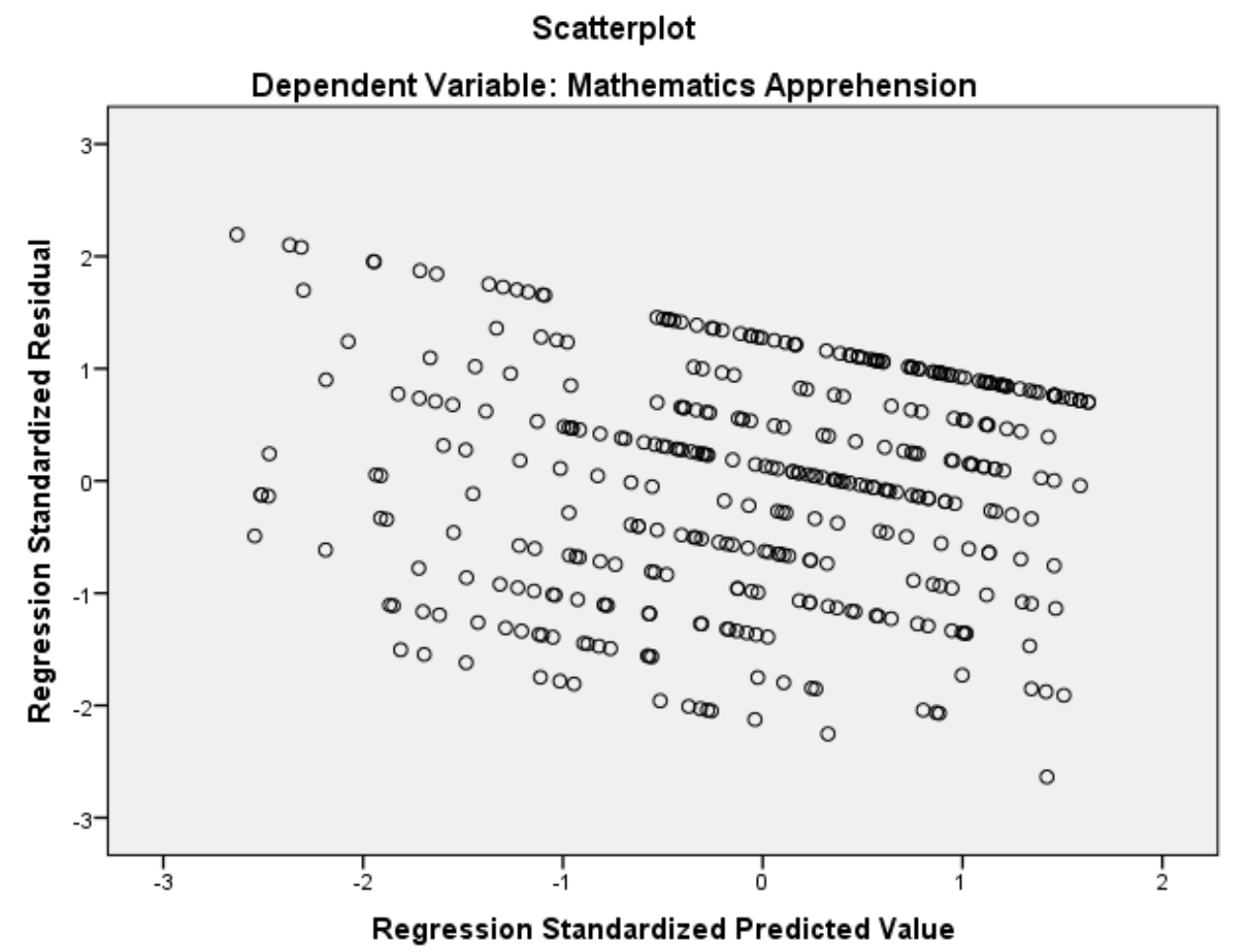

Figure 5. Regression Standardized Predicted Values versus the Regression Standardized Residuals Values for Mathematics Apprehension. 


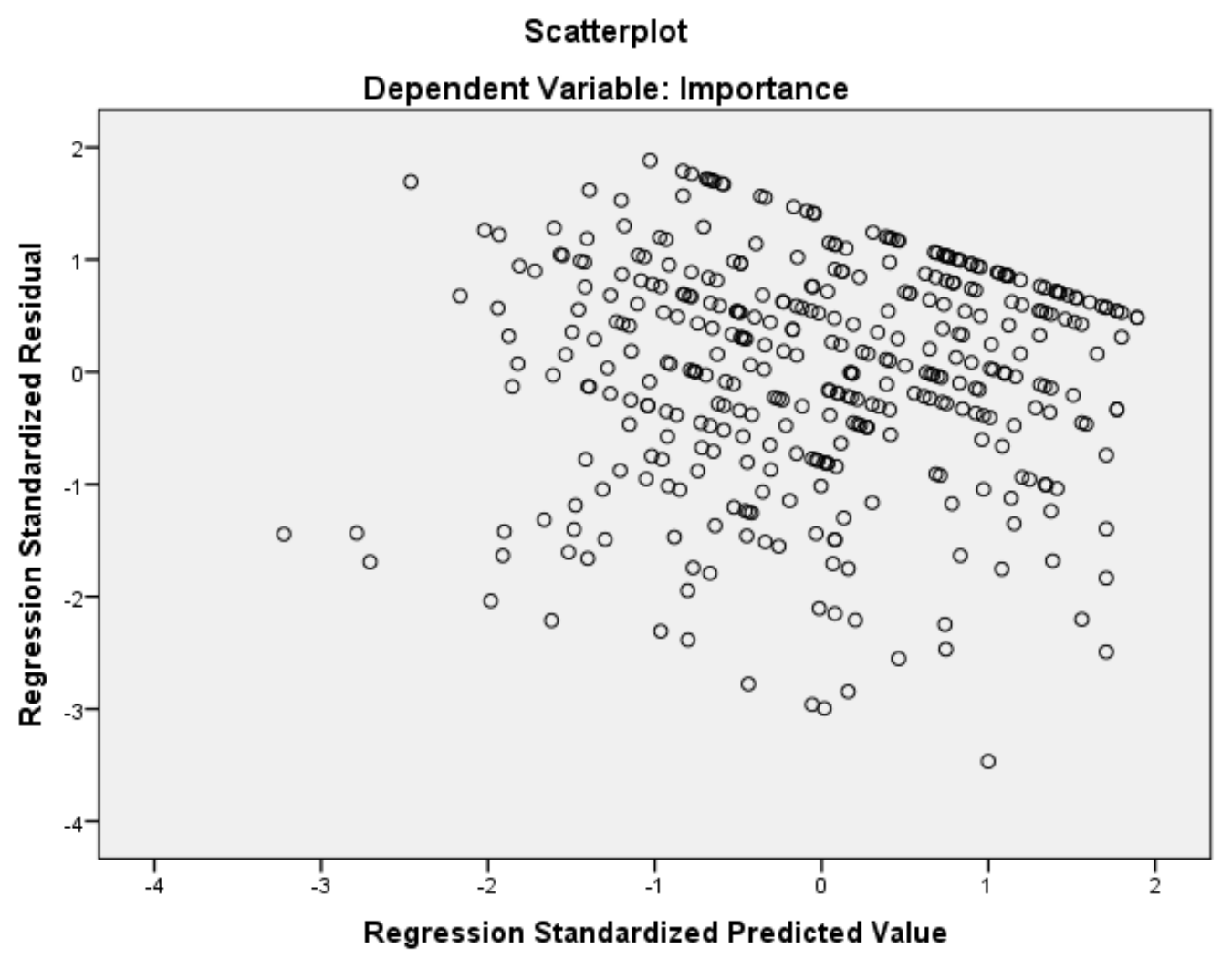

Figure 6. Regression Standardized Predicted Values versus the Regression Standardized Residuals Values for Importance.

The multivariate homogeneity of variances or homoscedasticity that measured the level of the variation about the predicted variables (Satisfaction, Mathematics Apprehension, and Importance) across the levels of gender (male/female) and mode of instruction (hybrid/face to face) was constant. The Levene's test was not significant for each of the predicted variables Importance, $F(18,367)=1.303, p=.182$, and Satisfaction, $F(18,367)=.854, \mathrm{p}=.636$. Similarly, the Box's $M$ test was not significant, $F(33,2846.015)=.857, p=.701$. These results suggest that there was equality of variance of the dependent variables across the levels of the gender and mode of instruction. 
Multicollinearity was ruled out in an analysis that showed no correlation in excess across independent variables. Values for the variance inflection factor (VIF) and tolerance were calculated by regressing one of the independent variables as the combination of the others. VIF values were not substantially greater than 1 for each of the independent variable as the tolerance values were greater than the threshold of .2.

Normality distribution of residuals or errors (difference between the real value and the predicted value) was assessed. As Figure 7, Figure 8, and Figure 9 show, the distribution of the residuals for both independent variables assessed by the histogram and the Normal P-P plots follows a normal distribution pattern.
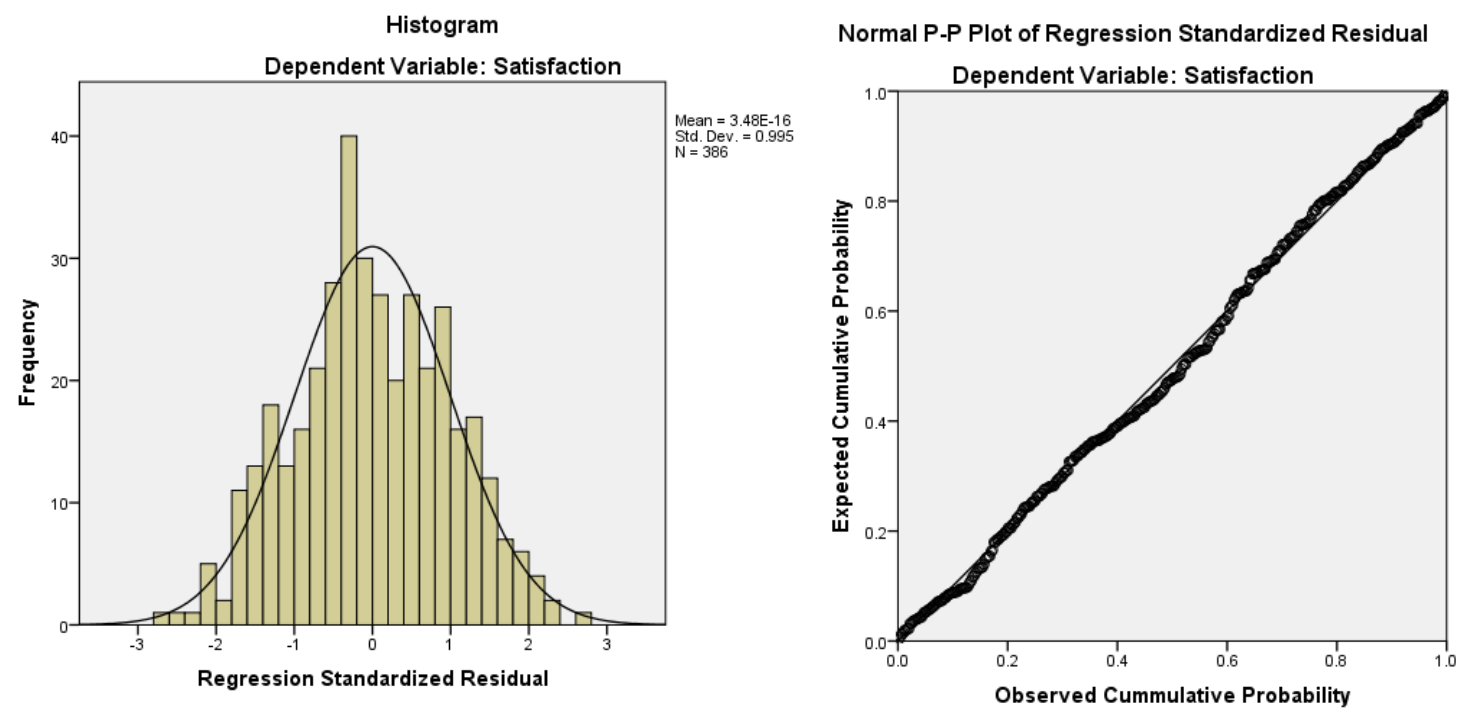

Figure 7. Distribution of the residuals for Satisfaction. 

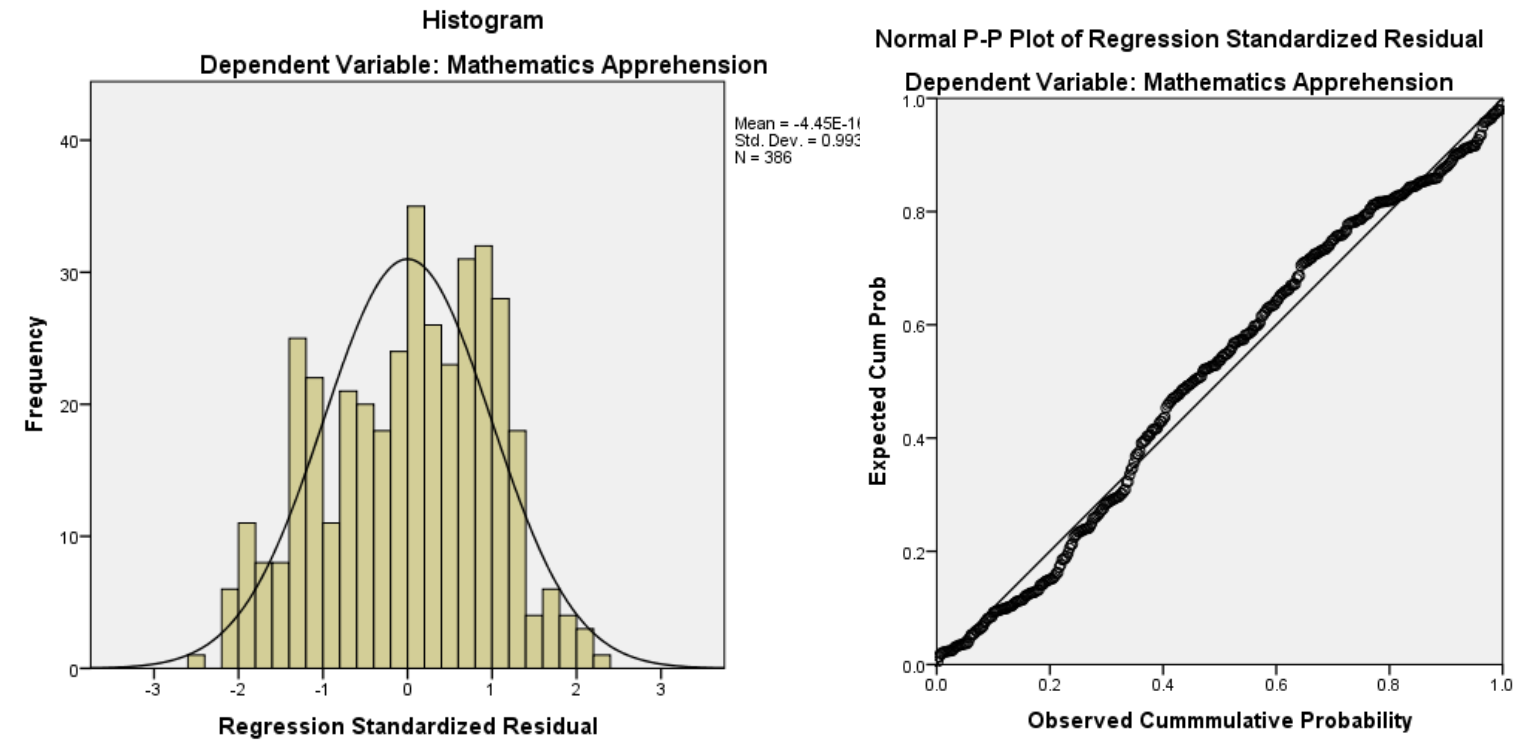

Figure 8. Distribution of the residuals for Mathematics Apprehension.
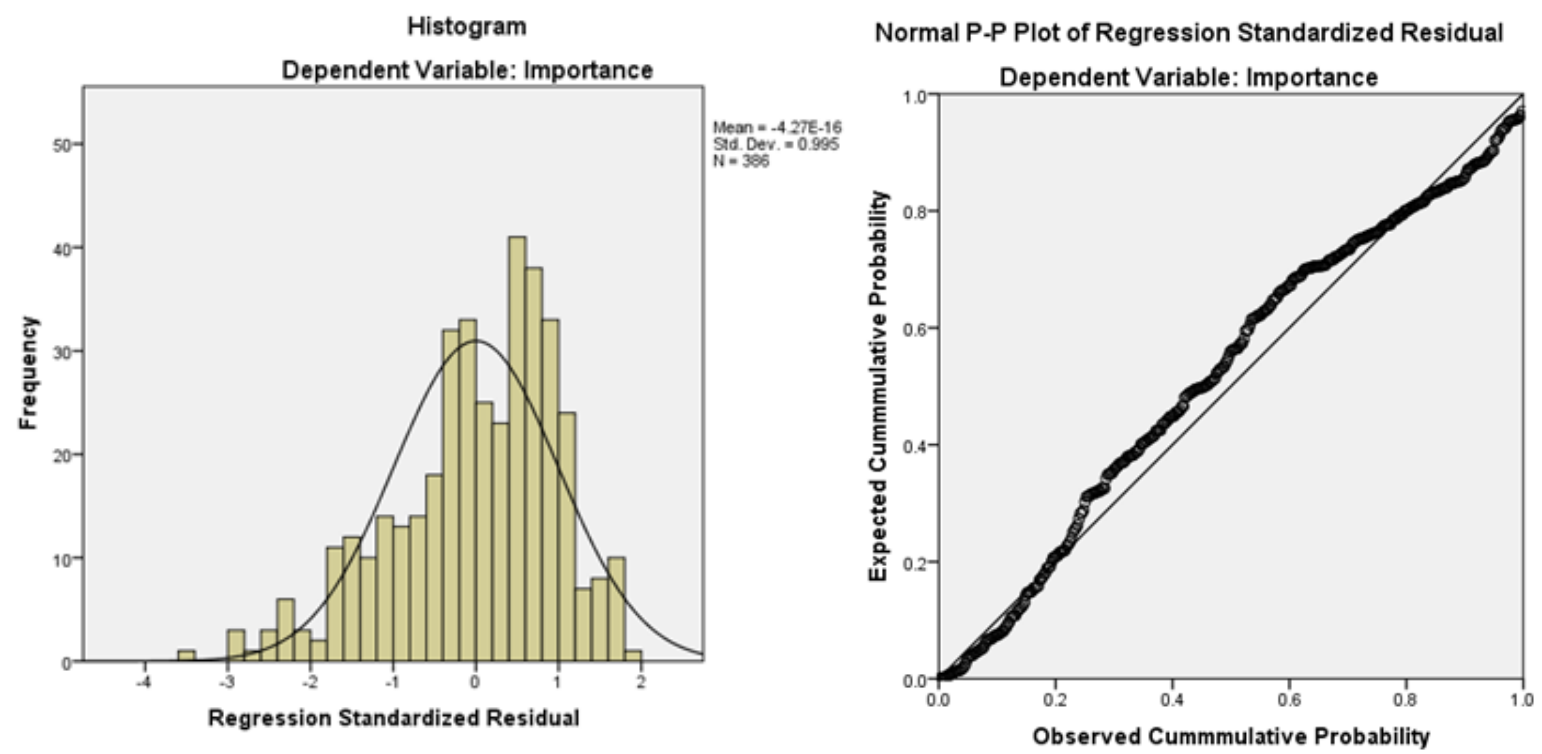

Figure 9. Distribution of the residuals for Importance.

The model that emerged from the exploratory factor analysis appears in Figure 2.

The model includes three outcomes (dependent or criterion) variables, Satisfaction, 
Mathematics Apprehension, and Satisfaction. These three criterions were deemed to be directly predictable from the perceived ability of students to accomplish mathematical procedures, student's beliefs about their capacity to solve mathematics problems that require the application of critical thinking, their judgements of encouragement and discouragement they received from the interaction with the mathematics teacher, and mode of instruction. The model also depicts Encouragement, Discouragement, Instructional Modality, and gender exerting an indirect effect on Satisfaction, Mathematics Apprehension, and Importance through Mathematical Procedures and Critical thinking. Additionally, the model included the influence of instructional modality on both Encouragement and Discouragement. A path analysis was conducted to assess the fit of the model on Figure 2. The path analysis in this study focused on evaluating the effect of factors underlying the constructs of teacher's effect and self-efficacy as well as the demographic factors of gender and mode of instruction on factors underlying attitudes of students to learn mathematics in the context of College Algebra in face-to-face and hybrid learning courses at a minority-serving institution of higher education.

$H_{3}$ : The factors underlying the constructs of teacher's effect, self-efficacy, and the demographic factors of instructional modality and gender account for a significant amount of the unique variance of student's attitudes toward mathematics delivered through face-to-face or hybrid learning modes.

Multiple linear regression was the path analysis approach that examined the fit of the model. Accordingly, an analysis for each of the endogenous variables was performed 
(Meyers at al., 2013). There are six endogenous variables in the model. As such, the following six regression analyses were conducted:

- Satisfaction was predicted from Mathematical Procedures, Critical Thinking, Encouragement, Discouragement, and Mode of Instruction.

- Mathematics Apprehension was predicted from Mathematical Procedures, Critical Thinking, Encouragement, Discouragement, and Mode of Instruction.

- Importance was predicted from Mathematical Procedures, Critical Thinking, Encouragement, Discouragement, and Mode of Instruction.

- Mathematical Procedures was predicted from Encouragement, Discouragement, Gender, and Mode of Instruction.

- Critical thinking was predicted from Encouragement, Discouragement, Gender, and Mode of Instruction.

- Encouragement was predicted from Mode of Instruction.

- Discouragement was predicted from Mode of Instruction.

The regression analysis of Satisfaction on Encouragement, Discouragement, $H_{3 a}$ : There is a significant prediction of Satisfaction by the combined effect of Mathematical Procedures, Critical Thinking, Encouragement, Discouragement, and Mode of Instruction.

Mathematical Procedures, Critical Thinking, and Mode of Instruction on importance showed that the prediction model explained $25.3 \%$ of the variance of Satisfaction. Tested with 5 and 380 degrees of freedom, the $F$ ratio of 25.75 evaluating the value of $R^{2}$ was statistically significant $(p<.001)$. Both Encouragement and Mathematical Procedures 
were significant predictors of Satisfaction. On the other hand, Discouragement, Critical Thinking, and Mode of Instruction were not significant predictors of Satisfaction. Table 23 presents the results of this analysis.

Table 23

Regression Analysis Summary for the Prediction of Satisfaction.

\begin{tabular}{lccccc}
\hline Variable & $\mathrm{B}$ & SE B & $\beta$ & $t$ & $p$ \\
\hline Encouragement & .562 & .100 & .276 & 5.599 & .000 \\
Discouragement & .281 & .157 & .086 & 1.794 & .074 \\
Mathematical & .553 & .121 & .243 & 4.570 & .000 \\
Procedures & .328 & .215 & .079 & 1.526 & .128 \\
Critical Thinking & -1.152 & .892 & -.056 & -1.292 & .197 \\
Instruction Mode & & & & & \\
\hline
\end{tabular}

$H_{3 b}$ : There is a significant prediction of Mathematics Apprehension by the combined effect of Mathematical Procedures, Critical Thinking, Encouragement, Discouragement, and Mode of Instruction.

The combine effect of Encouragement, Discouragement, Mathematical Procedures, Critical Thinking, and Mode of Instruction accounted for $11 \%\left(R^{2}=.110\right)$ of the variance of Mathematics Apprehension, $F(5,380)=9.367, p<.001$. Only Discouragement $(p<.001)$ was a significant predictor of Mathematics Apprehension (Table 24). 
Table 24

Regression Analysis Summary for the Prediction of Mathematics Apprehension.

\begin{tabular}{lccccc}
\hline Variable & B & SE B & $\beta$ & $t$ & $p$ \\
\hline Encouragement & .041 & .030 & .074 & 1.379 & .169 \\
Discouragement & .220 & .047 & .248 & 4.712 & .000 \\
$\begin{array}{l}\text { Mathematical } \\
\text { Procedures }\end{array}$ & .052 & .036 & .083 & 1.440 & .151 \\
Critical Thinking & .031 & .064 & .026 & .484 & .629 \\
Instruction Mode & -3.20 & .270 & -.058 & -1.185 & .237 \\
\hline
\end{tabular}

$H_{3 c}$ : There is significant prediction of Importance by the combined effect of Mathematical Procedures, Critical Thinking, Encouragement, Discouragement, and Mode of Instruction.

The combine effect of Encouragement, Discouragement, Mathematical Procedures, Critical Thinking, and Mode of Instruction explained 19.7\% $\left(R^{2}=.197\right)$ of the variability of Importance, $F(5,380)=18.618, p<.001$ (Table 25). Encouragement $(p<.001)$, Mathematical Procedures $(p<.05)$, Discouragement $(p<.025)$, and Mode of Instruction were the significant predictors of Satisfaction $(p<.025)$. 
Table 25

Regression Analysis Summary for the Prediction of Importance.

\begin{tabular}{lccccc}
\hline Variable & $\mathrm{B}$ & SE B & $\beta$ & $t$ & $p$ \\
\hline Encouragement & .278 & .051 & .276 & 5.404 & .000 \\
Discouragement & .212 & .080 & .132 & 2.639 & .009 \\
$\begin{array}{l}\text { Mathematical } \\
\text { Procedures }\end{array}$ & .134 & .062 & .119 & 2.159 & .031 \\
Critical Thinking & .114 & .110 & .056 & 1.036 & .301 \\
Instruction Mode & 1.190 & .465 & .118 & 2.558 & .011 \\
\hline
\end{tabular}

$H_{3 d}$ : There is a significant prediction of Mathematical Procedures by the combined effect of from Encouragement, Discouragement, Gender, and Mode of Instruction.

The predicting effect of Encouragement, Discouragement, Mode of Instruction, and Gender on Mathematical Procedures was significant, $F(4,381)=12.082, p<.001$, $R^{2}=.113$; only Encouragement $(p<.001)$ and Discouragement were significant predictors in this portion of the model $(p<.025)$.

$H_{3 e}$ : There is significant prediction of Critical thinking by the combined effect of from Encouragement, Discouragement, Gender, and Mode of Instruction.

Critical Thinking was significantly predicted from Encouragement,

Discouragement, Mode of Instruction, and Gender, $F(4,381)=7.475, p<.001, R^{2}=$ .073. Only Encouragement was a significant predictor in this path.

$H_{3 f}$ : There is significant prediction of Encouragement by Mode of Instruction. 
Encouragement was not significantly predicted by Mode of Instruction,

$\mathrm{F}(1,384)=0.114, p=.736, R^{2}=.017$.

$H_{3 g}$ : There is significant prediction of Discouragement by Mode of Instruction.

Mode of Instruction was not a significant predictor of Discouragement,

$\mathrm{F}(1,384)=0.104, p=.748, R^{2}=.016$. A summary of the path coefficients (standardized coefficients) for the complete model is presented in Table 26 under Direct Effect as well as they are displayed in Figure 10.

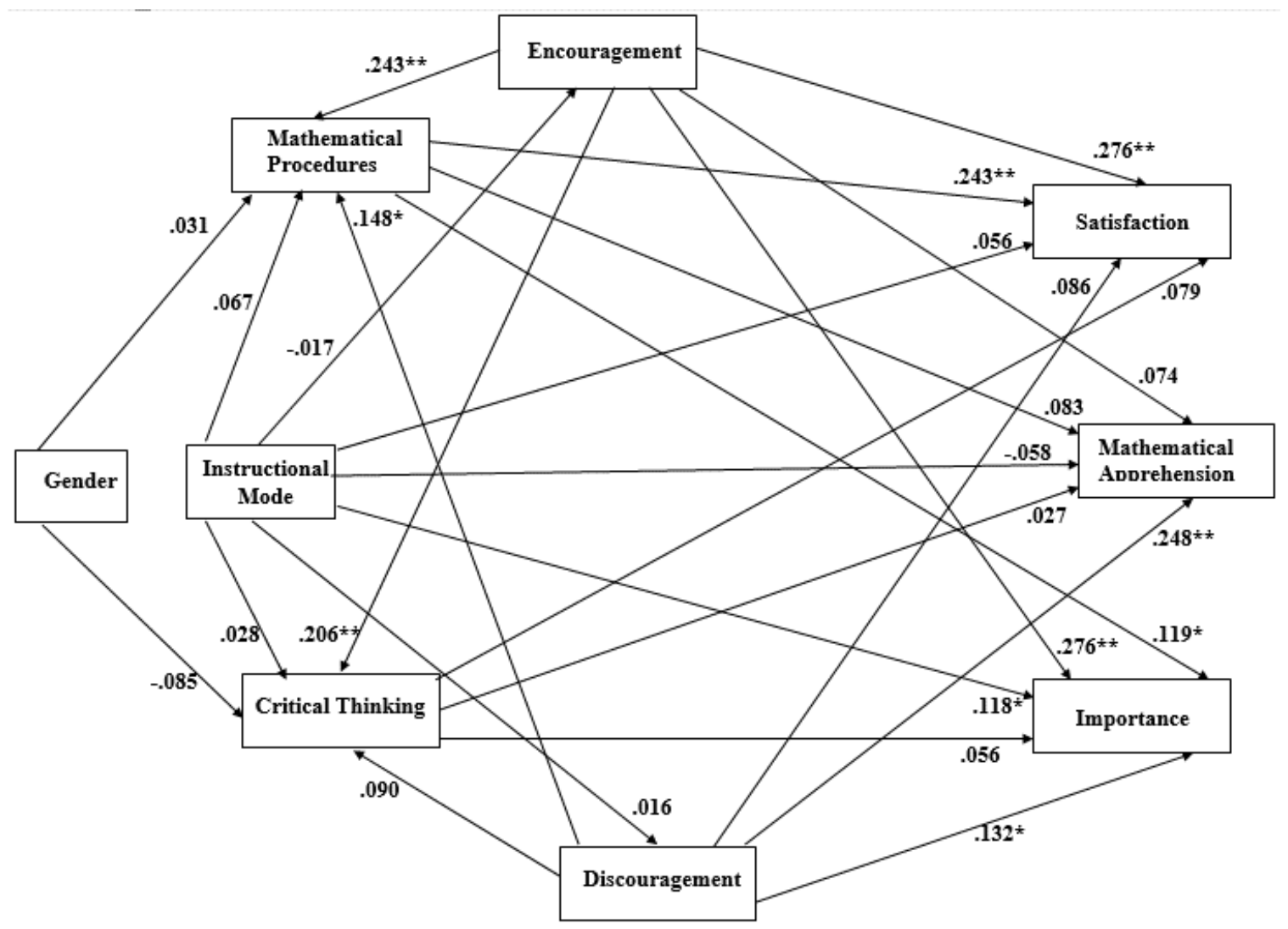

Figure 10. The path Model with Importance, Mathematics Apprehension, Satisfaction, Mathematical Procedures, Critical Thinking, Encouragement, and Discouragement Predicted. 
As Table 26 shows, the model accounted for $25.3 \%$ of the satisfaction students attributed to learning mathematics for their life. Almost of all the variance of Satisfaction was due to the direct effect of Encouragement and Mathematical Procedures. Eleven percent of the variance of Mathematics Apprehension was explained by the model; most of this variance was attributed to direct effect of Discouragement. Similarly, the model explained $19.7 \%$ of the variance of the importance students experienced from learning mathematics, being the direct effect of Encouragement, Discouragement, Mathematical Procedures, and Mode of Instruction responsible for most of the variability of Importance. The model was also able to explain $11.3 \%$ of the variance of Mathematical Procedures and 7.3 of the variance of Critical Thinking; critical thinking was primarily (directly) predicted by Encouragement, whereas Mathematical Procedures was predicted by the direct effects of Encouragement and Discouragement. Finally, the model did not predict the variability of Encouragement (.000\%) and Discouragement (.000\%) via Mode of Instruction. 
Table 26

Summary of causal Effects of the Hypothesized Model.

\begin{tabular}{|c|c|c|c|c|}
\hline \multicolumn{5}{|c|}{ Causal Effect } \\
\hline Outcome & Source & Direct & Indirect & Total \\
\hline $\begin{array}{l}\text { Encouragement } \\
\left(R^{2}=.000\right)\end{array}$ & Instructional Mode & -.017 & --- & .017 \\
\hline $\begin{array}{l}\text { Discouragement } \\
\left(R^{2}=.000\right)\end{array}$ & Instructional Mode & .016 & --- & -.016 \\
\hline \multirow{4}{*}{$\begin{array}{l}\text { Mathematical } \\
\text { Procedures } \\
\left(R^{2}=.113\right)\end{array}$} & Instructional Mode & -.060 & .003 & -.057 \\
\hline & Encouragement ${ }^{* * * *}$ & .274 & --- & .274 \\
\hline & Discouragement & .122 & --- & .122 \\
\hline & Gender & -.079 & --- & -.079 \\
\hline \multirow{4}{*}{$\begin{array}{l}\text { Critical Thinking } \\
\left(R^{2}=.073\right)\end{array}$} & Instructional Mode & -.028 & .002 & -.026 \\
\hline & Encouragement & .206 & --- & .206 \\
\hline & Discouragement & .090 & --- & .090 \\
\hline & Gender & .085 & --- & .085 \\
\hline \multirow{5}{*}{$\begin{array}{l}\text { Satisfaction } \\
\left(R^{2}=.253\right)\end{array}$} & Instructional Mode & .056 & .014 & .070 \\
\hline & Encouragement ${ }^{* * ⿰ ㇇ ⿰ 亅 ⿱ 丿 丶 丶 ~}$ & .276 & .075 & .351 \\
\hline & Discouragement & .086 & .043 & .129 \\
\hline & $\begin{array}{l}\text { Mathematical } \\
\text { Procedures }\end{array}$ & .243 & --- & .243 \\
\hline & Critical Thinking & .079 & --- & .079 \\
\hline \multirow{5}{*}{$\begin{array}{l}\text { Mathematics } \\
\text { Apprehension } \\
\left(R^{2}=.110\right)\end{array}$} & Instructional Mode & -.058 & .009 & -.049 \\
\hline & Encouragement & .074 & .026 & .100 \\
\hline & Discouragement ${ }^{* * * *}$ & .248 & .015 & .263 \\
\hline & $\begin{array}{l}\text { Mathematical } \\
\text { Procedures }\end{array}$ & .083 & --- & .083 \\
\hline & Critical Thinking & .027 & --- & .027 \\
\hline
\end{tabular}




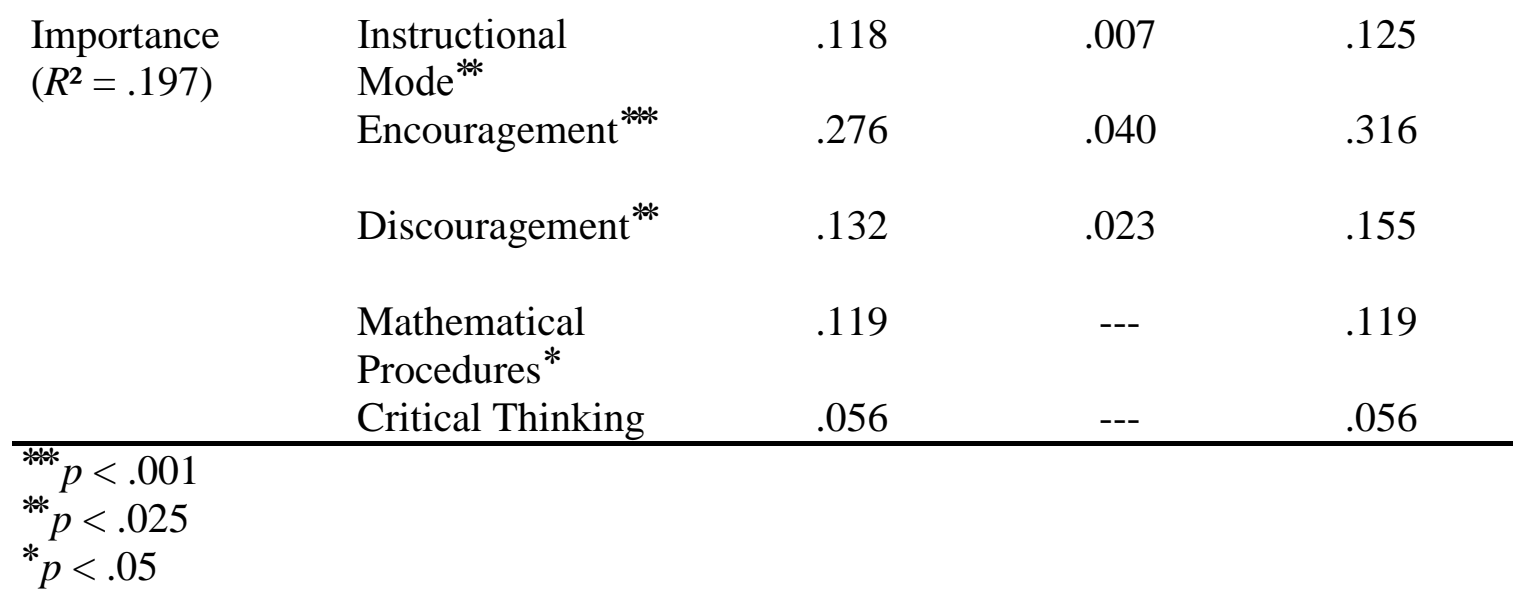

\section{Analysis of Mediation Effect}

Once the model is in place, Meyers et al. (2013) recommends analyzing mediation effects in the larger model using the Aroian test and the Freedman-Schatzkin test provided the following conditions are met. The predictor in the mediating analysis significantly predicts the outcome variable in isolation. The predictor significantly predicts the mediator in the larger model. The mediator significantly predicts the outcome variable in the larger model. As it was previously described in this study, the structure of the model in Figure 1 hypothesized a mediating effect as the factors underlying teacher's effect were going to act through the factors underlying self-efficacy in mathematics on the factors underlying attitudes toward mathematics. Additionally, such hypothesis was sustained in the model that emerged from the EFAs (Figure 2). That is, besides the direct effect of Encouragement and Discouragement on Importance, Mathematics Apprehension, and Satisfaction respectively, it was assumed that Mathematical Procedures and Critical Thinking would mediate the effect of Encouragement and Discouragement on Importance, Mathematics Apprehension, and Satisfaction. 
Four of the mediation relationships hypothesized satisfied all the conditions Meyers et al. (2013) outlined. The mediation hypotheses were tested based on three regression analyses. The first model assessed the direct effect of the predictor on the outcome in isolation. The second model assessed the effect of the predictor on the mediator in the larger model. Finally, the third model examined the effect of both the predictor and the mediator on the outcome variable in the so called larger model. They were as follows:

- Mathematical Procedures mediating the effect of Encouragement on Satisfaction. Encouragement significantly predicted Satisfaction in isolation, $\mathrm{F}(1,384)=72.190, p<.001, R^{2}=.158$, adjusted $R^{2}=.156 ;$ Encouragement significantly predicted Mathematical Procedures in the mediating model $(p<.001)$; Mathematical Procedures significantly predicted Satisfaction in the larger model $(p<.001)$.

- Mathematical Procedures mediating the effect of Encouragement on Importance. Encouragement significantly predicted Importance in isolation, $\mathrm{F}(1,384)=61.420, p<.001, R^{2}=.138$, adjusted $R^{2}=.136 ;$ Encouragement significantly predicted Mathematical Procedures in the mediating model $(p<.001)$; Mathematical Procedures significantly predicted Importance in the larger model $(p<.05)$.

- Mathematical Procedures mediating the effect of Discouragement on Satisfaction. Discouragement significantly predicted Satisfaction in isolation, $F(1,384)=27.898, p<.001, R^{2}=.068$, adjusted $R^{2}=.065 ;$ Discouragement 
significantly predicted Mathematical Procedures in the mediating model $(p<.025)$; Mathematical Procedure significantly predicted Satisfaction in the larger model $(p<.001)$.

- Mathematical Procedures mediating the effect of Discouragement on Importance. Discouragement significantly predicted Satisfaction in isolation, $\mathrm{F}(1,384)=31.027, p<.001, R^{2}=.075$, adjusted $R^{2}=.072 ;$ Discouragement significantly predicted Mathematical Procedures in the mediating model $(p<.05)$; Mathematical Procedure significantly predicted Importance in the larger model $(p<.05)$.

Meeting Meyers et al. (2013) conditions for these paths granted the application of the Aroian test and the Freedman-Schatzkin test to analyze the statistical significance of the mediation effect. As Meyers et al. comments on Baron and Kenny (1986), the Aroian test is a variation of the Sobel test that assesses the significance of a mediating effect. The test evaluates the null hypothesis of no indirect effect of a predictor on an outcome through the mediator variable (Meyers et al., 2013). The Freedman-Schatzkin test compares the strength of the unmediated model with that strength of the mediated model (Meyers et al., 2013). The computation of the Aroian test uses the raw score regression coefficient for the predictor predicting the mediator in the mediated model as well as the score regression coefficients of the mediator predicting the outcome in the mediated model. Additionally, it is required to use the standard error value of the raw regression coefficients. On the other hand, the Freedman-Schatzkin test uses the raw score regression coefficient for the predictor of the outcome in isolation, the raw score regression coefficient for the predictor predicting the outcome in the mediating model, 
the standard errors for these two raw score regression coefficients, and the Pearson correlation coefficient the describes the relationship between the predictor and the mediator (Meyers et al., 2013).

The $z$ value obtained for the Aroian test for the mediating role of Mathematical Procedures between Encouragement and Importance was $3.25(p<.05)$; the $z$ value obtained for the Aroian test for the mediation of Mathematical Procedures between Encouragement and Satisfaction was $1.93(p<.05)$; the $z$ value obtained for the Aroian test for the mediation of Mathematical Procedures between Discouragement and Importance was $2.38(p<.05)$; the $z$ value obtained for the Aroian test for the mediation of Mathematical Procedures between Discouragement and Satisfaction was 1.66 $(p<.05)$. Just the $\mathrm{z}$ values for the mediating path of Encouragement-Mathematical Procedures-Importance and the mediating path of Discouragement-Mathematical Procedures-Importance were higher than the critical threshold value of $1.96(p=.05)$, which indicated that a significant amount of mediation of Mathematical Procedures occurred in each of these two paths in the context of the larger model. As a result, the Freedman-Schatzkin test for the mediation strength in these paths was computed to compare the magnitudes of the regression coefficients from both Encouragement and Discouragement with the amount of Importance in the unmediated and mediated models. The Freedman-Schatzkin for the mediation of Mathematical Procedures between Encouragement and Importance was $t(384)=8.32(p<.05)$; the Freedman-Schatzkin test for the mediation of Mathematical Procedures between Discouragement and Satisfaction was $t(384)=14.80(p<.05)$. As all these $t$ values were greater than the critical value of 1.96 , they demonstrated that Mathematics Procedures significantly 
reduced the effect of both Encouragement and Discouragement on Importance when Mathematical Procedures was included as a mediator in the model. The regression coefficients of Encouragement and Discouragement were statistically significant with Mathematical Procedures in the larger (mediated) model, but they were reliably reduced compared to the coefficients in the unmediated model. Consequently, Mathematical Procedures partially mediated the effect of Encouragement on Importance as well as the effect of Discouragement on Importance.

\section{Summary}

This chapter presented the findings of the study. The chapter provided a description of the demographic characteristics of sample used in the study and discussed the statistical procedures used to respond to the research questions. Exploratory factor analyses were conducted to assess the dimensionality of the instruments used for data collection. Multiple linear regression analyzed the fit of the model that emerged from the EFAs as well as grounded in theoretical and empirical results. The chapter concluded with an analysis of the differences between the attitudes toward mathematics of students enrolled in blended College Algebra and face to face College Algebra. 


\section{CHAPTER V}

\section{DISCUSSION, IMPLICATIONS, AND RECOMMENDATIONS}

This chapter presents the discussion of the results. This discussion includes a descriptive analysis of the data and an analysis of the findings for each hypothesis. Implications for theory, research, and practice as well as limitations of the study are presented. The chapter ends with a summary of highlights.

\section{Discussion of the Results}

Grounded in theory and research, this study aimed to examine the effect of factors underlying the dimensions of teacher's effect to learn mathematics, self-efficacy in mathematics, as well as gender and mode of instruction on factors underlying students' attitude toward mathematics. Additionally, the study analyzed differences of factors underlying students' attitudes toward mathematics in terms of instructional modalities. The study was conducted in a minority-serving institution with students enrolled in faceto-face and hybrid College Algebra classes. This study examined a model where factors underlying teacher's effect in the mathematics classroom (Encouragement and Discouragement) influenced factors underlying self-efficacy toward mathematics (Critical Thinking and Mathematical Procedures) and factors underlying attitudes toward mathematics (Satisfaction, Mathematical Apprehension, and Importance). The model included a direct path of factors underlying self-efficacy toward mathematics influencing factors underlying attitudes toward mathematics. Additionally, the model included the effect of gender on the factors underlying self-efficacy toward mathematics and the effect of mode of instruction on every single factor. First, a discussion of the characteristics of 
the sample is provided followed by the discussion of the findings of each research question presented by their corresponding hypotheses.

\section{Descriptive Analysis of the Data.}

An analysis of demographic factors was conducted prior to addressing the research questions. The purpose in conducting this analysis was to evaluate the equivalence between the face-to-face and hybrid groups in terms of demographic indicators. The demographic indicators included instructional modality, race/ethnicity, gender, age, hybrid math class taken before, remedial math classes taken before, and area of future studies. As expected, most students (83.85\%) were Hispanic/Latino or had Hispanic/Latino roots. Besides, the percentage of Hispanic/Latino was also equivalent across both instructional modes. This result was expected as this study was conducted in a higher education institution whose enrollment is mainly composed of students from this ethnic group. Studies on higher education mathematics have fallen short on addressing the problem of students' beliefs about mathematics and its effect on important aspects such as their self-efficacy and attitudes toward the subject. Few studies have addressed this problem in minority populations. Hall and Ponton's (2005) comparison of selfefficacy in mathematics across academic levels was an important effort to inform educators that students beliefs about their ability to perform mathematics problems play a crucial role in their success in mathematics. However, Hall and Ponton studied judgements of mathematics self-efficacy in a sample that included a majority of White students. From this perspective, this study adds missing information on the perceptions about mathematics in an underrepresented population of students. Results from the analysis that assessed differences across instructional modes indicated that both groups 
were equivalent in terms of demographic indicators of race/ethnicity, gender, age, remedial math classes taken before, and area of future studies. That is, the statistical analysis conducted to evaluate differences of race/ethnicity, gender, age, remedial math classes taken before, and area of future studies across instructional modalities produced no significant differences $(p>.05)$. Yet, there was a significant difference between the groups with respect to whether students had previously taken mathematics classes in a hybrid modality. Seventy out 185 students (about $38 \%$ of students) in the hybrid group responded that they had taken a hybrid mathematics class before. Forty five out of 205 students (about $22 \%$ of students) in the face-to-face group reported that they had taken a hybrid mathematics class in the past. Therefore, more than $16 \%$ of students in the hybrid group responded reported that they had taken mathematics class before when compared to the group of face-to-face students. This result was not surprising. A probable reason for this difference is that some students in the hybrid group may have previously taken hybrid mathematics classes and they may had enjoyed the flexibility this mode of instruction offers. This outcome is in agreement with Caputo's (2010) findings in a study that analyzed students' attitudes toward mathematics in a hybrid calculus course. Caputo found that students thought that being enrolled in a hybrid mathematics course was a beneficial experience because they were able to complete school assignments at their own pace as they managed other personal life responsibilities. 


\section{Hypothesis 1}

The first hypothesis stated that there would be more than one reliable and interpretable factor underlying the constructs of teacher's effect, self-efficacy toward mathematics, and attitudes toward mathematics. Findings from the exploratory factor analysis indicated that the measures used to assess the constructs of Teacher's Effect, Self-efficacy toward Mathematics, and Attitudes toward Mathematics were represented by more than one reliable and interpretable factor. Consequently, these findings support hypothesis 1 . The following sections discuss the results of the EFAs on each measure.

\section{Teacher's Effect}

The dimensionality of the construct of Teacher's Effect was assessed using the Fennema and Sherman Mathematics Teacher scale (Fennema \& Sherman, 1976). The FSMAS Teacher scale is composed of 12 items that address the effect of teachers on learning mathematics from student's perspective. The EFA performed on the FSMAS Teacher scale produced two factors. The wording in the items that loaded strongly in the first factor express teacher support and encouragement for students to learn mathematics. These items included item 1, "My teachers have encouraged me to study more mathematics"; item 2, "My teachers think I'm the kind of person who could do well in mathematics"; item 3, "My mathematics teachers have been interested in my progress in mathematics"; item 5, "Mathematics teachers have made me feel I have the ability to go on in mathematics"; and item 6, "My mathematics teachers would encourage me to take the entire mathematics I can." The first factor was named Encouragement. The second factor was loaded with items that stressed student's feeling of neglect from their interaction with mathematics teachers. This factor included item 9, "Getting a 
mathematics teacher to take me seriously has usually been a problem"; item 10, "My teachers would think I wasn't serious if I told them I was interested in a career in science and mathematics"; item 11, "I have found it hard to win the respect of mathematics teachers"; and item 12, "I have had a hard time getting teachers to talk seriously with me about mathematics." The second factor was named Discouragement. Items 4, 7, and 8 did not load strongly in any of the factors. Item 4, "I would talk to my mathematics teachers about a career which uses math", highlights a positive perception of the effect of teachers to learning mathematics. However, the Encouragement factor did not capture the contribution of item 4 as the loading was much less than .7 and the communality was as low as .19. Item 7, "When it comes to anything serious, I have felt ignored when talking to mathematics teachers" and item 8, "My teachers think advanced mathematics is a waste of time for me" describe a lack of encouragement and commitment of teachers to help students learn mathematics. These two items contributed poorly to the Discouragement factor as their loadings (.51 and .61 , respectively) and communality (.27 and .38 , respectively) were not enough to represent it. The exploratory factor analysis produced two-factor solution, Encouragement and Discouragement. This solution explained $64.22 \%$ of the total variance. The correlation coefficient between factors reached .38. An analysis of the reliability via Cronbach alpha for each factor was performed after achieving the final solution. This analysis showed that Encouragement reached a Cronbach alpha value of 0.873 and Discouragement reached a Cronbach alpha value of 0.867 . In a sample of elementary school teachers, Thompson, Melacon, \& Becnel (1993) applied factor analysis to the Fennema and Sherman scales and found a one factor-solution for the teacher's scale. This solution included four items negatively 
worded and a positively worded item. The one factor structure found in the study of Thompson and colleagues included opposite items such as "I find it hard to win the respect of math teachers" and "Math teachers have been interested in my progress in math." Results in Thompson et al. study regarding to the structure of the Fennema and Sherman teacher's scale differs from the result achieved in this study. However, both studies pursued different purposes. Thompson et al. looked for assessing the structure of all scales in the Fennema and Sherman instrument which included the Attitudes toward success in Mathematics scale, the Mathematics as a male domain scale, the mother and father scales, the teacher scale, the confidence in learning Mathematics scale, the Mathematics anxiety scale, the effectance motivation scale in mathematics, and the Mathematics usefulness scale. Thompson et al. compared it with that structure Fennema and Sherman found. On the other hand, the present study focused on examining the dimensionality of the Fennema-Sherman teacher's scale only to evaluate its effect on other constructs. Consequently, it was expected to arrive to different structures.

\section{Self-Efficacy toward Mathematics}

According to Bandura (1997), an effective measure of self-efficacy addresses the construct by collecting individual perceptions of efficacy to perform a specific task, such as adding factions with different denominators. However, research studies have not addressed in depth judgements of self-efficacy of students when performing specific tasks in mathematics in higher education. The present study followed Altman's (1997) recommendation of including a mathematics problems subscale and a diversity of sample to explore self-efficacy. Accordingly, in the present study, an EFA on the Hackett and Betz (1982) Mathematics Self-Efficacy subscale was performed. This scale is composed 
of 18 problems addressing different areas in mathematics (see Appendix D). A first twofactor solution produced low communalities and loadings of most items. Only items 7, 8, $10,11,16,17$, and 18 showed communalities higher than 0.5 . Similarly, just items 1,2 , 12,17 , and 18 loaded at a value 0.7 or above. As it is noted, no item reached the desired level of communality and loading. Under this condition, several items were considered as potential candidates for removal in the analysis as they did not meet the criteria for being retained in a plausible solution. A series of EFAs were conducted to retain the maximum number of factors that would share fair levels of communalities and loading in their respective factors. The final solution also produced two factors. Factor 1 included item 17, "If $3 \mathrm{x}-2=16$, what does $\mathrm{x}$ equal?"; item 18, "Fred's bill for some household supplies was $\$ 13.64$. If he paid for the items with a $\$ 20$, how much change should he receive?”; and item $16, " 33 / 4-1 / 2=$ ". All these items propose solving mathematics problems using different mathematical procedures. Therefore, Factor 1 was labeled as Mathematical Procedures. Factor 2 included item 1 "In Starville, an operation ${ }^{\circ}$ on any numbers $\mathrm{a}$ and $\mathrm{b}$ is defined by", item $2{ }^{\prime} \mathrm{a}{ }^{\circ} \mathrm{b}=\mathrm{a} \times(\mathrm{a}+\mathrm{b})$. Then $2^{\circ} 3$ equals ?"; item 6, "Five points are on a line. T is next to G. $\mathrm{K}$ is next to $\mathrm{H}$. C is next to T. $\mathrm{H}$ is next to G. Determine the relative positions of the points along the line"; and item 14 "On a certain map, 7/8 inch represents 200 miles. How far apart are two towns whose distance

apart on the map is $3 \frac{1}{2}$ inches?". Items in Factor 2 involve solving mathematics problems that require some level of abstraction. For this reason, Factor 2 was named as Critical Thinking. Cronbach alpha values for Mathematical Procedures (.836) and Critical Thinking (.72) reached acceptable values. Previous research studies have used other 
measures of self-efficacy toward mathematics to address the structure of this construct. Liu and Koirola (2009) studied the relationship between self-efficacy in mathematics and mathematics achievement in high school sophomore students. Liu and Koirola applied exploratory factor analysis to a 5-item instrument that addressed general perceptions of self-efficacy in mathematics. Items in the instrument asked students to express their agreement or disagreement with questions such as "When I do mathematics, I sometimes get totally absorbed" and "Most people can learn to be good at math". Liu and Koirola found a single factor structure. That is, all items loaded on a single factor. This result is not surprising as the methodology Liu and Koirola used did not follow the guidelines to evaluate self-efficacy when performing a specific task. Liu and Koirola failed to describe genuine judgements of self-efficacy in mathematics as they assessed general beliefs about mathematics rather than evaluating self-efficacy in context-specific conditions. Zimmerman (2002) advised researchers to address self-efficacy under academic contextspecific conditions rather than examining a broad view of the construct. Zimmerman added that a student's responses to general prompts on self-efficacy may not reflect the student's real perception of efficacy on accomplishing specific tasks. Bandura (1997) argued that items on which self-efficacy is to be assessed must be aligned to those objectives on which performance is to be measured. The Mathematics Self-Efficacy Scale (MSES) is a scale that applies to specific objectives related to College Algebra curriculum and includes items addressing the solution of content specific mathematics problems from a broad number of areas of mathematics. As few studies on assessing selfefficacy toward mathematics have followed Bandura's guidelines, the two-factor solution in this study strengthens the theoretical framework around self-efficacy. Zarch and 
Kadivar (2006) analyzed the predictive effect of mathematics ability and mathematics self-efficacy on performance. In their study, Zarch and Kadivar used a 15 items mathematics self-efficacy questionnaire covering content-specific areas of the subject and assessing the same topics used to measure performance. Those topics included linear equation, algebra, geometry, arithmetic and vector. Zarch and Kadivar found a two factor-solution in an exploratory factor analysis. One factor included items from four content areas and another factor included only geometry items. Despite the present study used a different instrument and did not cover the same exact topics as Zarch and Kadivar's study did, the two factor-solution found in this study has similarities with Zarch and Kadivar' structure. Both studies used items addressing different areas of mathematics and both studies found a two-factor solution. One factor in Zarch and Kadivar's study included items on the topics on linear equation, algebra, arithmetic, and vector. The other factor included items only on geometry. In this study, one factor included items that required applying critical thinking but in different mathematics context. The other factor in this study included mathematical procedures that required the used of arithmetic operations.

\section{Attitudes toward Mathematics}

The construct of attitude toward mathematics was measured with the Lim and Chapman (2013) instrument, a 19-items version of the Attitudes toward Mathematics Inventory (APPENDIX F). A first exploratory factor analysis performed on this scale produced a three-factor solution that corroborated item inter-correlation. An additional EFA was conducted to increase the explained variance. For this purpose, item 10, "Studying mathematics makes me feel nervous" and item 13, "I am always confused in 
my mathematics class" were removed from factor 3 as they were the items with the lowest values of loading and communality. With the removal of these items, the variance explained increased from $62.43 \%$ to $72.11 \%$. Satisfaction was one of the factors in the final solution in this analysis. This factor included items such as item 1, "I have usually enjoyed studying mathematics in school" and item 9, "The challenge of mathematics appeals to me". Another factor in this solution included items such as item 15, "Mathematics is a very worthwhile and necessary subject" and item 19, "A strong mathematics background could help me in my professional life". As a result, this factor was named Importance. The last factor included items such as item 11, "I am always under a terrible strain in a mathematics class". This last factor was named Mathematics Apprehension.

The attitude toward mathematics measure used in this study was the Lim and Chapman (2013) measure (see Appendix F), a shortened survey created from the Tapia and Marsh (2002) ATMI survey. Tapia and Marsh applied an exploratory factor analysis to a survey of 49 items they administered to students in a college preparatory bilingual school in Mexico City. From this analysis, Tapia and Marsh found a 4-factor structure which they named as Self-confidence, Value of Mathematics, Enjoyment of Mathematics, and Motivation. Lim and Chapman (2013) reduced the number of items to 19 and obtained a 4-factor structure in a Chinese sample from Singapore when they created the scale used in the present study. This study found a 3 -factor structure with a different loading to the 4-factor solution Lim and Chapman found. The difference was that in this study items 1 through 9 loaded in only one factor (Satisfaction) while in the 
Lim and Chapman structure items 1 through 5 clustered in a factor (Enjoyment) and items 6 through 9 clustered in another factor (Motivation).

\section{Hypothesis 2}

The second hypothesis stated that there were differences in the factors underlying the constructs of attitudes toward mathematics across instructional modalities. The oneway MANOVA conducted to evaluate the effect of mode of instruction (face-to-face and hybrid) on Satisfaction, Mathematics Apprehension, and Importance was significant,

Wilks's $\Lambda=.978, F(3,382)=2.881, p<.05$. There was a weak association between mode of instruction and the linear combination of Satisfaction, Mathematics Apprehension, and Importance. The multivariate $\eta^{2}$ based on the Wilks's $\Lambda$ was quite low, .022, meaning that only $2.2 \%$ of multivariate variance of Satisfaction, Mathematics Apprehension, and Importance was associated with mode of instruction.

Univariate ANOVAs on Satisfaction, Mathematics Apprehension, and Importance were obtained, as the MANOVA was significant. Only the ANOVA for the importance students attributed to learning mathematics for their life showed significant differences between the modes of instruction, $F(1,384)=6.059, \mathrm{p}<.017$. These results suggest that students enrolled in the hybrid classes showed higher concern about the need of learning mathematics and the benefit of mastering mathematics would bring for their careers than students under face-to-face instruction. On this subject, it is possible to speculate that the hybrid instructional approach had had positive effects on learning experiences of students in the hybrid group that face-to-face students had not the chance to experience. Students under hybrid instruction were expected to function more independently than their 
counterpart in face-to-face instruction as direct contact with the instructor was significantly reduced. Consequently, enhanced interaction may had replaced the lack of direct contact with the instructor and in turn enhance student's experiences.

Previous research studies have compared instructional modalities from different perspectives. One of this perspective have focused on measures of achievement. Bargagliotti, Botelho, Gleason, Haddock, and Windsor (2012) found that the Memphis Mathematics Method (MMM) was a successful mode of instruction in increasing retention and student success in a study on the effect of blended instruction in postsecondary mathematics courses. The MMM is a blended learning instructional model that uses technology with short lectures in traditional mathematics classroom (Bargagliotti et al., 2012). Bargagliotti et al. reported that students enrolled in blended courses showed higher success and less dropout rates as a norm across mathematics courses. According to Bargagliotti et al., the pedagogy used in the blended classes rendered better results in Elementary Calculus with $79 \%$ higher odds of success than traditional instruction. Similarly, the dropout rate in MMM was $10 \%$ versus $13 \%$ in traditional teaching and learning modality.

More recently, Czaplewski (2014) examined differences in knowledge acquisition in a hybrid pre-calculus class with respect to knowledge acquisition in a face-to-face precalculus class in a study that investigated the effect of mode of instruction on student's achievement in mathematics. The study of Czaplewski used students not pursuing a mathematics major in a higher education institution with a population that included about of $88 \%$ of White students of its enrollment. According to Czaplewski, the study was conducted "to address the declining attitudes towards the subject by students" (p. 54). 
The comparative analysis of achievement across mode of instruction indicated that students in blended courses outperformed students in the face-to-face courses in both, the grades of a final exam the final grade in the course.

Compelling evidence such as the results Bargagliotti et al. (2012) and Czaplewski (2014) found in their study suggest that adopting hybrid instruction in mathematics may render positive outcomes. Yet, the existing body of academic literature has overlooked addressing the concerning lack of attitude toward learning mathematics across instructional modalities beyond postsecondary education. The present study did not compare levels of success across instructional modalities. It neither considered retention rate in the scope of the study. Lack of attitudes toward learning mathematics is a recurrent issue in postsecondary education and as such needs to be examined in all modalities of course offering. Just few studies (Czaplewski, 2014; Krishnan, 2016; Smith and Suzuki, 2015) have addressed beliefs toward mathematics within hybrid learning, rather than establishing a comparison across instructional modalities. Despite the limited attempts to establish a comprehensive analysis on attitudes toward mathematics across instructional modalities, there exits evidence that maps to the findings in the present study.

Findings in the study regarding to satisfaction and apprehension in mathematics revealed that those students in face-to-face and hybrid courses showed similar levels of satisfaction and mathematics apprehension. It also appears that these students perceived similar levels of anxiety and challenging expectations respectively for being enrolled in a College Algebra course. Clute (1984) found different results in a study that examined differences of level of anxiety in students under "direct instruction discovery method" 
and "direct instruction expository method" in mathematics. Clute found that those students who showed higher level of mathematics anxiety achieved significantly lower in mathematics than those students with lesser level of anxiety. Clute further found that those students with high-level of anxiety functioned better in the direct instruction expository method while direct instruction discovery method was a more appropriated instructional setting for low-level anxiety students.

Smith and Suzuki (2015) compared learning experiences and satisfaction with instructional modality between hybrid instruction and live-lecture classroom in a high school Algebra II course. Blended learning in Smith and Suzuki (2015) study consisted in screen-captured lectures, what they called "embedded blended learning", which were available to hybrid students only inside and outside classroom. According to Smith and Suzuki, an overwhelming majority of students under the screen-capture lectures (hybrid instruction) stated that they would prefer teacher's online lessons than traditional lecture. Smith and Suzuki added that those students who received embedded multimedia lessons seemed to have more productive learning experiences as more students in this group expressed that they learned mathematics better than the students in the live-lecture group. Students under hybrid instruction also expressed that the teaching techniques were easy to follow. In fact, 8 out of 10 students who identified screen capture lectures (embedded in hybrid learning) as a better learning strategy than live-lecture instruction indicated their preference for online learning for future course enrollment. According to Smith and Suzuki, one of the reasons for student's preference toward teacher's online lessons as a modality of hybrid learning was the flexibility to handle their own learning. 
Further, Smith and Suzuki (2015) found that students' satisfaction and learning experiences in blended learning was higher than the satisfaction and learning experiences in a group of students under live-lecture classroom instruction. Students in the hybrid group stated that accessing the screen-captured lectures from anywhere was an advantage. Despite this, most hybrid students indicated that watching the videos (screencaptured lectures) in class was better for them than watching them from home because they were able to receive real-time feedback from the teacher when they needed clarification in understanding concepts. Avoiding distraction was another reason students expressed for their preference for watching video lessons in the classroom. This finding in the study of Smith and Suzuki (2015) do not correlate with findings in the present study as they suggest that students who received hybrid instruction were more satisfied under hybrid learning format than students learning mathematics under face-to-face instruction.

Studies comparing levels of satisfaction and expressions of mathematics apprehension across instructional modalities that include web-based instruction are limited. Few attempts have evaluated these two dimensions in the context of web-based learning in mathematics. Krishnan (2016) compared perceptions of students regarding the two-learning mode, face- to- face mode and the online mode, inside a hybrid mathematics course. Krishnan conducted the study in a sample of students enrolled in a Calculus and a course in Engineering Mathematics at a private international university in Malaysia. An overwhelming number of students in the study of Krishna preferred faceto-face learning over the online learning. These students indicated that they learned more from in classroom interactions than from online-based instruction interaction. More 
important, students expressed that face-to-face instruction were the best learning environment to grasp and master the academic content in mathematics. However, more than half of students participating in this study remarked that overall hybrid instruction (the combination of face-to-face and online instruction) was an appropriate instructional mode to learn mathematics.

Gecer and Dag (2012) found that effective application of instructional strategies in hybrid instruction (the blend of face-to-face and e-learning methods) may have a positive effect in student's learning. Gecer and Dag studied the perceptions towards a blended (hybrid) computing course in a group of students enrolled in Mathematics Teaching and Primary Teaching. Results from a qualitative analysis on the student's responses to 7 open-ended questions indicated that students under hybrid instruction learned course content more effectively (Gecer \& Dag, 2012). Instruction in hybrid course rely strongly on applications of learning management systems (LMS). It appears that course activities used in the study of Gecer and Dag were carefully designed to foster active interaction. For this reason, students found interesting and useful "following the content of the course, homework and projects online" (p. 438). The last finding in Gecer and Dag work supports the higher level of importance to learning mathematics students in the hybrid courses this study found.

In a hybrid precalculus class, Czaplewski (2014) studied changes of attitudes toward mathematics and attitudes toward blended learning over time. The analysis of the attitudes toward mathematics included the two-time administration of the Attitude toward Mathematics (ATMI) questionnaire that includes the factors Enjoyment of Mathematics, Motivation for Mathematics, Self-Confidence in Mathematics, and Value of Mathematics 
According to Czaplewski, students showed more enjoyment and attributed more value to learning mathematics at the end of the course when compared to the beginning of the term. Further, Czaplewski reported that working in groups produced positive effect in student's attitudes toward mathematics. Students expressed that working in groups made learning mathematics more enjoyable, facilitated understanding while sharing ideas, and reduce anxiety. Findings in the study of Czaplewski correlate in some ways with the findings of the present study. On one hand this study found that students under both instructional modalities, face-to-face and hybrid instruction, experience same level of satisfaction and mathematics apprehension. Czaplewski was unable to compare attitudes of students toward mathematics in term of instructional modality not even within the face-to face group. Czaplewski only assessed changes of attitudes in the hybrid group. Hybrid students in this study did not enjoy learning mathematics at a higher level and were not under lower levels of anxiety when working mathematics problems than those students in the face-to-face group. It appears that the instructional strategies used in hybrid courses in this study were not effective enough so that these students would experience learning mathematics as a more enjoyable process with reduced level of anxiety when compared to students in face-to-face classes. On the other hand, students in hybrid course in this study valued learning mathematics at a higher level than face-toface students, which is congruent with what Czaplewski found in the within hybrid course analysis. 


\section{Hypothesis 3}

The third hypothesis claimed that the factors underlying the constructs of teacher's effect, self-efficacy, and the demographic factors of instructional modality and gender would account for a significant amount of the unique variance of students' attitudes toward mathematics delivered through face-to-face or hybrid learning modes. The model that arose from the exploratory factor analyses (Hypothesis 1) was used to assess this hypothesis. The regression analyses conducted on the paths of the model evaluated the predictive influence of the factors underlying teacher's effect, the factors underlying self-efficacy, and demographic factors on the factors underlying attitudes toward mathematics produced mixed results. The model consisted of Encouragement and Discouragement as factors underlying teacher's effect influencing directly Mathematical Procedures and Critical Thinking, factors underlying self-efficacy, a direct effect of Satisfaction, Mathematics Apprehension, and Importance as factors of attitudes toward mathematics. The model included direct paths from Mathematical Procedure and Critical Thinking influencing Satisfaction, Mathematics Apprehension, and Importance. Finally, the model included a direct effect of mode of instruction to each of the factors as well as direct influence of gender on Mathematical Procedures and Critical Thinking.

The linear combination of Mathematical Procedures, Critical Thinking, Encouragement, Discouragement, and Mode of Instruction was significantly related to Satisfaction, $F(5,380)=25.75, p<.001$. The sample multiple correlation coefficient was .503 , indicating that approximately $25.3 \%$ of the variance of Satisfaction in the sample was accounted by the linear combination of Mathematical Procedures, Critical Thinking, Encouragement, Discouragement, and Mode of Instruction. Encouragement 
and Mathematical Procedures had a strong effect on Satisfaction $\left(\beta_{E}=.276\right.$ and $\beta_{M P}=.243$, respectively). It appears that those students who perceived encouragement from their teacher as well as with strong perceptions on their efficacy to perform mathematical procedures were highly pleased in their mathematics class and experienced the comfort required to function properly in the mathematics classroom. Encouragement and Mathematical Procedures accounted for $6.15 \%$ and $4.12 \%$ respectively of the variance of Satisfaction. This result indicates that the combined effect of Encouragement and Mathematical Procedures uniquely explained about $40 \%$ of the total variance explained by the model of the satisfaction students attributed from engaging in learning mathematics. The effect of Critical Thinking, Discouragement, and Mode of Instruction was small and not statistically significant.

Mathematics Apprehension was significantly predicted by the combined effect of Mathematical Procedures, Critical Thinking, Encouragement, Discouragement, and Mode of Instruction, $F(5,380)=9.367, p<.001$. Approximately $11 \%$ of the variance of Mathematics Apprehension in the sample was accounted by the linear combination of Mathematical Procedures, Critical Thinking, Encouragement, Discouragement, and Mode of Instruction. Discouragement $(\beta=.248)$ was the only significant predictor of Mathematics Apprehension. As expected, those students who perceived poor support from the teacher where more insecure and reticent to function mathematically. Discouragement accounted for about 5.2\% of the variance of Mathematics Apprehension. In fact, Discouragement accounted for about $47 \%$ of the total variance explained by the model of the apprehension of students to interact with mathematics content in the sample. 
The regression analysis on the predictive path of Importance showed that the linear combination of Mathematical Procedures, Critical Thinking, Encouragement, Discouragement, and Mode of Instruction worked as a significant predictor, $F(5,380)=18.618, p<.001$. The combined effect of the predictors explained $19.7 \%$ of the variance of Importance. The largest effect on Importance was from Encouragement $(\beta=.276, p<.001)$, which explained $6.15 \%$ of its unique variance; students who were more mathematically oriented better appreciated the value of learning mathematics. Surprisingly, Discouragement had a moderate but significant effect on Importance, $(\beta=.132, p<.025)$. A couple of factors may have contributed to this singular result. College Algebra is a mathematics course that includes several topics that college students may find familiar, as students who enroll in this course have been exposed to a significant portion of the content this course covers, regardless if students come or not directly from high school. Besides, more than half of the participants in this study (54.87\%) reported that they had not taken a remedial mathematics class as well as almost $60 \%$ of them reported that they would pursue STEM related careers. These facts suggest that some students may have attributed merit to learning mathematics as well as they may have found value to mastering mathematics concepts to succeed in future educational endeavors, despite these students may have a felt lack of support from the teacher. Mode of instruction predicted Importance, but to a lesser extent $(\beta=.118, p<.05)$ than other indicators, explaining only $1.4 \%$ of the variance of Importance. These findings suggest that those students in hybrid College Algebra attributed more importance to learning mathematics than those students enrolled in face-to-face College Algebra. Finally, 
Mathematical Procedures $(\beta=.132, p<.025)$ poorly accounted for about $1 \%$ of the variance of Importance, meaning that those students with strong beliefs in their efficacy to perform mathematical procedures showed slightly more importance to mastering mathematics for their life.

Mathematical Procedures, students' perceptions of their ability to solve problems involving different mathematics procedures, was significantly predicted by Encouragement, Discouragement, Mode of Instruction, and Gender, $F(4,381)=12.082$, $p<.001$. The combined effect of the Mathematical Procedures predictors explained $11.3 \%$ of its variability. Encouragement $(\beta=.243, p<.001)$ and Discouragement $(\beta=.148, p<.01)$ were the significant predictors in this path. Encouragement uniquely accounted for $5.12 \%$ of the changes in Mathematical Procedures, while Discouragement accounted for almost $2 \%$. While it was expected that Encouragement would significantly contribute to explain students' perceptions of their ability to solve problems involving different mathematics procedures, it is not that surprising that Discouragement would have helped to explain a portion of Mathematical Procedures. This study was conducted in a sample of students attending a higher education institution. It is likely that their College Algebra class was not the first time these students were exposed to working out problems that required the use of mathematical procedures. Some of these students may have perceived that teachers were not quite dedicated and committed to their progress. Despite these feelings of discouragement, these same students may have felt committed to work out problems that required mathematical procedures. Problems involving application of mathematical procedures may have been topics these students were 
familiar with since they have been previously exposed to this academic content over the years of learning mathematics.

Critical thinking was significantly predicted by the combined effect of

Encouragement, Discouragement, Gender, and Mode of Instruction, $F(4,381)=7.475$, $p<.001$. Only Encouragement $(\beta=.206, p<.001)$ has a moderate effect on Critical Thinking uniquely accounting for $3.7 \%$ of the total variance of $7.3 \%$ explained by the linear combination of the predictors. This effect of Encouragement on Critical Thinking highlights the role of instructors in motivating students to attempt difficult tasks. In other words, it appears that those students that saw the teacher as a supportive agent in the class were inspired to accomplish mathematics problems that required a high level of abstraction.

This study assumed that the type of instructional mode and gender would have an impact on both the way students would perceive their ability to perform mathematics problems that required the application of mathematical procedures and on the way students would perceive their ability to perform mathematics problems that required the application of critical thinking. Neither mode of instruction nor gender were indicators of how students saw themselves as capable to accomplish the solution of mathematical procedures or critical thinking problems. Students in both face-to-face and hybrid College Algebra classes and regardless of their gender expressed equivalent believes about their level of mathematics efficacy to complete procedural and critical thinking problems. An explanation for this result in terms of gender could be that the enrollment of female students in postsecondary education have increased over the years and more of these 
students are pursuing mathematics related careers. The lack of predictive effect of mode of instruction on both factors underlying self-efficacy in mathematics (Mathematical Procedures and Critical Thinking) may have been attributed to the fact that both groups of students were exposed to the same instructional material. That is, both modes of instruction used the same book and ancillaries, which in turn produced the same effect on both groups of students on their beliefs of capabilities to perform mathematical procedures and critical thinking problems. Besides, student's beliefs built over time prior to enrolling in College Algebra may have had an effect as well.

Similarly, it was assumed that mode of instruction would have an influence in the way students would perceive the level of commitment of the teacher in supporting their learning as well as on the degree of concern the teacher would show in students' progress in the course (Encouragement/Discouragement). The findings of this study established that mode of instruction was not a factor that affected student's beliefs about the role of the teacher in their learning. That is, the judgment of those students in the face-to-face classes who perceived that the teacher was helpful and encouraging as well as those students who saw the teacher as negligent and discouraging did not differ to perception of those students who belief they were encouraged or discouraged by their teacher in the hybrid classes. As previously elaborated, the fact that students in both modes of instruction used the same instructional materials may have led to a similar effect on both groups of students on their judgements about the effect of the instructor in their classroom.

The analysis of mediator variables showed that Mathematical Procedures mediated the relationship between Encouragement and Satisfaction as well as the 
relationship between Discouragement and Satisfaction. Most of the effect of Encouragement and Discouragement on Satisfaction was primarily direct. However, a portion of the effect of Encouragement and Discouragement on Satisfaction was indirect through Mathematical Procedures. As previously expressed students with both high and low expectations from their teacher perceived themselves as driven to solve mathematics procedural problems. This result is not an unusual outcome for those students that felt motivation and support from their teachers to further their learning. It is also not unusual to have experienced satisfaction when working on some mathematics problems for those students who found no support from their teachers because mathematics procedural problems were a content that students were likely exposed at in previous mathematics courses. Consequently, the findings suggest that the partial mediating effect of Mathematical Procedures can be attributed to the fact that those students who perceived encouragement from the teacher as well as those students who perceived neglect from the teacher had high expectations in solving mathematics problems that they were familiar with such as the problems using mathematical procedures. Under this sense of comfort, it is likely that students improved their beliefs of course satisfaction.

Findings in this study are in alignment with results from previous research studies. Wheeler and Montgomery (2009) established the role of the teacher in student's mindset. In a study that explored student's subjective views toward mathematics, Wheeler and Montgomery found three types of mathematics learners. The first group was that of the active learners who perceived that they could perform well based on their potential despite negative experiences and not being excited about mathematics. It appears that these students were most often taught using traditional techniques of 
instruction. Wheeler and Montgomery also found that skeptical learners were those students who believed that the teacher plays an important role in their success. These students blamed the teacher for their poor performance. The third type of mathematics learner included the confident learners. Those students were mathematics-oriented and did not refrain from persisting in achieving success. Those students in the confident learners believed the instructor's role was crucial in fostering meaningful learning experiences and nurturing their positive attitude toward mathematics. These findings indicate the instructors' influence in molding students' beliefs and self-efficacy in mathematics (Wheeler \& Montgomery, 2009).

Aldridge, Afari, and Fraser (2013) found mixed results but of a different nature in a study that investigated the effect of learning environment on students' attitudes in college mathematics. Contrary to results in this study, Aldridge et al. (2013) found that teacher's support was not a significant predictor of academic efficacy. Despite not being a statistically significant relationship, teacher's support did account for a significant amount of the variance of enjoyment of mathematics. According to Aldridge et al. (2013), students who received more support from their instructors showed higher enjoyment when learning mathematics.

Students with different background experiences in mathematics enroll in colleges and universities. For some students, their first mathematics class is a remedial course while other students are ready to enroll in college level mathematics courses (Dogbey, 2010; Hood, 2012). Still the effect of teacher's strategies on students' beliefs and success is critical in both cases (Hall \& Ponton, 2005; Wheeler \& Montgomery, 2009). 
Students build their judgements about the effectiveness of their teachers in their progress in mathematics from all forms of feedback. The importance of feedback was established in a study by Rakoczy, Harks, Klieme, Blum, and Hochweber (2013) that compared the effect of two forms of feedback in mathematics on the development of interest and achievement. The two forms of feedback included process-oriented feedback (written feedback that informs students about their performance in mathematics so that they overcome learning challenges) and social comparative feedback (feedback based on grades of students in an assessment). One of the goals of Rakoczy et al. study was to compare which of the two forms of feedback, process-oriented feedback or socialcomparative feedback, had a more positive effect on the development of student's interest and achievement in mathematics. They also analyzed which of the two forms of feedback had a more positive indirect effect "on the development of interest and achievement via perceived usefulness support and perceived usefulness than social-comparative feedback" (p. 66). In the context of the study of Rakoczy et al., perceived competence support represented the support students needed for becoming competent. Perceived usefulness was that feedback "perceived as useful for cognitive and behavioral adaptive reactions". Findings from the analysis of the direct effect indicated that there was not a significant difference between forms of feedback as both forms of feedback had a positive effect on interest and achievement development. That is, process-oriented feedback was not a better form of feedback when compared to social comparative feedback in developing either interest and achievement in mathematics in any of the models. However, there was a more positive indirect effect of process-oriented feedback on the development of student's interest in mathematics mediated by perceived competence support when 
compared to the effect of social comparative feedback (Rakoczy et al., 2013). This result indicates that students saw process-oriented feedback as a more effective strategy for competence support when compared to social comparative feedback that in turn enhanced their interest but not their achievement. Rakoczy et al. found an indirect effect of processoriented feedback on the development of student's interest and achievement in mathematics via usefulness, effect not found from comparative feedback (Rakoczy et al., 2013). Students perceived process-oriented feedback as more useful than social comparative feedback in enhancing both their interest and achievement toward mathematics.

The no significant differences found in Rakoczy et al. on the comparison about what form of feedback, process-oriented feedback or social-comparative feedback, produced more positive direct effect on interest and achievement in mathematics remarks a key role of providing feedback. All form of feedback, if effectively delivered, may provide an opportunity that helps students to improve their skills and find usefulness of learning mathematics. From this perspective, Rakoczy et al. findings support findings in the present study. In this study those students who found encouragement were able to experience more satisfaction in mathematics and attributed greater importance to learning this subject that those students who expressed feelings of neglect from the teacher, regardless mode of instruction.

Calderon, Ginsberg, and Ciabocchi (2012) addressed the effect of feedback on students' satisfaction in blended courses in a private university. Most students in the study of Calderon et al. were female students (more than 80\%). Calderon et al. found that students identified flexibility to complete course assignments from anywhere and anytime 
as the main reason for preference of hybrid courses over face to face courses. Overall, students expressed their satisfaction with blended courses as an alternative for learning. These students pointed out that flexible schedule to learn at their own pace and communication with peer students and the instructor meetings emerged as the most effective features of blended courses for students' preferences to enroll in blended courses. Additionally, students indicated that satisfaction in blended learning was a direct function of availability of resources to support instruction. In fact, sufficiency of resources for blended learning emerged as the best predictor of students' satisfaction (Calderon et al). The present study found no differences between the levels of satisfaction of those students in hybrid classes with respect to the level of satisfaction experienced by those students in the face-to-face classes. Such results in this study do not contradict the findings in the study of Calderon et al. Calderon et al. did not compare beliefs of satisfaction across modes of instruction. Calderon et al. collected judgements regarding student's experiences in blended vs. face-to-face courses only in a group of students enrolled blended curses. It is important to remark that the difference of students who reported that had taken hybrid courses in the past in this study was more than $16 \%$, favoring the students in the hybrid group. However, hybrid students in this study reported higher level of importance to learning mathematics. It is possible that the benefits blended courses offered to hybrid students in this study (flexibility of schedule) was the reason that led students in the hybrid instructional mode to express higher levels of importance.

Kesici and Erdogan (2009) examined the effect of self-efficacy for learning and performance as a measure of motivational beliefs on mathematics anxiety. Kesici and 
Erdogan reported that self-efficacy for learning and performance was a factor of motivational beliefs that accounted for a significant amount of the variance of mathematics anxiety. Kesici and Erdogan's (2009) finding indicates that perceived selfefficacy, as a form of motivational belief, has a direct effect in reducing negative attitudes toward learning mathematics such as anxiety. The predictive effect of Mathematical Procedure on both Satisfaction and Importance in this study is congruent with Kesici and Erdogan's study.

Motivational beliefs are even more crucial in the case when learning involves reduction in the direct contact with the teacher as it is the case of hybrid learning. Less direct contact with the teacher is an intrinsic characteristic in hybrid learning, students are more independent. Therefore, the teaching orientation in a hybrid mode of instruction demands a different dynamic than in regular face-to-face courses. Rather than lecturing, the teaching orientation in hybrid classes during the face-to-face meeting time should focus on clarifying those conceptual gaps students could not tackle themselves in the time allocated for individual or group learning online. In a study that explored factors influencing student success in online mathematics courses at community colleges, Lee (2011) found that contact between students and faculty was a strong indicator of students' success. According to Lee, wise use of the academic resources higher institutions provide to support education in mathematics courses that rely strongly in technology can enhance students' experiences in mathematics courses. This resource "allows the instructors and students to work together on the discussion board" (Lee, 2011, p. 107). On this note, it is possible that the academic resources implemented in the higher education institution this 
study used rendered positive effect in students that in turn enhance student's perspective regarding the usefulness of learning mathematics.

Peters (2013) conducted a study that analyzed the relationship among classroom climate, self-efficacy, and achievement in a sample of College Algebra students. A larger proportion of students in the sample were female students $(58.5 \%)$ and about $60 \%$ of students in the sample were White students. As expected, higher self-efficacy was associated with higher performance. Contrary to findings in the present study, classroom climate was a significant predictor of self-efficacy favoring those classrooms that adopted teacher-center learning. The finding of the present study regarding no significant effect of mode of instruction (face-to-face vs. hybrid) on any of the measures of self-efficacy (Mathematical Procedures, Critical Thinking) indicates that there was homogeneity of instruction across learning mode as it appears from students' responses.

Peters (2013) found an association between gender and self-efficacy. According to Peters, "boys reported higher mathematics self-efficacy than girls" (p.459). Conversely, the present study found no differences regarding beliefs of self-efficacy across gender. This result may be related to the fact that colleges have been receiving more female students willing to pursue mathematics-related careers. Clutts (2010) found a similar result in a study that investigated the predictive effect of gender, among other variables, on self-efficacy toward mathematics in a sample of unspecified ethnic composition. Clutts found no association between gender and self-efficacy toward mathematics; however, this result was too close to call it as conclusive. Clutts recommended conducting additional studies evaluating the relationship between gender and self-efficacy as the $p$ value in his analysis was close enough to the threshold value of 
.05. From this perspective, the present study contributes to clarifying the relationship between gender and self-efficacy in mathematics as it is in agreement with Clutts finding. Additionally, the present study explicitly includes the ethnic composition of the sample. It adds meaningful information that corroborates findings in previous studies.

Clute (1984) examined the effect of "direct instruction discovery" (studentcentered learning) and "direct instruction expository" (instructor-centered learning) to explore mathematics anxiety, instructional method, and achievement using a survey course that covered problem solving and critical thinking in mathematics in higher education. Clute found a significant interaction between level of anxiety and instructional method. As an average, students with low and medium level of anxiety performed better in mathematics in the direct instruction discovery group, while students with higher levels of mathematics anxiety performed, as an average, better in the direct instruction expository method. Results like this may be taken into consideration when planning resources that provide assistance and support that fill in the learning demands of a wide range of students as well as when advising students about the appropriate mode of learning that satisfies their needs. This study does not directly support the findings in the study of Clute regarding the association between anxiety in mathematics and achievement in mathematics as achievement in mathematics was not in the scope of this study. However, this study found that those students who perceived lack of support from the instructor were the same students who showed higher beliefs of mathematics apprehension, regardless the instructional mode they chose to enroll at. From this perspective, results in this study align with Clute's findings. Both studies, Clute's and this study, point out that feelings anxiety and apprehension may interfere in student's 
progress and performance. At present, there is no indication that higher education institutions will reduce the offering of hybrid instruction. Rather, there is an increase in both the offering and enrollment in hybrid courses across academic disciplines (Means, Toyama, Murphy, \& Bakia, 2013). In fact, hybrid instruction has reduced the offering of face-to-face instruction. On the other hand, face-to-face instruction is still a popular mode of instruction among those students who enjoy and need frequent contact with the teacher. Consequently, it is imperative that institutions provide a repertoire of instructional strategies that ease student's distress when learning mathematics.

Findings in the present study fill in the gap on the existing research on students' beliefs toward mathematics in postsecondary education. These findings not only provide insights on the perceptions students from Hispanic origins hold about dimensions underlying teacher's effect in the mathematics classroom, self-efficacy in mathematics, and attitudes toward mathematics, but also provides a picture about beliefs of students in higher education in a context specific setting in mathematics. While previous research studies have focused on using achievement as the primary indicator for success in mathematics, this study used Bandura' self-efficacy theory as the framework to examine the dynamic of judgments around the learning of mathematics in a context specific setting from the perspective of college students at present in areas that were not yet explored. Bandura (1997) stated that performance itself does not offer a reliable measure of the capability an individual has to complete a task. On the contrary, self-efficacy captures better the actual judgments of capability a person has to carry out an activity "because efficacy judgments encompass more information than just the executed action" (Bandura, 1997, p. 81). Further Bandura remarks that judgments of self-efficacy are to be 
measure when performing a specific task. This study followed these principles of Bandura's self-efficacy theory as a response to close the gap in the academic literature regarding self-efficacy in mathematics in higher education.

Rather than capturing general beliefs about mathematics, this study collected student's views about their self-efficacy to accomplish mathematics problems in the specific context of College Algebra. To the knowledge of the researcher, no previous study has explored beliefs of self-efficacy in mathematics in public minority-serving postsecondary institutions. In the same way, no previous study has analyzed the interrelationship among self-efficacy in mathematics, teacher's effect in mathematics, and attitudes toward mathematics in the population of concern of this study. The application of fundamental principles of Bandura's self-efficacy theory in this study led to obtaining student's judgments on their capabilities to perform mathematics problems that map with the content of the College Algebra course. It is essential to know what our student's beliefs are beyond the secondary level. Knowing student's perception about their efficacy to learn mathematics, perceptions of the effect of external factors such as the influence of the teacher in their learning, perceptions of the value they attribute to learn mathematics, as well as the dynamic of the relationship of these perceptions is crucial when developing resources that support education in traditional and emerging instructional modalities. 


\section{Implications}

It is important to understand better the mathematics experiences of college students from minority groups (Hispanics, Blacks, and others). Many of them are not succeeding at mathematics at this academic level and consequently do not complete college education (NCES, 2015; Ross, Kena, Rathbun, KewalRamani, Zhang, Kristapovich, Manning, \& National Center for Education Statistics, 2012; Villarreal, \& Cabrera, 2012). More effective instructional strategies can be developed with a deeper understanding of the relationships between students' perceptions regarding the role they attribute to the mathematics teacher in their learning, the judgments of their self-efficacy to solve mathematics problems, and their attitudes toward mathematics as expressed in various aspects such as their belief of satisfaction, importance, and mathematics apprehension.

The findings from this study are useful to the community of postsecondary educators, academic program developers, instructional modality designers, and administrators as they provide valuable feedback about student's mathematics-related beliefs of a population not commonly included in research studies. It is also valuable for curriculum specialists who look for developing academic programs that foster students' learning engagement, course satisfaction, and retention. The complexity that flows out from the findings in this study should be interpreted as an invitation for educators and administrators to plan offering opportunities as alternative to those in-class activities that help students strengthen their judgment of self-efficacy and their abilities to successfully complete mathematics tasks. The implications for practice of the findings of the current 
study impact not only the population of students of the interest in this study but to every student enrolled in higher education.

High failure rate in mathematics at undergraduate level across U.S. has reach epidemic proportion (Bargagliotti, Botelho, Gleason, Haddock, \& Windsor, 2012). Poor performance in mathematics has become a hardship that affects students enrolled in all modes of instruction. Therefore, there is an urgency of adopting interventions that facilitate student's success in mathematics and the completion of their academic program. Extracurricular activities can be developed so that students expand their experiences in mathematics beyond the classroom. These extracurricular activities should be available to students from all instructional modalities and may be conducted throughout clubs that offer academic support and mentoring. Higher education institutions may adopt mentoring programs using students learning assistants. Learning assistants are usually those skillful students who perform at a high level in a discipline. Learning assistants can adopt peer students with low self-efficacy and attitudes in mathematics. Learning assistants may guide peer students in need to release the stress and anxiety they feel toward mathematics.

Mathematics departments can hold monthly meetings that gather students and faculty in informal conversations to reflect on ways to overcome failure in mathematics. In these meetings, faculty and learning assistants can present simple applications of mathematics to solve daily life situations. The efforts to enhance student's experience in mathematics should not neglect an instructional modality to favor another. The increase in the offering of web-based courses is a fact (Means, Toyama, Murphy, Bakia, \& Jones, 2009; Means, Toyama, Murphy, \& Bakia, 2013). Additionally, there is no indication that 
face-to-face instruction will be eliminated. Both type of instructional modalities in mathematics are in demand and as such the needs of student's beliefs should be addressed.

Another way to boost student's beliefs toward mathematics may include offering one-on-one tutoring sessions that serve as an incentive for those students who would like overcome failure barriers in mathematics but who are trapped on negative experience over years of mathematics instruction. On-campus and virtual laboratories at student's disposal during the whole academic term can assist students not only on clarifying mathematics conceptual gaps but to encourage them to attempt further application problems in mathematics. This in turn may increase student's belief on their efficacy to achieve in mathematics and reverse the lack of attitude toward the subject Czaplewski (2014) found in his courses.

Besides, mathematics educators should diversify course requirements so that student's performance does not rely significantly on exams. This study found that students under hybrid learning attributed more importance to learn mathematics than those students in the face-to-face classes. This result may be caused because students in hybrid classes were required to complete a quiz prior to attending to face-to-face meeting. Consequently, mathematics educators may consider using assignments such as warm-up activities, conceptual homework, and video reflections to reinforce student's skills and self-efficacy in mathematics. With warm-up activities students have an initial interaction with the content where they explore by themselves the basic ideas of a theme. Conceptual homework can be assignments that include more in-depth reflection questions and intended to reinforce student's mastering of concepts. Video reflection may be that 
assessment that allows students to apply what they have learned to solve real life problems.

Another useful strategy to expand student's mindset toward mathematics and increase their interest toward the subject could be the implementation of interdisciplinary learning communities. These activities could help students appreciate usefulness of learning mathematics for their future. Class project assignments that allow students working independent and in groups outside class on developing connections between mathematics and areas of interest related to student's majors may serve as a tool that strengthens their self-efficacy beliefs toward mathematics. At the same time class project assignments may become the tool that builds in students a sense of value toward learning mathematics.

Special attention need to be directed to assist mathematics educator in enhancing their pedagogical skills beyond the point of delivering course content. College and university instructors spend a great deal of their time preparing lectures and/or conducting research. Being a knowledgeable instructor is not a guarantee for exhibiting effective teaching. Higher education instructors and learning assistants rarely receive professional development training on pedagogical strategies that furnish them with skills to comply with commonly ambitious course coverage at the same time of meeting the needs of diverse learning style. Research studies have addressed the need of providing training in pedagogy need to be a vital component for those willing to teach in higher education institutions (Robinson \& Hope, 2013).

Robinson and Hope (2013) examined the judgments of college and university professors about the need of including pedagogical training for higher education 
prospective instructors. Most participants in the study of Robinson and Hope expressed favorable comments toward the need for including some type of training in pedagogy either through academic courses or workshops that provides "a lot of practical examples". As a result, the current study recommends offering regular professional development training on pedagogical tools to both all mathematics faculty. Faculty from education school may assist in planning and delivering the professional development training sessions.

These efforts can be useless if proper funding is not available to sustain them. Consequently, the implications for practice must also concern those who make decisions on how to spend financial resources in education. Higher education need to prioritize providing equal access to instructional resources to all students. One way to achieve this goal is through developing a partnership alliance with publisher companies that helps those disenfranchised students with limited access to financial resources and/or who lack funding to have access to technological resources so that they can function as other students. Additionally, state and federal legislators should put close attention to the needs of the emergent population of students that is eager to have the same learning opportunities as of those traditionally represented in research studies. Official in charge of assigning, managing, and distributing education budget have the responsibility to ensure that education is not a privilege but a right. Bureaucrats who dictate education policy need to promote inclusion in higher education regardless income level, social, and/or racial background so that "the traditional value of a college degree in the United States" is not just a slogan. 
With the proliferation of diverse learning modes that respond to the needs of different learners, the findings of this study indicate a need for further research in several areas. This study found that both factors underlying self-efficacy in mathematics, judgments of capabilities of performing mathematical procedures and critical thinking, were identified as predictors of beliefs of satisfaction in mathematics. Further mode of instruction and both factors underlying self-efficacy in mathematics significantly predicted judgments of importance toward learning mathematics. These results provide empirical evidence that supports the central role of self-efficacy in Bandura's social cognitive theory (SCT). Bandura (1997) remarks that judgments of self-efficacy itself are "the key factor of human agency" (p. 3). According to Bandura, self-efficacy captures individuals' capabilities of task accomplishment as no other expectancy belief. The effect of individuals' judgments of their capability to perform mathematics problems that involve mathematical procedures and critical thinking found in this study highlights the role of self-efficacy as an important antecedent of students' attitudes in mathematics.

The evidence this study provides with respect to the predictive effect of the factors underlying self-efficacy toward mathematics on two of the factors underlying attitudes toward mathematics becomes a compelling call to further research studies that expand the knowledge of the effect of students' beliefs about mathematics in their success in college. The explanatory effect of the model used in this study could be enhanced with the addition of variables that account for the effect on student's beliefs about their attitudes toward mathematics. Researchers may consider using variables such as parent's expectations, home support, and peers support as indicators of student's attitudes toward mathematics. Parent's expectations, home support, and peer support 
have been used in the Trends in International Mathematics and Science Study (TIMSS) data collection. Researchers are also encouraged to explore measures addressing factors of the construct of self-efficacy in mathematics that responds to the specific context of present day course offering and technology use. These measures may include items that explicitly refers to solving mathematics problems through using technological devises and software in hybrid instruction.

Gender was not a significant predictor of any of the variables used in the model. A potential explanation for this outcome could be that the number of female students in college has increased over the years as well as more female students have pursued mathematics related careers (NCES, 2010, 2014, 2015). Future research studies can benefit from examining differences among minority male and female students in mathematics. Besides, research studies may use stratified sampling methodology. Stratified sampling methodology is the type of sampling that divides the population in non-overlapping subpopulations or groups, in this case samples from different institutions across the nation, and then sampling from each of the groups. This technique may help to understand the role of gender in mathematics in minority populations because samples from different universities would be collected.

The gap in the number of students who enter higher education and the number of graduates is a fact (U.S. Department of Education, 2009). Mathematics is one of the general education prerequisites that affects student graduation (Bargagliotti, Botelho, Gleason, Haddock, \& Windsor, 2012). This study found that students in hybrid classes attributed more importance to learning mathematics than students in the face-to-face classes. This finding advocates for academic program directors and curriculum designers 
to come up with interventions that create sustainable opportunities for students to function in diverse learning environments. The study also found that encouragement influenced satisfaction, discouragements had an effect on mathematics apprehension, and that both encouragements and discouragement had an effect on importance. Therefore, the interventions described above should provide students with consistent feedback that allows tracking course progress, identifying deficiencies, and opportunities for improvement. Environments in which developing resources that enhance interaction with the instructor, with classmates, and with the course resources is a top priority to enhance the intellectual capacity of students. Environments built on performing tasks that include both comfort and challenge are likely conducive to genuine learning and mastering.

\section{Limitations}

Research studies are not exempt of limitations. Rather than considering limitations as research flaws, pointing them out is an exercise of constructive criticism as it helps to advance research. A limitation of this study was the sampling technique used. This study used a convenience sample of students who are not representative of the population attending most higher education institutions of the nation. Most participants in this study came from Hispanics roots. One of the minority groups with highest representation in American colleges and universities is that of Hispanic students. Despite that, it appears that the presence of Hispanic origins has not reached the level required so that research studies address their educational needs. For this reason, responses from the participants in this study may have not reflected the judgmental representations about 
teacher's effect in the mathematics classroom, self-efficacy in mathematics, and attitudes toward mathematics of college students from other populations.

Another limitation for this study is that students did not declare the major they were pursuing. Most students indicated that they would pursue STEM-related majors. However, not all STEM-related careers involve the same prerequisites in mathematics. Therefore, students may have built their responses about beliefs toward mathematics on their expectations of future course taking in mathematics.

The use of 7 instructors became a factor that produced different types of learning environments. To minimize the effect of using several instructors both the face-to-face and the hybrid classes that participated in this study used the same instructional material and the same assessment system which included the use of e-book, mandatory homework on the same online platform, e-book-based optional homework, four in class exams and an optional final exam. Despite these provisions, each teacher had their own teaching methodology and used different communication approaches in the face-to-face and hybrid courses. These aspects limit the generalizability of the results of this study.

\section{Summary}

This chapter discussed the findings from the Path Analysis that investigated the predictive effect of factors underlying teacher's effect, factors underlying self-efficacy toward mathematics, instructional modality, and gender on factors underlying attitudes toward mathematics. This chapter also addressed the results of the differences of factors underlying attitudes toward mathematics in terms of mode of instruction. Implications for 
theory, research, and practice as well as the limitations of the study were presented in this chapter.

Findings showed significant effects of the prediction variables for most of the paths. Beliefs about encouragement from the teacher and mathematics capability to solve problems that required applying procedures, predicted judgments of satisfaction for being enrolled in College Algebra as well as judgements of the importance students attributed to learning mathematics for their life. Mode of instruction was also a significant predictor of importance. Mathematics apprehension was significantly predicted by discouragement. Perceptions to perform mathematics problems that required applying several procedures was significantly predicted by the combined effect of judgments of encouragement and discouragement from the teacher. Perceptions of being encouraged from the teacher significantly predicted beliefs about performing critical thinking problems in mathematics.

The study produced significant differences in the level of importance students attributed to learning mathematics for their life in terms of mode of instruction. It was found that those students who learned mathematics in the hybrid setting believed that learning and mastering mathematics would become an advantageous factor for their life. Hybrid instruction is a teaching and learning modality that provide flexibility for students to learn at their own pace. Additionally, hybrid instruction depends strongly in the use of technology and requires that students explore and learn by themselves. As technology is a key tool for students mastering course material, hybrid students may have felt more motivation toward learning mathematics than face-to-face students. It is possible that students under hybrid instruction deployed more effort to master concepts and were more 
committed to learning mathematics than face-to-face students. As a result, students in hybrid classes may have understood mathematics concepts better than students in the face-to-face courses. This in turns may have increased hybrid student's importance to learn mathematics at a significantly higher level when compared to students in the faceto-face classes. 


\section{REFERENCES}

Aldridge, J. M., Afari, E., \& Fraser, B. J. (2012). Influence of teacher support and personal relevance on academic self-efficacy and enjoyment of mathematics lessons: A structural equation modeling approach. Alberta Journal of Educational Research, 58(4), 614-633.

Allen, M., Bourhis, J., Burrell, N. \& Mabry, E. (2002). Comparing Student Satisfaction with Distance Education to Traditional Classrooms in Higher Education: A MetaAnalysis. American Journal of Distance Education, 16(2), 83-97.

Allen, M., Mabry, E., Mattrey, M., Bourhis, J., Titsworth, S. \& Burrell, N. (2004). Evaluating the effectiveness of distance learning: a comparison using metaanalysis. Journal of Communication, 54, 3, 402-420.

Altman, J. H. (1997). The relative contribution of antecedent sources to math selfefficacy (Unpublished Doctoral dissertation, University of Illinois at UrbanaChampaign).

Ajzen, I. (1988). Attitudes, personality, and behavior. Chicago: Dorsey Press.

Bandura, A. (1986). Social foundations of thought and action: A social cognitive theory. Englewood Cliffs, NJ: Prentice-Hall.

Bandura, A. (1989). Social cognitive theory. In R. Vasta (Ed.), Annals of child development. Vol. 6. Six theories of child development (pp. 1-60). Greenwich, CT: JAI Press.

Bandura, A. (1993). Perceived self-efficacy in cognitive development and functioning. Educational Psychologist, 28, 117-148.

Bandura, A. (1997). Self-efficacy: The exercise of control. New York: Freeman.

Bandura, A. (1999). Social cognitive theory of personality. In L. Pervin \& John, O. P. (Ed.), Handbook of personality: Theory and research (2nd ed., pp. 154-196). New York: Guilford Publications.

Bandura, A. (2006). Guide for constructing self-efficacy scales. In F. Pajares \& T. Urdan (Eds.), Self-efficacy beliefs of adolescents (pp.1-43). Greenwich, CT: Information Age.

Bandura, A. \& Jourden, F. J. (1991). Self-regulatory mechanisms governing the impact of social comparison on complex decision making. Journal of Personality and Social Psychology, Vol 60(6), Jun 1991, 941-951. http://dx.doi.org/10.1037/00223514.60.6.941. 
Bargagliotti, A., Botelho, F., Gleason, J., Haddock, J., \& Windsor, A. (2012). The Effectiveness of Blended Instruction in Core Postsecondary Mathematics Courses. International Journal for Technology in Mathematics Education, 19(3), 83-94.

Barkley, B. W. (2010). The effects of blended online versus face-to-face learning environments on student outcomes for eighth grade algebra I students (Doctoral Dissertation). Retrieved from ProQuest Digital Dissertations. (AAT 3413019).

Bernard, R. M., Abrami, P. C., Lou, Y., Borokhovsk, E., Wade, A., Wozney, L., \& Huang, B. (2004). How Does Distance Education Compare with Classroom Instruction? A meta-analysis of the empirical literature. Review of Educational Research, 74(3), 379-439.

Birgan, L. J. (2010). The effects of multimedia technology on students' perceptions and retention rates in mathematics at a community college. (Doctoral Dissertation). Retrieved from ProQuest Digital Dissertations. (AAT 3405887).

Brewer, D. S. (2009). The effects of online homework on achievement and self-efficacy of college algebra students. (Doctoral Dissertation). Retrieved from ProQuest Digital Dissertations. (AAT 3366157)

Calderon, O., Ginsberg, A. P., \& Ciabocchi, L. (2012). Multidimensional assessment of pilot blended learning programs: Maximizing program effectiveness based on student and faculty feedback. Journal of Asynchronous Learning Networks, 16(4), 23-37.

Caputo, M. G. (2010). Undergraduate mathematics students' attitudes towards online mathematics education and achievement in a hybrid calculus course. (Doctoral Dissertation). Retrieved from ProQuest Digital Dissertations. (AAT 3424916)

Champion, J., Parker, F., Mendoza-Spencer, B., \& Wheeler, A. (2011). College algebra students' attitudes toward mathematics in their careers. International Journal of Science and Mathematics Education, 9(5), 1093-1110.

Cheema, J. R., \& Kitsantas, A. (2014). Influences of disciplinary classroom climate on high school student self-efficacy and mathematics achievement: A look at gender and racial-ethnic differences. International Journal of Science and Mathematics Education, 12(5), 1261-1279.

Chemers, M. M., Hu, L., \& Garcia, B. F. (2001). Academic Self-Efficacy and First-Year College Student Performance and Adjustment. Journal of Educational Psychology, 93(1), 55-64. 
Chen, X. \& Soldner, M. (2013). STEM attrition: college students' paths into and out of STEM Fields. Statistical Analysis Report. NCES 2014-001. National Center for Education Statistics and RTI. Retrieved from https://nces.ed.gov/pubs2014/2014001rev.pdf.

Clute, P. S. (1984). Mathematics Anxiety, Instructional Method, and Achievement in a Survey Course in College Mathematics. Journal for Research In Mathematics Education, 15(1), 50-58.

Clutts, D. W. (2010). Mathematics Self-Efficacy of Community College Students in Developmental Mathematics Courses. (Doctoral Dissertation). Retrieved from ProQuest Digital Dissertations. (AAT 3432441).

Czaplewski, J. R. (2014). An Evaluation of Blended Instruction in Terms of Knowledge Acquisition and Attitude in an Introductory Mathematics Course. (Doctoral Dissertation). Retrieved from ProQuest Digital Dissertations. (AAT 3612692).

Day, J. C. \& Bauman, K. J. (2000). Have we reached the top? Educational attainment projections of the U.S. population. Working Paper Series No. 43. Washington, DC: United States Census Bureau, Population Division.

Dawes, John G. (2012). Do data characteristics change according to the number of scale points used? An experiment using 5-point, 7-point and 10-point scales. International Journal of Market Research, 51(1).

DePriter, T. N. (2008). Individual or collaborative learning: An investigation of teaching strategy in the distance learning mathematics classroom. (Unpublished Doctoral dissertation). Morgan State University, Baltimore, MD.

Dogbey, G. (2010). Attitudes of Community College Developmental Students toward Mathematics and Their Perception of Mathematically Intensive Careers. (Doctoral dissertation). (Doctoral Dissertation). Retrieved from ProQuest Digital Dissertations. (AAT 3413027).

Ellington, R. M., \& Frederick, R. (2010). Black high achieving undergraduate mathematics majors discuss success and persistence in mathematics. Negro Educational Review, 61(1), 24.

Fennema, E., \& Sherman, J. A. (1976). Fennema-Sherman Mathematics Attitudes Scales: Instruments Designed to Measure Attitudes Toward the Learning of Mathematics by Females and Males. Journal for Research in Mathematics Education, 7(5), 324-326. 
Field. A. (2009). Discovering statistics using SPSS. Thousand Oaks, CA: Sage.

Furuto, M. (2013). A case study on a diverse college algebra classroom: Analyzing pedagogical strategies to enhance students' mathematics self-efficacy. (Doctoral Dissertation). Retrieved from ProQuest Digital Dissertations. (AAT 3574279).

Gall, M. D., Gall, J. P., \& Borg, W. R. (2007). Educational Research: An introduction. Boston: Pearson/Allyn \& Bacon.

Gecer, A., \& Dag, F. (2012). A Blended Learning Experience. Educational Sciences: Theory and Practice, 12(1), 438-442.

Graf, E. A. (2009). Defining mathematics competency in the service of cognitively based assessment for grades 6 through 8. Research report. ETS RR-09-42. Retrieved from http://www.eric.ed.gov/contentdelivery/servlet/ERICServlet?accno=ED507809

Hackett, G., \& Betz, N. E. (1982). Mathematics self-efficacy expectations, mathematics performance, and the consideration of math-related majors. Retrieved from http://www.eric.ed.gov/contentdelivery/servlet/ERICServlet?accno=ED218089. (ED218089).

Hackett, G., \& Betz, N. E. (1989). An exploration of the mathematics selfefficacy/mathematics performance correspondence. Journal for Research in Mathematics Education, 20(3), 261-273.

Hair, J. F., Black, W. C., Babin, B. J., \& Anderson, R. E. (2010). Multivariate data analysis. Upper Saddle River, NJ: Prentice Hall.

Hall, J. M. \& Ponton, M. K. (2005). Mathematics self-efficacy of college freshman. Journal of developmental education, 28(3), 26-28.

Hamburg, M. (1991). Statistical analysis for decision making. Orlando, FL: Harcourt Brace Javonich.

Haver, W., Small, D., Ellington, A., Edwards, B., Kays, V. and Haddock, J. (2007). College Algebra. In V. Katz (Eds.), Algebra: Gateway to a Technological Future (pp. 33-40). Washington, D.C.: The Mathematical Association of America.

Herriott, S. R., \& Dunbar, S. R. (2009). Who Takes College Algebra? Primus, 19(1), 74-87.

Hodges, C. B. (2009). Self-regulation of learners in an asynchronous university math course. Quarterly Review of Distance Education, 10(2), 233-237. 
Hodges, C. B., \& Kim, C. (2013). Improving college students' attitudes toward mathematics. TechTrends: Linking Research and Practice to Improve Learning,57(4), 59-66.

Hood, O. D. (2012). Differentiated instruction in developmental mathematics classes and achievement of ethnic minority students. (Doctoral Dissertation). Retrieved from ProQuest Digital Dissertations. (AAT 3495148).

Keith, Z. T. (2006). Multiple regression and beyond. Boston, MA: Pearson Education, Inc.

Kesici, S., \& Erdogan, A. (2009). Predicting college students' mathematics anxiety by motivational beliefs and self-regulated learning strategies. College Student Journal, 43(2), 631-642.

Kim, C., \& Keller, M. J. (2010). Motivation, volition and belief change strategies to improve mathematics learning. Journal of Computer Assisted Learning, 26(5), 407-420.

Krishnan, S. (2016). Students' Perceptions of Learning Mode in Mathematics. Malaysian Online Journal of Educational Sciences, 4(2), 32-41.

Krosnick, J. A., \& Fabrigar, L. R. (1997). Designing Rating Scales for Effective Measurement in Surveys. In L. E. Lyberg, P. P. Biemer, M. Collins, E. de Leeuw, C. Dippo, N. Schwarz, D. Trewin (Eds.), Survey Measurement and Process Quality (141-164). New York: John Wiley.

Joët, G., Usher, E. L., \& Bressoux, P. (2011). Sources of self-efficacy: An investigation of elementary school students in France. Journal of Educational Psychology, 103(3), 649-663.

Langenfeld, T. E., \& Pajares, F. (1993). The mathematics self-efficacy scale: A validation study. Retrieved from http://www.eric.ed.gov/contentdelivery/servlet/ERICServlet?accno=ED364413.

Lee, L. S. (2011). Success of online mathematics courses at the community college level. (Doctoral Dissertation). Retrieved from ProQuest Digital Dissertations. (AAT 3495148)

Lee, J., \& Paek, I. (2014). In search of the optimal number of response categories in a Rating scale. Journal of Psychoeducational Assessment, 32(7), 663-673. 
Li, W., Lee, A. M., \& Solmon, M. A. (2005). Relationships among Dispositional Ability Conceptions, Intrinsic Motivation, Perceived Competence, Experience, Persistence, and Performance. Journal of Teaching in Physical Education, 24(1), 51-65.

Lim, S. Y., \& Chapman, E. (2013). Development of a short form of the attitudes toward mathematics inventory. Educational Studies in Mathematics, 82(1), 145-164.

Lissitz, R. W., \& Green, S. B. (1975). The effect of the number of scale points on reliability: A Monte Carlo approach. The Journal of Applied Psychology, 60, 10-13.

Liu, X., \& Koirala, H. (2009). The effect of mathematics self-efficacy on mathematics achievement of high School students. Northeastern Educational Research Association (NERA) Annual Conference, University of Connecticut. Retrieved from

http://digitalcommons.uconn.edu/cgi/viewcontent.cgi $?$ article $=1029 \&$ context $=$ nera -2009.

Lorah, J. \& Ndum, E. (2013). Trends in achievement gaps in first-year college courses for racial/ethnic, income, and gender subgroups: a 12-year study. ACT Research Report Series 2013 (8). Retrieved from http://209.235.214.158/research/researchers/reports/pdf/ACT_RR2013-8.pdf.

Lou, Y., Bernard, R. M., \& Abrami, P. C. (2006). Media and Pedagogy in Undergraduate Distance Education: A Theory-Based Meta-Analysis of Empirical Literature. Educational Technology Research \& Development, 54(2), 141-176.

Ma, X., \& Kishor, N. (1997). Assessing the relationship between attitude toward mathematics and achievement in mathematics: A meta-analysis. Journal for Research in Mathematics Education, 28(1), 26-47. doi:http://dx.doi.org.ezproxy.fiu.edu/10.2307/749662

Majeed, A. A., Darmawan, I. G. N., \& Lynch, P. (2013). A confirmatory factor analysis of Attitudes Toward Mathematics Inventory (ATMI). The Mathematics Educator, 15(1), 121-135.

Means, B., Toyama, Y., Murphy, R., Bakia, M., \& Jones, K. (2009). Evaluation of evidence-based practices in online learning: A meta-analysis and review of online learning studies. Retrieved from http://www.eric.ed.gov/contentdelivery/servlet/ERICServlet?accno=ED505824

Means, B., Toyama, Y., Murphy, R. F., \& Bakia, M. (2013). The effectiveness of online and blended learning: a meta-analysis of the empirical literature. Teachers College Record, 115(3). 
Meyers, L. S., Gamst, G., \& Guarino, A. J. (2013). Applied multivariate research: Design and interpretation. Thousand Oaks, CA: Sage.

Munce, R. \& Fraser, E. (2013). Where are the STEM Students? What are their Career Interests? Where are the STEM Jobs? My College Options \& Stem Connector. Cisco. Retrieved from http://www.dailyherald.com/assets/PDF/DA127758822.pdf.

National Center for Education Statistics (2015). Condition of Education. Washington, DC: U.S. Department of Education. Retrieved from https://nces.ed.gov/pubsearch/pubsinfo.asp?pubid=2015144.

National Center for Education Statistics (2014). Condition of Education. Washington, DC: U.S. Department of Education. Retrieved from http://nces.ed.gov/pubs2014/2014083.pdf.

National Center for Education Statistics (2010). Condition of Education. Washington, DC: U.S. Department of Education. Retrieved from http://nces.ed.gov/pubs2010/2010028.pdf.

Nordstrom, D. E. (2012). Motivational, parental, and cultural influences on achievement and persistence in basic skills mathematics at the community college. Doctoral Dissertation). Retrieved from ProQuest Digital Dissertations. (AAT 3513821).

Nunez-Pena, I., Suarez-Pellicioni, M., \& Bono, R. (2013). Effects of mathematics anxiety on student success in higher education. International Journal of Educational Research, 58, 36-43.

Obama, B. (2015). Remarks by the President, Secretary Arne Duncan, and Dr. John King in Personnel Announcement. Retrieved from https://www.whitehouse.gov/thepress-office/2015/10/02/remarks-president-secretary-arne-duncan-and-dr-johnking-personnel.

O'Reilly, R. (1975). Classroom climate and achievement in secondary school mathematics classes. Retrieved from http://www.eric.ed.gov/contentdelivery/servlet/ERICServlet?accno=ED101473

Paden, R. (2006). A comparison of student achievement and retention in an introductory math course delivered online, face-to-face, and blended modalities (Unpublished Doctoral dissertation). Capella University, MN. 
Pajares, F. (2006). Self-efficacy beliefs during adolescence: Implications for teachers and parents. In F. Pajares \& T. Urdan (Eds.), Adolescence and education. Vol. 5: Selfefficacy beliefs of adolescents (pp. 339-367). Information Age Publishing: Greenwich, CT.

Pajares, F., \& Miller, M. D. (1994). Role of Self-Efficacy and Self-Concept Beliefs in Mathematical Problem Solving: A Path Analysis. Journal Of Educational Psychology, 86(2), 193-203.

Pajares, F., \& Kranzler, J. (1995). Role of self-efficacy and general mental ability in mathematical problem-solving: A path analysis Retrieved from http://www.eric.ed.gov/contentdelivery/servlet/ERICServlet?accno=ED387342

Parker, M. (2004). Placement, retention, and success: A longitudinal study of mathematics and retention. Journal of General Education, 54(1), 22-40.

Peters, M. L. (2013). Examining the relationships among classroom climate, selfefficacy, and achievement in undergraduate mathematics: A multi-level analysis. International Journal of Science and Mathematics Education, 11(2), 459-480.

Phipps, R., \& Merisotis, J. (1999). What's the difference? A review of Contemporary Research on the Effectiveness of Distance Learning in Higher Education. The Institute for Higher Education Policy. Retrieved from http://www.nea.org/assets/docs/HE/WhatsTheDifference.pdf

Rakoczy, K., Harks, B., Klieme, E., Blum, W., \& Hochweber, J. (2013). Written feedback in mathematics: Mediated by students' perception, moderated by goal orientation. Learning and Instruction, 27, 63-73.

Ren, L., Green, J. L., \& Smith, W. M. (2016). Using the fennema-sherman mathematics attitude scales with lower-primary teachers. Mathematics Education Research Journal, 28(2), 303-326.

Robinson, T. E., \& Hope, W. C. (2013). Teaching in Higher Education: Is There a Need for Training in Pedagogy in Graduate Degree Programs? Research in Higher Education Journal, 21

Ross, T., Kena, G., Rathbun, A., KewalRamani, A., Zhang, J., Kristapovich, P., Manning, E. \& National Center for Education Statistics. (2012). Higher education: gaps in access and persistence study. Statistical Analysis Report. NCES 2012-046. Retrieved from http://www.eric.ed.gov/contentdelivery/servlet/ERICServlet?accno=ED534691 
Russell, T. L., (1999). The no significant difference phenomenon. Raleigh: North Carolina State University, Office of Instructional Telecommunications.

Ruseffendi, E. T. (1986). A comparison of participation in mathematics of male and female students in the transition from junior to senior high school in West Java. (Unpublished Doctoral dissertation). Ohio: The Ohio State University.

Simonson, M. R., Smaldino S., Albright, M., Zvacek, S. (2012). Teaching and learning at a distance: Foundation of Distance education. $\left[5^{\text {th }}\right.$ Ed.]. Boston, MA: Pearson.

Schunk, D. H., \& Meece, J. L. (2005). Self-Efficacy Development in Adolescences. In T. Urdan \& F. Pajares (Eds.), Self-Efficacy Beliefs of Adolescents (pp. 71-96). Greenwich, CT: Information Age Publishing.

Schunk, D. H. \& Pajares, F. (2002). The Development of Academic Self-Efficacy. In A. Wigfield \& J. Eccles (Eds.), Development of achievement motivation. San Diego: Academic Press.

Schoenfeld, A.H. (1992). Learning to think mathematically: Problem solving, metacognition, and sense making in mathematics. In D. Grouws (Ed.), Handbook for research on mathematics teaching and learning. (pp.334-370). New York, NY: Macmillan.

Schoenfeld, A. H. (1985). Mathematical problem solving. Orlando, FL: Academic Press.

Smith, G. J., \& Suzuki, S. (2015). Embedded blended learning within an algebra classroom: A multimedia capture experiment. Journal of Computer Assisted Learning, 31(2), 133-147.

Stevens, T., Olivarez, A., Lan, W. Y., \& Tallent-Runnels, M. (2004). Role of mathematics self-efficacy and motivation in mathematics performance across ethnicity. Journal of Educational Research, 97(4), 208.

Tabachnick, G., \& Fideel, L., S. (2007). Using multivariate statistics. Boston: Pearson/Allyn \& Bacon.

Tapia, M. (1996). The attitudes toward mathematics instrument. Retrieved from http://files.eric.ed.gov/fulltext/ED404165.pdf.

Tapia, M., \& Marsh, G. E. (2002). Confirmatory factor analysis of the attitudes toward mathematics inventory. Retrieved from http://www.eric.ed.gov/contentdelivery/servlet/ERICServlet?accno=ED471301. 
Tapia, M., \& Marsh, G. E., II. (2004). An instrument to measure mathematics attitudes. Academic Exchange Quarterly, 8(2), 16-21. Retrieved from http://www.rapidintellect.com/AEQweb/cho253441.htm.

Thompson, B., Melacon, J. G., Becnel, S. (1993). Measurement Integrity of Scores from the Fennema-Sherman Mathematics Attitudes Scales: The Attitudes of Public School Teachers. Retrieved from http://www.eric.ed.gov/contentdelivery/servlet/ERICServlet?accno=ED356245.

Triola, M. F. (2001). Elementary Statistics. New York, N.Y.: Addison Wesley Longman.

Thirunarayanan, M. O., \& Perez-Prado, A. (2001). Comparing Web-based and classroom-based learning: a quantitative study. Journal of Research on Technology in Education, 34(2), 131-137.

U.S. Department of Education (2009). Speeches: Under Secretary Martha Kanter's Remarks to the New England Board of Education. Retrieved from http://www2.ed.gov/news/speeches/2009/10/10262009.html.

Usher, E. L. \& Pajares, F. (2009). Sources of self-Efficacy in mathematics: a validation study. Contemporary educational psychology, 34(1), 89-101.

Villarreal, R. C. \& Cabrera, A. F. (2012). Charting a Course towards Latino Student Success in Science, Technology, Engineering and Mathematics. Manuscript prepared for the HACU Hispanic Higher Education Research Collective, (H3ERC). Retrieved from https://www.hacu.net/images/hacu/OPAI/H3ERC/2012_papers/Villarreal\%20cabr era $\% 20$ friedrich $\% 20-\% 201$ atino $\% 20$ student $\% 20$ success $\% 20 \mathrm{in} \% 20$ stem $\% 20$ $\% 20$ updated\%202012.pdf.

Vilorio, D. (2014). STEM 101: Intro to tomorrow's jobs. U.S. Department of Labor. Retrieved from http://www.bls.gov/careeroutlook/2014/spring/art01.pdf

Wakita, T., Ueshima, N., \& Noguchi, H. (2012). Psychological distance between categories in the likert scale: Comparing different numbers of options. Educational and Psychological Measurement, 72(4), 533-546.

Wheeler, D. L., \& Montgomery, D. (2009). Community college students' views on learning mathematics in terms of their epistemological beliefs: A "Q" method study. Educational Studies in Mathematics, 72(3), 289-306.

Zarch M. K., Kadivar P. (2006). The role of mathematics self-efficacy and mathematics ability in the structural model of mathematics performance. WSEAS Transactions on Mathematics, 6, 713-720. 
Zientek, L. R., Yetkiner Ozel, E. Z., Fong, C. J., \& Griffin, M. (2013). Student success in developmental mathematics courses. Community College Journal of Research and Practice, 37(12), 990-1010.

Zimmerman, B. J., Bandura, A., Martinez-Pons, M. (1992). Self-motivation for academic attainment: The role of self-efficacy beliefs and personal goal setting. American Educational Research Journal, 29(3), 663-676.

Zimmerman, B. J. (2000). Self-efficacy: An essential motive to learn. Contemporary Educational Psychology, 25(1), 82-91.

Zimmerman, B. J. (2002). Becoming a self-regulated learner: An overview. Theory into Practice, 41(2), 64-72. 


\section{APPENDIX A}

\section{DEMOGRAPHIC INFORMATION}

\section{Directions:}

Your participation in this study is voluntary. No risks are foreseen from participating in this survey. The researchers will be the only persons that will see your responses. No other individual will have access to your responses. This survey is conducted only for academic purposes. The administrative authorities of your college have reviewed and approved this study.

For items \#1-14, please circle the one choice that corresponds to the best answer.

1. What is your college level?
A) Freshman
B) Sophomore
C) Senior

2. What is your gender?
A) Male
B) Female

3. Which race/ethnicity best describes you?
A) African American or Black
B) Asian American or Asian
C) Caucasian
D) Hispanic or Latino
E) Other

4. What is your age?
A) 25 or under
B) $\quad 26-40$
C) $\quad 41-55$
D) More than 55

5. What is your primary language?
A) English
B) Spanish
C) Other

6. Were you born in the U. S.?
A) Yes
B) $\quad \mathrm{No}$ 
7. If you answered No to question 6, at what school level did you come to the U.S.?
A) Elementary School
B) Middle School
C) High School
D) > High School

8. How many hours do you work a week?
A) 0
B) $1-20$
C) $\quad 21-40$
D) More than 40

9. Have you ever taken a hybrid mathematics class before in college?
A) Yes
B) No

10. What grade did you earn in the last math class you took?
A) $\mathrm{A}$
B) $\mathrm{B}$
C) $\mathrm{C}$
D) $\mathrm{D}$
E) F

11. Expected Grade: What grade do you expect to earn this semester in your current mathematics class?
A) $\mathrm{A}$
B) $\mathrm{B}$
C) $\mathrm{C}$
D) $\mathrm{D}$
E) F

12. How many math remedial courses have you taken in college?
A) 0
B) 1
C) 2
D) 3 or more

13. How far in your education do you expect to go?
A) Associate's degree (2-year college program)
B) Bachelor's degree (4-year college program)
C) Master's degree or professional degree
D) Doctorate

14. If you plan to continue your education, which area do you intend to study?
A) Science, Technology, Engineering, Mathematics (STEM)
B) Non-STEM 


\section{APPENDIX B}

\section{SURVEY DIRECTIONS:}

This document contains a set of statements about your perceptions and judgements of the teacher effect in the mathematics classroom, your self-efficacy in mathematics, and your attitudes toward mathematics. Notice that there are no right or wrong answers to this survey. Answer every question as accurately as possible so that your responses reflect your genuine beliefs. While reading each statement, you will know whether you agree or disagree.

Completing the survey will not take too long, approximately 20 minutes. Just make sure to answer every statement. The only correct responses are those that reflect your beliefs. The survey is anonymous; therefore, you do not need to provide any information that identifies you as a participant.

Your participation in this study is voluntary. No risks are foreseen from participating in this survey. The researcher will be the only persons that will see your responses. No other individual will have access to your responses. This survey is conducted only for academic purposes. The administrative authorities of your college have reviewed and approved this study.

Thanks for your participation. 


\section{APPENDIX C}

\section{Part I The Fennema and Sherman Mathematics Teacher Scale.}

Directions: Please, circle the best option that describes your judgements (beliefs) for the teacher's effect in the mathematics classroom.

Please, use this scale for your responses:
(1) Strongly Disagree
(2) Disagree
(3) Neutral
(4) Agree
(5) Strongly Agree

1. My teachers have encouraged me to study more mathematics. $\begin{array}{llllll}\mathbf{1} & \mathbf{2} & \mathbf{3} & \mathbf{4} & \mathbf{5}\end{array}$

2. My teachers think I'm the kind of person who could do well in $\begin{array}{llllll}\mathbf{1} & \mathbf{2} & \mathbf{3} & \mathbf{4} & \mathbf{5}\end{array}$ mathematics.

3. My mathematics teachers have been interested in my progress $\begin{array}{llllll}\mathbf{1} & \mathbf{2} & \mathbf{3} & \mathbf{4} & \mathbf{5}\end{array}$ in mathematics.

$\begin{array}{lllllll}\text { 4. I would talk to my mathematics teachers about a career which } & \mathbf{1} & \mathbf{2} & \mathbf{3} & \mathbf{4} & \mathbf{5}\end{array}$ uses math.

5. Mathematics teachers have made me feel I have the ability to $\quad \begin{array}{llllll} & 1 & 2 & 3 & 4 & 5\end{array}$ go on in mathematics.

6. My mathematics teachers encourages me to take the entire mathematics I can.

$\begin{array}{lllll}1 & 2 & 3 & 4 & 5\end{array}$

7. When it comes to anything serious, I have felt ignored when $\quad \begin{array}{llllll} & \mathbf{1} & \mathbf{2} & \mathbf{3} & \mathbf{4} & \mathbf{5}\end{array}$ talking to mathematics teachers.

8. My teachers think advanced mathematics is a waste of time $\quad \begin{array}{llllll} & \mathbf{1} & \mathbf{2} & \mathbf{3} & \mathbf{4} & \mathbf{5}\end{array}$ for me. 
9. Getting a mathematics teacher to take me seriously has usually $\quad \begin{array}{llllll} & \mathbf{2} & \mathbf{3} & \mathbf{4} & \mathbf{5}\end{array}$ been a problem.

10. My teachers would think I wasn't serious if I told them I was $\quad \begin{array}{llllll}\mathbf{1} & \mathbf{2} & \mathbf{3} & \mathbf{4} & \mathbf{5}\end{array}$ interested in a career in science and mathematics.

11. I have found it hard to win the respect of mathematics teachers. $\begin{array}{lllll}1 & \mathbf{2} & \mathbf{3} & \mathbf{4} & \mathbf{5}\end{array}$

12. I have had a hard time getting teachers to talk seriously with $\quad \begin{array}{llllll}\mathbf{1} & \mathbf{2} & \mathbf{3} & \mathbf{4} & \mathbf{5}\end{array}$ me about mathematics. 


\section{APPENDIX D}

Part II The Hackett and Betz Mathematics Self-Efficacy Expectations Scale. (1982)

Directions: Please, circle the best option that describes your judgements (beliefs) about your competence for solving the problems in the self-efficacy toward mathematics.

Please, use this scale for your responses:

(1) No Confidence at all that I can solve it.

(2) Little Confidence at all that I can solve it.

(3) Some Confidence at all that I can solve it.

(4) Much Confidence at all that I can solve it.

(5) Complete Confidence at all that I can solve it.

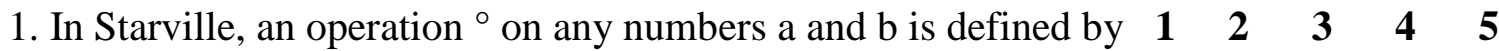
$a^{\circ} b=a x(a+b)$. Then $2^{\circ} 3$ equals ?

2. Sally needs three pieces of poster board for a class project. If the $\begin{array}{lllll}1 & 2 & 3 & 4 & 5\end{array}$ boards are represented by rectangles $\mathrm{A}, \mathrm{B}, \mathrm{C}$, arrange their areas in increasing order. (assume $b>a$ )

A

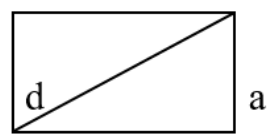

b
B

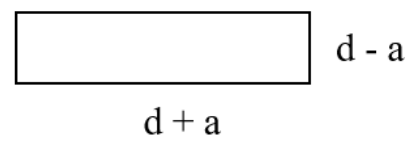

$\mathrm{C}$

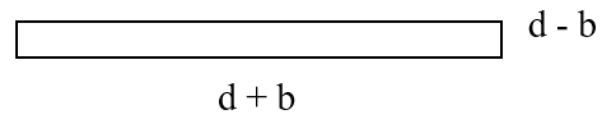

3. The average of three numbers is 30 . The fourth number is at least $\begin{array}{lllll}1 & \mathbf{2} & \mathbf{3} & \mathbf{4} & \mathbf{5}\end{array}$ 10 . What is the smallest average of the four numbers?

4. To construct a table, Michele needs 4 pieces of wood 2.5 feet $\quad \begin{array}{lllll}\mathbf{1} & \mathbf{2} & \mathbf{3} & \mathbf{4} & \mathbf{5}\end{array}$ long for the legs. She wants to determine how much wood she will need for five tables. She reasons: $5 \times(4 \times 2.5)=(5 \times 4) \times 2.5$. Which number principle is she using?

5. The opposite angles of a parallelogram are $?$

6. Five points are on a line. $\mathrm{T}$ is next to G. $\mathrm{K}$ is next to $\mathrm{H}$. C is next $\begin{array}{lllll}\mathbf{1} & \mathbf{2} & \mathbf{3} & \mathbf{4} & \mathbf{5}\end{array}$ 
to $\mathrm{T}$. $\mathrm{H}$ is next to $\mathrm{G}$. Determine the relative positions of the points along the line.

7. There are three numbers. The second is twice the first, and the $\begin{array}{llllll}1 & 2 & 3 & 4 & 5\end{array}$ first is one-third of the other number. Their sum is 48 . Find the largest number.

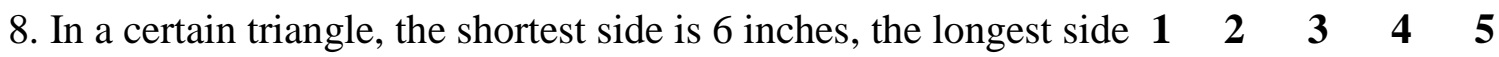
is twice as long as the shortest side and the third side is 3.4 inches

shorter than the longest side. What is the sum of the three sides in inches?

9. The hands of a clock form an obtuse angle at o'clock.

$\begin{array}{lllll}1 & 2 & 3 & 4 & 5\end{array}$

10. Bridget buys a packet containing 9-cent and 13-cent stamps for $\begin{array}{llllll}\mathbf{1} & \mathbf{2} & \mathbf{3} & \mathbf{4} & \mathbf{5}\end{array}$ $\$ 2.65$. If there are 25 stamps in the packet, how many are 13-cent stamps?

11. A living room set consisting of one sofa and one chair is priced $\begin{array}{llllll}\mathbf{1} & \mathbf{2} & \mathbf{3} & \mathbf{4} & \mathbf{5}\end{array}$ at $\$ 200$. If the price of the-sofa is $50 \%$ more than the price of the chair, find the price of the sofa.

12. Write an equation which expresses the condition that "The $\quad \begin{array}{llllll} & \mathbf{1} & \mathbf{2} & \mathbf{3} & \mathbf{4} & \mathbf{5}\end{array}$ product of two numbers $\mathrm{R}$ and $\mathrm{S}$ is one less than twice their sum."

13. Set up the problem to be done to find the number asked for $\quad \begin{array}{lllllll} & \mathbf{1} & \mathbf{2} & \mathbf{3} & \mathbf{4} & \mathbf{5}\end{array}$ in the expression "six less than twice 4?"

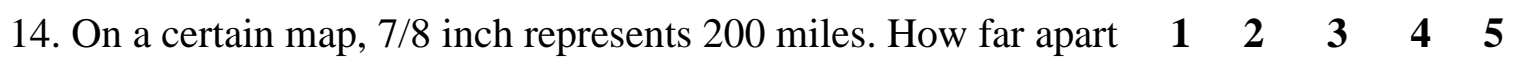
are two towns whose distance apart on the map is $3 \frac{1}{2}$ inches?

15. The formula for converting temperature from degrees Centigrade $\begin{array}{lllll}1 & \mathbf{2} & \mathbf{3} & \mathbf{4} & \mathbf{5}\end{array}$ to degrees Fahrenheit is $F=9 / 5(C+32)$. A temperature of 20 degrees

Centigrade is how many degrees Fahrenheit?

16. $33 / 4-1 / 2=$

$\begin{array}{lllll}1 & 2 & 3 & 4 & 5\end{array}$ 
17. If $3 x-2=16$, what does $x$ equal?

$\begin{array}{lllll}1 & 2 & 3 & 4 & 5\end{array}$

18. Fred's bill for some household supplies was $\$ 13.64$. If he paid $\quad \begin{array}{llllll}\mathbf{2} & \mathbf{2} & \mathbf{3} & \mathbf{4} & \mathbf{5}\end{array}$ for the items with a $\$ 20$, how much change should he receive? 


\section{APPENDIX F}

\section{Part III}

The Lim and Chapman shortened version of the Attitudes Toward Mathematics Inventory.

Directions: Please, circle the best option that describes your judgements (beliefs) for the attitude toward mathematics.

Please, use this scale for your responses:

(1) Strongly Disagree

(2) Disagree

(3) Neutral

(4) Agree

(5) Strongly Agree

1. I have usually enjoyed studying mathematics in school.

2. I like to solve new problems in mathematics.

3. I really like mathematics.

4. I am happier in a mathematics class than in any other class.

5. Mathematics is a very interesting subject.

6. I am confident that I could learn advanced mathematics. mathematics.

7. I am willing to take more than the required amount of

8. I plan to take as much mathematics as I can during my education. $\begin{array}{lllll}1 & 2 & 3 & 4 & 5\end{array}$

$\begin{array}{lllll}1 & 2 & 3 & 4 & 5\end{array}$

$\begin{array}{lllll}1 & 2 & 3 & 4 & 5\end{array}$

$\begin{array}{lllll}1 & 2 & 3 & 4 & 5\end{array}$

$\begin{array}{lllll}1 & 2 & 3 & 4 & 5\end{array}$

$\begin{array}{lllll}1 & 2 & 3 & 4 & 5\end{array}$

$\begin{array}{lllll}1 & 2 & 3 & 4 & 5\end{array}$

$\begin{array}{lllll}1 & 2 & 3 & 4 & 5\end{array}$ 
9. The challenge of mathematics appeals to me.

10. Studying mathematics makes me feel nervous.

11. I am always under a terrible strain in a mathematics class.

12. It makes me nervous to even think about having to do a mathematics problem.

13. I am always confused in my mathematics class.

14. I feel a sense of insecurity when attempting mathematics.

15. Mathematics is a very worthwhile and necessary subject.

16. Mathematics is important in everyday life.

17. Mathematics is one of the most important subjects for people to study.

18. College mathematics lessons would be very helpful no matter $\begin{array}{llllll}\mathbf{1} & \mathbf{2} & \mathbf{3} & \mathbf{4} & \mathbf{5}\end{array}$ what I decide to study in future.

19. A strong mathematics background could help me in my professional life. $\begin{array}{lllll}1 & 2 & 3 & 4 & 5\end{array}$

$\begin{array}{lllll}1 & 2 & 3 & 4 & 5\end{array}$

$\begin{array}{lllll}1 & 2 & 3 & 4 & 5\end{array}$

$\begin{array}{lllll}1 & 2 & 3 & 4 & 5\end{array}$

$\begin{array}{lllll}1 & 2 & 3 & 4 & 5\end{array}$

$\begin{array}{lllll}1 & 2 & 3 & 4 & 5\end{array}$

$\begin{array}{lllll}1 & 2 & 3 & 4 & 5\end{array}$

$\begin{array}{lllll}1 & 2 & 3 & 4 & 5\end{array}$

$\begin{array}{llll} & 3 & 4 & 5\end{array}$

$\begin{array}{lllll}1 & 2 & 3 & 4 & 5\end{array}$ 


\section{MEMORANDUM}

To:

CC:

From:

Date:

Proposal Title:
Dr. Maria L. Fernandez

Nelson De La Rosa

Maria Melendez-Vargas, MIBA, Coordinator

October 3, 2016

"A PATH ANALYSIS EXPLORATION OF TEACHER EFFECT, SELFEFFICACY, AND ATTITUDES TOWARD MATHEMATICS AMONG COLLEGE STUDENTS ATTENDING A MINORITY SERVING INSTITUTION IN FACE-TO-FACE AND HYBRID MATHEMATICS COURSES"

Approval \# IRB-16-0354

Reference \# 104708

The Florida International University Office of Research Integrity has approved the following modification(s):

- Changed the Title of the research project.

There are no additional requirements in regards to your study. However, if there are further changes in the protocol after you commence your study, then you are required to resubmit your proposal for review. For further information, you may visit the FIU IRB website at http://research.fiu.edu/irb. 


\section{MEMORANDUM}

To: Dr. Maria Fernandez

CC: $\quad$ Nelson De La Rosa

From: Maria Melendez-Vargas, MIBA, IRB Coordinator W

Date: September 13, 2016

Protocol Title: "An exploration on the interplay of teacher's effect, self-efficacy, and attitudes toward mathematics in college face to face and hybrid mathematics classes"

The Florida International University Office of Research Integrity has reviewed your research study for the use of human subjects and deemed it Exempt under 46.101(b) (1) of the Common Rule via the Exempt Review process.

IRB Protocol Exemption \#: IRB-16-0354 IRB Exemption Date: 08/29/16 TOPAZ Reference \#: $\quad 104708$

As a requirement of IRB Exemption you are required to:

1) Submit an Event Form and provide immediate notification of:

- Any additions or changes in the procedures involving human subjects.

- Every serious or unusual or unanticipated adverse event as well as problems with the rights or welfare of the human subjects.

2) Submit a Project Completion Report Form when the study is finished or discontinued.

Special Conditions: N/A

For further information, you may visit the IRB website at http://research.fiu.edu/irb.

MMV/em 
Rita Menéndez, Ph.D.

Chair, Institutional Review Board

Phone: (305) 237-7488

FAX: (305) 237-7496

Email: rmenende@mdc.edu

November 8th, 2016

Dear Nelson De La Rosa:

The Miami Dade College's Institutional Review Board has reviewed the research proposal referenced below. On October 31st, 2016 the CASSC Research and Testing Committee also reviewed it and voted to APPROVE the research via the expedited review process.

When gathering participant consent, use the consent forms that are IRB approved. Signed consent forms must be kept in a locked cabinet for three years after completion of your study.

IRB Approval will expire on October 31st, 2017. If more time is needed to collect data, you will need to submit a Change of Study form to request an extension at least 60 days prior to expiration.

You also must submit a Change of Study form if any additions or changes to your procedures or materials arise. All changes must be reviewed and approved by the IRB before they are implemented.

If any adverse event occurs during or as a result of your study, or if problems arise regarding rights or welfare of participants, you must submit an Adverse Event report immediately.

Finally, the committee is very interested in the results of your research. Please provide an executive summary of your findings at the conclusion of your study.

Proposal: DeLaRosa_2016-09-19

Proposal: A path analysis exploration of teacher effect, self-efficacy, and attitudes toward mathematics among college students attending a minority serving institution in face-to-face and hybrid mathematics courses.

Primary Researcher: Nelson De La Rosa (Miami Dade College Faculty/Florida International University)

Best of luck in your research.

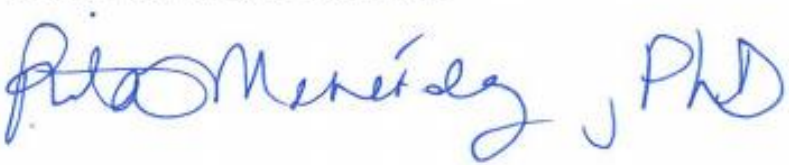

Rita Menéndez, PhD

Chair, Miami Dade College Institutional Review Board

The Mission of Miami Dade College is to change lives through the opportunity of education.

As demacracy's college. MDC provides high-quality teaching and leaming experiences that are accessible and affordable to meet the nceds of our diverse students and prepare them to be responsible glabal citizens and successful lifelong learners. The College embraces its responsibility to serve as an economic, cultural and civic beacon in our community. 


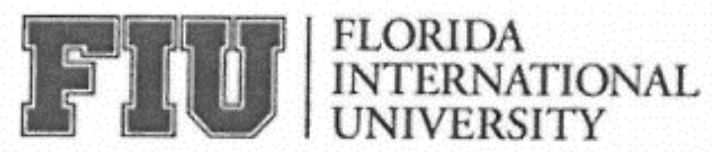

\section{ADULT VERBAL CONSENT TO PARTICIPATE IN A RESEARCH STUDY}

\section{An exploration on the interplay of teacher's effect, self-efficacy, and attitudes toward mathematics in college face-to-face and hybrid mathematics classes.}

Hello, my name is Nelson De La Rosa. You have been chosen at random to be in a research study about your perceptions and judgements of a face-to-face or hybrid College Algebra class. The purpose of this study is to examine the relationship between teacher's effect, self-efficacy, modes of instruction, demographics, and attitudes in the context of College Algebra in face-toface and hybrid learning courses at a minority-serving institution of higher education. Additionally, this study aims to analyze differences in students' attitudes toward College Algebra in both instructional modalities, face-to-face and hybrid learning. If you decide to be in this study, you will be one of 240 people in this research study. Participation in this study will take 30 minutes of your time. If you agree to be in the study, I will ask you to do the following things:

1. Complete each of the parts in the instrument (survey) I will hand out once I read this verbal consent for voluntary participation in this study. The instrument contains four parts and will be completed anonymously. In the first part you will provide general demographic information about yourself. In the second part you will provide inputs on your perceptions and judgements of teacher's effect in mathematics. In the third part you will provide perceptions and judgements of your self-efficacy in mathematics. Finally, in the fourth part you will provide perceptions and judgements of your attitude toward mathematics. Notice that there are no right or wrong answers in any of the questions in part 2 through part 4.

2. Please, place your survey inside the manila envelope above this table once you complete the survey.

All information in each part of this survey will be kept strictly confidential. Only the researcher will have access to the data which will be kept in a locked file cabinet in a locked room. Your identity will remain anonymous since it is not required that you provide any identification marker.

There are no foreseeable risks or benefits to you for participating in this study. It is expected that this study will benefit society by adding to the literature the missing knowledge about beliefs toward mathematics of students from non-traditional populations. The new knowledge this study produces will strengthen the theory and findings around self-efficacy. Additionally, this study will serve as a scaffold for institutions of higher education when developing interventions that enhance students' experiences across teaching and learning modalities in mathematics and will reduce patterns of unequal success in mathematics between racial groups. Additionally, mentoring programs and learning strategies may be developed as a result from the findings in this study. 
There is no cost or payment to you. If you have questions before and/or while taking the instrument, please stop me and ask.

I would like to emphasize that your identity will remain anonymous. In any sort of report where we might publish findings from this study, we will not include any information that will make it possible to identify you as a subject. Research records will be stored securely and only the researcher will have access to the records.

If you have questions for the researcher conducting this study or about the study you may contact Nelson De La Rosa at ndelaro1@mdc.edt or at 305-237-2453.

If you would like to talk with someone about your rights of being a subject in this research study or about ethical issues with this research study, you may contact the FIU Office of Research Integrity by phone at 305-348-2494 or by email at ori@fiu.edu and/or the Institutional Research Board of Miami Dade College (MDC IRB) at IRB@mdc.edu or at 305-237-7488.

Your participation in this research is voluntary, and you will not be penalized or lose benefits if you refuse to participate or decide to stop. You can withdraw from the study at any time, and your grade will not be affected (1) by your decision to participate in the study or not, nor (2) by the information you will provide in the study.

\section{Voluntary Consent:}

I certify that I understood the consent form and that I am 18 years of age or older. All of my questions have been answered, and I have received a copy of this consent form.

Do you consent to participate in this project?

If yes, please complete the surveys as I read before. If you decide not to participate feel free to stay or leave the room.

Thanks,

Nelson De La Rosa

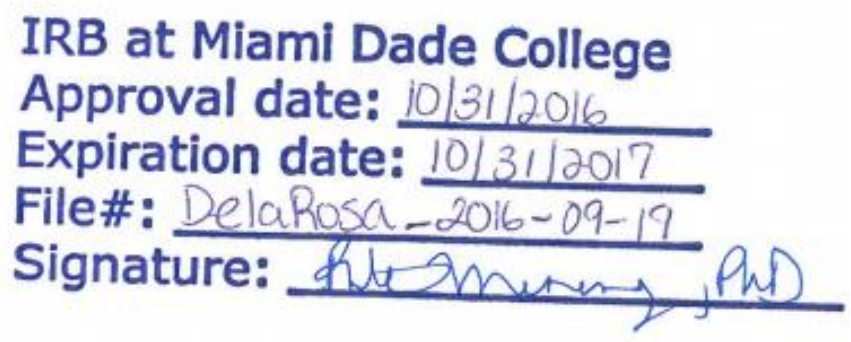

Page 2 of 2 
VITA

NELSON DE LA ROSA

Born, Havana, Cuba

EDUCATION

1986-1992

B.A., Telecommunication Engineering

Technological University of Havana

Havana, Cuba

1992-1997

Telecommunication Engineer

Ministry of Communication

Havana, Cuba

1997-1999

Instructor

Venezuelan American Institute

Caracas, Venezuela

1999-2004

Professional Teacher

Miami Senior High School

Miami, Florida

2000-2003

M.S., Mathematics Education

Florida International University

Miami, Florida

2003-2005

M.S., Mathematical Science

Florida International University

Miami, Florida

2009-2013

Educational Specialist, Curriculum and Instruction.

NCATE Accredited

Florida International University

Miami, Florida 
Instructor

Miami Dade College

Miami, Florida

2007-2010

Assistant Professor

Miami Dade College

Miami, Florida

2010-2013

Associate Professor

Miami Dade College

Miami, Florida

2013-Present

Associate Professor Senior

Miami Dade College

Miami, Florida

\section{PUBLICATIONS AND PRESENTATIONS}

Barrientos, R., de la Rosa, N., \& Ginory, E. (in press). Proposal to align Secondary and Postsecondary Curriculum for Mathematics. In Significant Discussions: Aligning Secondary and Postsecondary Math Curriculum. Chandler, AZ: League for Innovation in the Community College. https://www.league.org/

De La Rosa \& Espinal (2011, April). Enhancing students experience in online learning. Presenter. 10th Annual College of Education and Graduate Student Network Research Conference. Miami, FL: COE.

De La Rosa \& Espinal (2009, April). Geometer's sketch pad, a useful tool to encourage students to learn. 6th Annual Conference Day. Miami, FL.

De La Rosa \& Espinal (2006, April). Applications of financial mathematics in College Algebra and Statistics. 3rd Annual Conference Day. Miami, FL. 